\title{
Spatially-resolved urban energy systems model to study decarbonisation pathways for energy services in cities
}

\author{
Francisca Jalil-Vega $^{\mathrm{a}^{*}}$, Iván García Kerdan ${ }^{\mathrm{a}}$, Adam D. Hawkes ${ }^{\mathrm{a}}$ \\ ${ }^{a}$ Department of Chemical Engineering, Imperial College London. Exhibition Road, London, \\ SW7 2AZ, United Kingdom
}

\section{Abstract}

This work presents the COMET (Cities Optimisation Model for Energy Technologies) model, a spatially-resolved urban energy systems model that takes into account energy service demands for heating, cooling, electricity, and transport, and finds cost-effective pathways for supplying these demands under carbon constraints, trading-off energy supply, network infrastructure, and end-use technologies. Spatially-resolved energy service demands were obtained for the city of Sao Paulo, and six scenarios were modelled. Results show that district cooling is cost-effective in the highest linear cooling density zones, with full penetration in zones with over $1100 \mathrm{kWh} / \mathrm{m}$ by 2050 . This threshold diminishes with tighter carbon constraints. Heating is electrified in all scenarios, with electric boilers and air-source heat pumps being the main supply technologies for the domestic and commercial sectors respectively by 2050 . In the most carbon constrained scenario with a medium decarbonised electricity grid, ground source heat pumps and hydrogen boilers appear as transition technologies between 2030 and 2045 for the commercial and domestic sectors respectively, reaching $95 \%$ and $40 \%$ of each sector's heat installed capacity in 2030 . In the transport sector, ethanol cars replace gasoline, diesel, and compressed natural gas cars; compressed natural gas buses replace diesel and electric buses; and lorries continue using diesel. In carbon constrained scenarios, higher penetrations of electric cars and buses are obtained, while no change is observed for lorries. Finally, the most expensive scenario was only $6 \%$ more expensive than the reference scenario, meaning that achieving decarbonisation targets is not much costlier when comparing scenarios from a system-wide perspective.

Keywords: Energy systems modelling; spatially-resolved; transport; district cooling; heating; decarbonisation.

\section{Introduction}

Cities around the world are the main source of energy demand, and as such are accountable for around $70 \%$ of the world's carbon emissions and the associated effects of climate change [1]. More broadly, growing demands and technological shifts are changing global energy systems. For example, innovative technologies such as electric vehicles in the

*Corresponding author: Francisca Jalil-Vega, francisca.jalil12@imperial.ac.uk 
transport sector, and new equipment in the buildings sector, are projected to increase electricity demands in urban areas [2]. Cooling demands are the fastest growing end-use in buildings, with subsequent extra load on electricity networks [3].

In order to be able to analyse decarbonisation pathways for energy service demands in cities, a systems-wide perspective that takes into consideration the trade-offs between different components of the energy system is needed. For example, electrification of transport puts an extra burden on the electricity network and required power system capacity [2], and therefore network reinforcement and additional generation capacity is needed. Increases in cooling demands and electric air-conditioning units cause the same effect [3]. Moreover, if electrification of transport, cooling, or other energy services does not go hand in hand with the decarbonisation of the power sector, then electrification of the supply of energy services does not imply decarbonisation of the system.

Pfenninger, Hawkes, and Keirstead [4] have identified the need for more spatial detail among one of the main challenges in energy systems models. Jalil-Vega and Hawkes [5] discuss the importance of spatial resolution in energy systems models and how modelling with coarser spatial resolutions can produce homogeneous areas, under or over-estimating penetrations of certain networks or technologies. Siala and Mahfouz [6] show that the choice of regions impacts outputs of energy systems models, and that zone clustering should be chosen considering homogeneous areas with respect to a certain parameter. These three studies demonstrate how the choice of regions, zone clustering, and adequately fine spatial resolution is a crucial aspect to be considered in energy systems models.

This paper presents a mixed-integer linear programme optimisation model that takes into account end-use technologies, network infrastructure, and energy supply, to provide cooling, heating, transport, and electricity for appliances in a spatially-resolved urban area. The modelling time horizon is from 2015 to 2050. Investment and decommissioning decisions are made at the beginning of every 5-year periods, and informed by lifetimes of end-use technologies, district technologies, and network assets. Finally, years are subdivided into time-slices to account for seasonal and daily demand variations. The model is then applied to the case study of the city of Sao Paulo, in order to study potential decarbonisation pathways.

The main contributions of this work are the following: First, it proposes a method for estimating spatially and temporally-resolved energy service demands for heating, cooling, electricity for appliances, and transport. Second, this work proposes a spatially-resolved urban energy systems model that supplies heating, cooling, electricity for appliances, and demands for transport. And third, the model is applied for studying decarbonisation pathways for the city of Sao Paulo, where insights for urban energy service decarbonisation are obtained.

The article is organised as follows: the following section reviews existing analytical approaches to supply the aforementioned energy services in cities. The Methods section explains how spatially-resolved demands were obtained, presents the formulation of the model, and states the assumptions made and the scenarios studied. Results for the different scenarios are then presented and discussed, leading to a conclusion that summarises the insights gained. 


\subsection{Urban energy systems modelling for heating, cooling, electricity, and transport demands}

Proposed alternatives to decarbonise heat demands include heat networks in heat dense areas [7], heat pumps in less heat dense areas [8] or for renewable integration and grid price variation [9], fuel cells, and hydrogen-based technologies [10]. Heat supply and decarbonisation have been broadly studied using energy systems models through several approaches. Lund et al. [11] study the case of Denmark at national scale, and the most costeffective solutions to decarbonise heat demand. They conclude that the best combination is installing individual-dwelling heat pumps, and expanding the district heating network and supplying it by combined heat and power (CHP) plants. The TURN model proposed by Keirstead, Samsatli, Shah and Weber[12] is a spatially-resolved model that includes demands for electricity and heat, considering network infrastructure. It has been used to study the case of decarbonising and retrofitting Newcastle [13], and to study CHP planning restrictions in urban energy systems efficiencies [12]. The HIT model [14] is also a spatiallyresolved model that has been used to study decarbonisation pathways for heat in urban areas in the UK, which includes demands for heat and electricity, together with network infrastructure trade-offs.

Cooling demands can be supplied either by individual technologies, such as air-conditioning (AC) split systems or window-type AC, or by technologies that supply a building or district. Dominković, Bin Abdul Rashid, Romagnoli, Pedersen, Leong, Krajačić, and Duić [15] show that in hot and humid climates where space cooling demands are steadier throughout seasons, the use of district cooling systems in urban areas is more efficient, less energy intense, presents lower systems $\mathrm{CO}_{2}$ emissions, and is cheaper than supplying space cooling demands using individual units. Likewise, Lake, Rezaie, and Beyerlein [16] review results from research in district heating and cooling and conclude that district energy systems are more efficient than individual heating and cooling units. Dominković, Dobravec, Jiang, Nielsen, and Krajačić [17] conduct a literature review showing that while the topic of district heating in smart energy systems has been extensively researched, there is a lack of research concerning the integration of district cooling into smart energy systems, specifically in tropical regions. They therefore propose a model that integrates power, cooling, gas, mobility, and water desalinisation sectors in an urban energy systems model. The model however has no spatial or network representation.

Energy systems models that specifically include cooling demands and district cooling networks include Söderman [18], Khir and Haouari [19], and Al-Noaimi, Khir, and Haouari [20]. Söderman [18] proposes an energy systems model to optimise investment and operations for new or expanding district cooling networks. This model includes seasonal demand variations and the spatial layout of the network, district cooling plants, and loads. Khir and Haouari [19] propose a model to optimise plant and network sizes for district cooling networks which includes hydraulic and thermal constraints, with predetermined locations of the district cooling plant and storage system. Al-Noaimi, Khir, and Haouari [20] build on [19] by including several plant types, and the possibility of choosing plant and storage locations. In these three studies, no other urban service demands besides cooling are included, and district cooling is not tested against other cooling supply technologies -for 
example, individual air-conditioning units. Ameri and Besharati [21] present a model to optimise distributed energy systems total costs, including district cooling and district heating networks, together with electricity demands in urban areas. This model also imposes constraints on pipelines for both networks and considers spatial locations of demands and supply. However. it only allows for the possibility of installing district networks to supply cooling and heating demands, and -as the previous three models- does not allow for heating and cooling to be supplied by individual technologies in different areas. Comodi, Bartolini, Carducci, Nagaranjan, and Romagnoli [22] present a model that explore network synergies to supply local community with demands for cooling, heating, and electricity. This model does not include transport demands, and has the drawback that even though it includes capital and operating costs of networks and technologies, it models the system in a 20-years period assuming that all investments are done at the beginning. Therefore, rather than assisting an urban energy system's planning, it can better aid a comparison of a set of different alternatives.

Gerboni, Grosso, Carpignano, and Dalla Chiara [23] stress the importance of linking energy and transport models to study energy systems and support policy decisions, highlighting that energy use in transport is one of the main demands of the overall energy system. Likewise, Venturini, Hansen, and Andersen [24] study the integration of the buildings and transport sectors' narratives for studying transport scenarios. They generate a model in TIMES-DK which incorporates quantitative and qualitative methods for the transport scenario, concluding on the importance of system's integration and the use of mixed methods for building coherent storylines. Pye and Daly [25] use the ESME energy systems model to analyse the role of modal shift options in the transport sector in low carbon scenarios in the UK, concluding that sustainable options become cost-effective with proper policies that disincentivise car use. Daly, Ramea, Chiodi, Yeh, Gargiulo, and Gallachóir [26] incorporate detailed aspects of the transport sector such as travel behaviour and time into the TIMES model to study modal shift in different mitigation scenarios. All these researches use energy systems models to incorporate transport. However, none of them present the results in the context of the total energy system, but only focused on the transport sector.

Lovrić, Blainey, and Preston [27] present the ITRC-MISTRAL model, which is a national transport model for the UK that represents multi scales and multiple modes of transport for passengers and freight. The model simulates transport demands by mode using demand elasticities. Interdependencies with the energy system are considered through energy demand and its impact in energy prices. However, other than transport infrastructure, no other city or building infrastructure is considered.

Sterchele, Kersten, Palzer, Hentschel, and Henning [28] present the REMod model to assess flexible charging for electric vehicles in the context of the wider energy system. The model takes into account demand patterns for heat and electricity in order to find optimal charging of electric vehicles and assist grid flexibility. This model operates in a single region, and cooling demands are not included.

In [29], Novosel, Perković, Ban, Keko, Pukšec, Krajačić, and Duić, modelled hourly energy use of electric vehicles at a national level (Croatia), and studied their interactions with the power sector. The agent-based model MATSim was used to calculate hourly demands on a simplified spatial layout. Then, the EnergyPLAN model was used to understand the effects of large-scale electric vehicles deployment on the wider energy system, with special focus on 
wind and photovoltaics in the power sector. The work also shows that electrification of transport can widely reduce energy consumption due to the increased efficiency of electric vehicles over internal combustion vehicles, when effectively coupled with the power sector to take into account the increase of electricity consumption.

Helgesen, Lind, Ivanova, and Tomasgard [30] propose a hard link between TIMES and REMES (a computable general equilibrium model) to analyse the economic implications of reducing greenhouse gas (GHG) emissions from the Norwegian transport sector. In this case, REMES provides energy demand inputs to TIMES. TIMES covers services such as heating, cooling, transport and raw materials, at a coarse spatial resolution (national level). The modelling outputs suggest that emission targets could be reached by large investment in hydrogen vehicles limiting capital stock growth and household welfare.

Barone, Buonomano, Calise, Forzano, and Palombo [31] implement a model in MatLab to study an energy management system for buildings connected to a micro-grid, considering electric vehicles as dynamic components of the system. The study focuses on 'building to vehicle to building' dynamics and thus includes buildings and mobility consumptions in the energy balance. Electric vehicles are considered as one of the electricity vectors for buildings. In this model, however, there is no spatial representation of networks in a city, and it only considers electric mobility.

In [32] Osório, McCullen, Walker, and Coley propose a methodology for estimating energy consumption in buildings and transport in a spatially-resolved manner. This research is not an energy systems model, but it introduces a new data-based energy metric to calculate energy consumption of both buildings and transport that can serve as input for other spatially-resolved energy systems models that include mobility and building energy demands. Likewise, Fichera, Inturri, La Greca, and Palermo [33] consider building and transport as strongly interrelated sectors responsible for energy and material flows within the city, and develop a model based on analytical data to estimate energy demands of these sectors in cities. The model is divided into two stages: the first, calculates energy demand by sector, while the second provides a global energy assessment of neighbourhoods. The structure of the model itself, organised into sub models, allows evaluation of energy consumption either in a disaggregated way or for the whole. For both studies results are illustrated using GIS.

\subsection{Energy systems models for multi energy services}

Table 1 shows a selection of models which include heating, cooling, electricity for appliances, and transport energy service demands. The table shows which energy services are included, if and how spatial aspects are taken into account, and whether the model represents network infrastructure. 


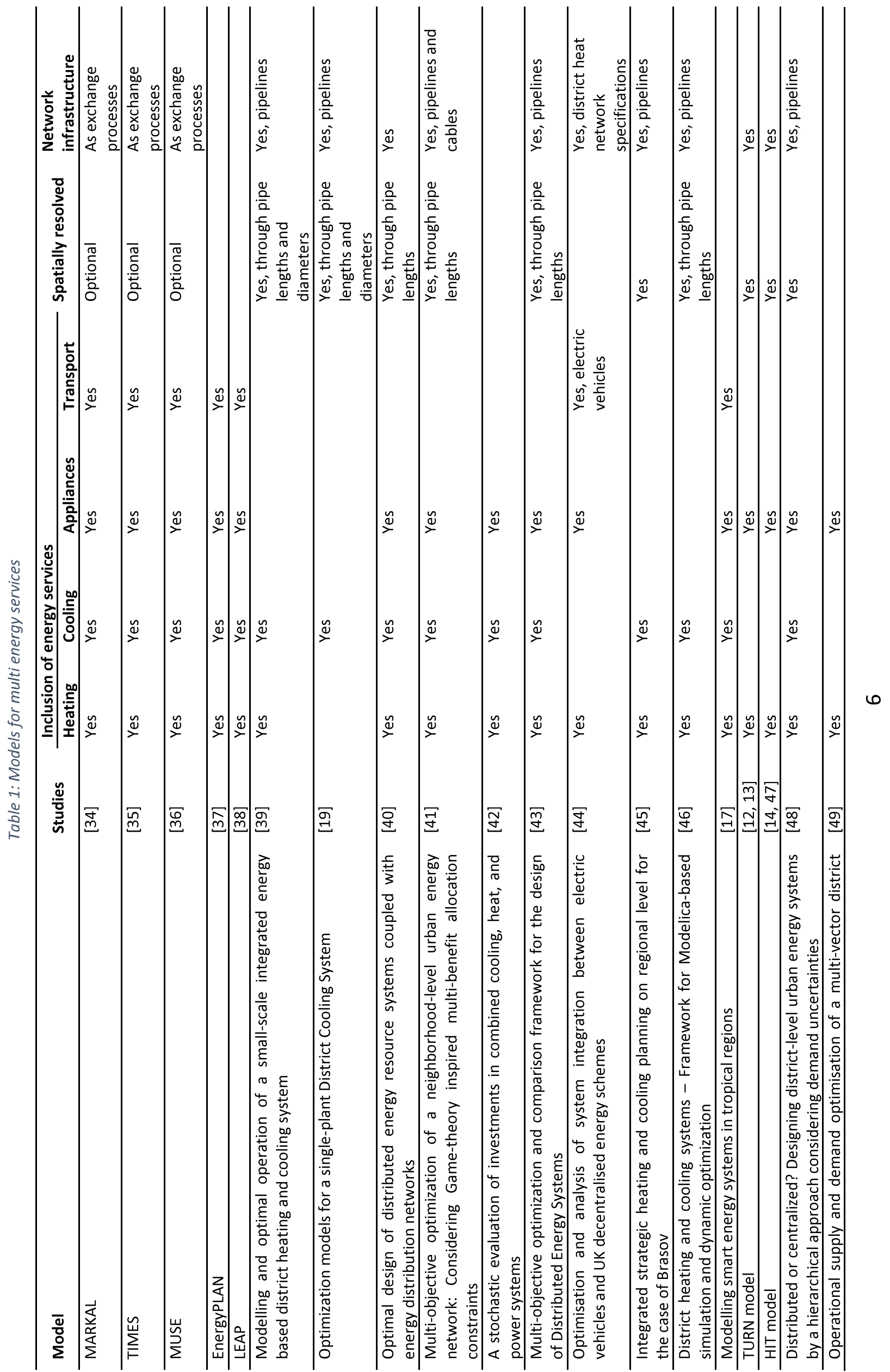




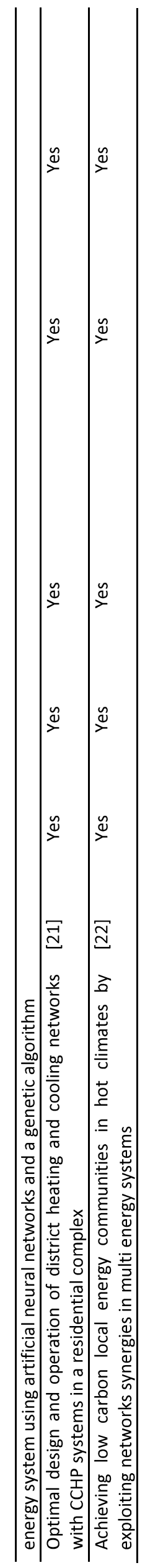




\subsection{Research objective}

As discussed in the literature review and from Table 1, at the time of writing, most urban energy systems modelling focuses on the provision of some energy service demands within heating, cooling, transport, and electricity for appliances; or uses coarse spatial resolutions such as integrated assessment models, which model national or regional scales (such as the MARKAL model [34], the ESME model [50] or the TIMES model [24]); or focus on specific technologies or on specific energy service demands (for example, Chiam, Easwaran, Mouquet, Fazlollahi, and Millás [51] optimise the operation of a district cooling network; del Hoyo Arce, Herrero López, López Perez, Rämä, Klobut, and Febres [52] model district heating and cooling; Pye and Daly [25] focus on urban transport; and Liu, Ho, Lee, Hashim, Lim, Klemeš, and Yee Mah [53] model distributed generation for supplying service demands for heat and electricity). No modelling framework exists that simultaneously includes the demand for heating, cooling, transport, and electricity for appliances, at a fine spatial resolution, and taking into account the trade-offs between supply, network infrastructure, and end-use technologies for all the aforementioned energy service demands simultaneously. Given the lack of such analytical tools, the aims of this work are to:

- Develop a model that addresses these gaps

- Develop a method to determine spatially-resolved energy service demands for the city of Sao Paulo to be used as inputs in the model. The city of Sao Paulo is an alpha global city [54], worthy of investigation as it is the most populous city in Brazil and the largest economy by GDP in Latin America.

- Implement it to study decarbonisation pathways for the case of the city of Sao Paulo.

This research is relevant for this journal as it covers topics such as analysis and optimisation of sustainable energy systems and the optimal use energy resources, and how to develop and plan more sustainable and optimised urban energy systems.

\section{Methods}

In the following section, a general description of the model proposed in this research is introduced. Then, the case study is presented, and the methods for characterising spatially resolved energy service demands for heating, space cooling, electric appliances, and transport are explained. Finally, the mathematical model formulation is detailed, and the studied scenarios are defined.

\subsection{General description of the model}

This research presents the COMET (Cities Optimisation Model for Energy Technologies) model. COMET builds on the HIT (Heat Infrastructure and Technology) model- presented in [14] and adapted to include hydrogen in [47]- to include other energy service demands and supply in urban areas. The HIT model is a spatially-resolved mixed integer linear optimisation programme that finds the cost optimal pathways to supply heat and electricity to residential and commercial sectors. Taking energy service demands disaggregated into zones and time slices as inputs, the HIT model builds network infrastructure and installs building and district level end-use technologies to supply these demands through 2050. It 
considers the lifetimes of assets to inform commissioning and decommissioning decisions and minimises the total system's costs including investments and operation.

The COMET model presented hereby further includes other critical energy service demands in urban areas -space cooling and transport- and thus includes the respective networks and technologies to supply these services.

\subsection{Characterisation of energy service demands}

The City or Municipio of Sao Paulo was broken down into 32 zones, corresponding to the Subprefectures (Subprefeituras) administrative units [55]. Table 2 shows the zone numbers assigned to each Subprefecture that will be used later in the analysis.

Table 2: Assigned zone number for each Subprefecture

\begin{tabular}{|ll|ll|}
\hline Zone & Subprefecture & Zone & Subprefecture \\
\hline 1 & Perus & 17 & Campo Limpo \\
2 & Pirituba & 18 & M'Boi Mirim \\
3 & Freguesia/Brasilândia & 19 & Capela do Socorro \\
4 & Casa Verde/Cachoeirinha & 20 & Parelheiros \\
5 & Santana/Tucuruvi & 21 & Penha \\
6 & Jaçanã/Tremembé & 22 & Ermelino Matarazzo \\
7 & Vila Maria/Vila Guilherme & 23 & São Miguel \\
8 & Lapa & 24 & Itaim Paulista \\
9 & Sé & 25 & Mooca \\
10 & Butantã & 26 & Aricanduva/Formosa/Carrão \\
11 & Pinheiros & 27 & Itaquera \\
12 & Vila Mariana & 28 & Guaianazes \\
13 & Ipiranga & 29 & Vila Prudente \\
14 & Santo Amaro & 30 & São Mateus \\
15 & Jabaquara & 31 & Cidade Tiradentes \\
16 & Cidade Ademar & 32 & Sapopemba \\
\hline
\end{tabular}

Metered data for electricity consumption of individual residential and commercial consumers were requested for the year 2016 for the city of Sao Paulo- via the information access page [56]- to the National Electricity Agency (Agência Nacional de Energia Elétrica ANEEL). The raw data obtained was monthly electricity consumption for each property for the whole year. This data was aggregated into zones in order to characterise demand consumption profiles for residential and domestic consumers, and to find the proportion of the total annual demand and of the total customers of each type that can be allocated into each zone. Energy service demands are projected through 2050 as described later for the whole city, represented in Figure 1 and Figure 2, and because of data availability it is assumed that the share of demands and number of customers per zone remain constant through 2050. The demand was then aggregated into Winter and Summer seasons.

In Sao Paulo, most residential [57] and commercial [58] energy service demands are supplied by electricity. Liquified petroleum gas is used for cooking, but water and space heating, and air conditioning, are supplied by electricity. Table 3 shows the percentage of annual electricity demand used for heat and air-conditioning in the residential sector in Sao Paulo according to Ghisi, Gosch, and Lamberts [57], and the average efficiencies of the 
appliances to supply these service demands [58]. Using these parameters and the total annual residential demand for electricity in 2016, the seasonal and annual service demands for heat and space-cooling were calculated. Therefore, the difference of annual electricity demand and electricity used for heating and cooling is considered the annual service demand for non-heat and non-space-cooling electricity, or electricity service demand for the residential sector here on.

Table 3: Percentage of residential seasonal electricity demand consumed by air-conditioning and electric showers in Sao Paulo [57], and average efficiencies [58].

\begin{tabular}{llll}
\hline & $\begin{array}{l}\text { Electricity consumption per appliance [57] } \\
\text { Summer }\end{array}$ & $\begin{array}{l}\text { Average appliance } \\
\text { efficiency [58] }\end{array}$ \\
\hline $\begin{array}{l}\text { Electric shower (hot } \\
\text { water) }\end{array}$ & $26 \%$ & $26 \%$ & 0.95 \\
Air-conditioning & $11 \%$ & $1 \%$ & 0.6 \\
\hline
\end{tabular}

Table 4 shows the percentage of annual electricity demand used for heat and airconditioning in the commercial sector in Sao Paulo and the average efficiencies of the appliances to supply these service demands according to Mosquim, de Oliveira Junior, and Keutenedjian Mady [58]. As for the residential sector, annual service demands for heat, space-cooling, and electricity service were calculated using these parameters and the total annual electricity demand for the commercial sector.

Table 4: Percentage of annual commercial electricity demand consumed by air-conditioning and electric heat in Sao Paulo and average efficiencies [58].

\begin{tabular}{lll}
\hline & $\begin{array}{l}\text { Annual electricity consumption per } \\
\text { appliance }\end{array}$ & $\begin{array}{l}\text { Average appliance } \\
\text { efficiency }\end{array}$ \\
\hline Air-conditioning & $36.7 \%$ & 0.6 \\
Electric heat & $20.1 \%^{2}$ & 0.8 \\
\hline
\end{tabular}

Energy service demands for heat, electricity, and space cooling, were projected through 2050 using GDP per capita and growth projections for the Southeast region [59, 60], and past annual commercial and residential electricity demands and number of customers for the city (Municipio) of Sao Paulo obtained from annual energy reports [61-70]. The proportion of these three energy service demands to the total annual electricity demand were assumed to be as the base year 2016. Figure 1 and Figure 2 show the adjusted log-log curve for the energy service demands, and the coefficient of determination $\left(R^{2}\right)$.

\footnotetext{
${ }^{2}$ For the commercial sector, $36.7 \%$ is used for air-conditioning, $43.1 \%$ for electrical appliances, lighting, and equipment, and thus the remaining $20.1 \%$ was assumed to be for heat [4].
} 


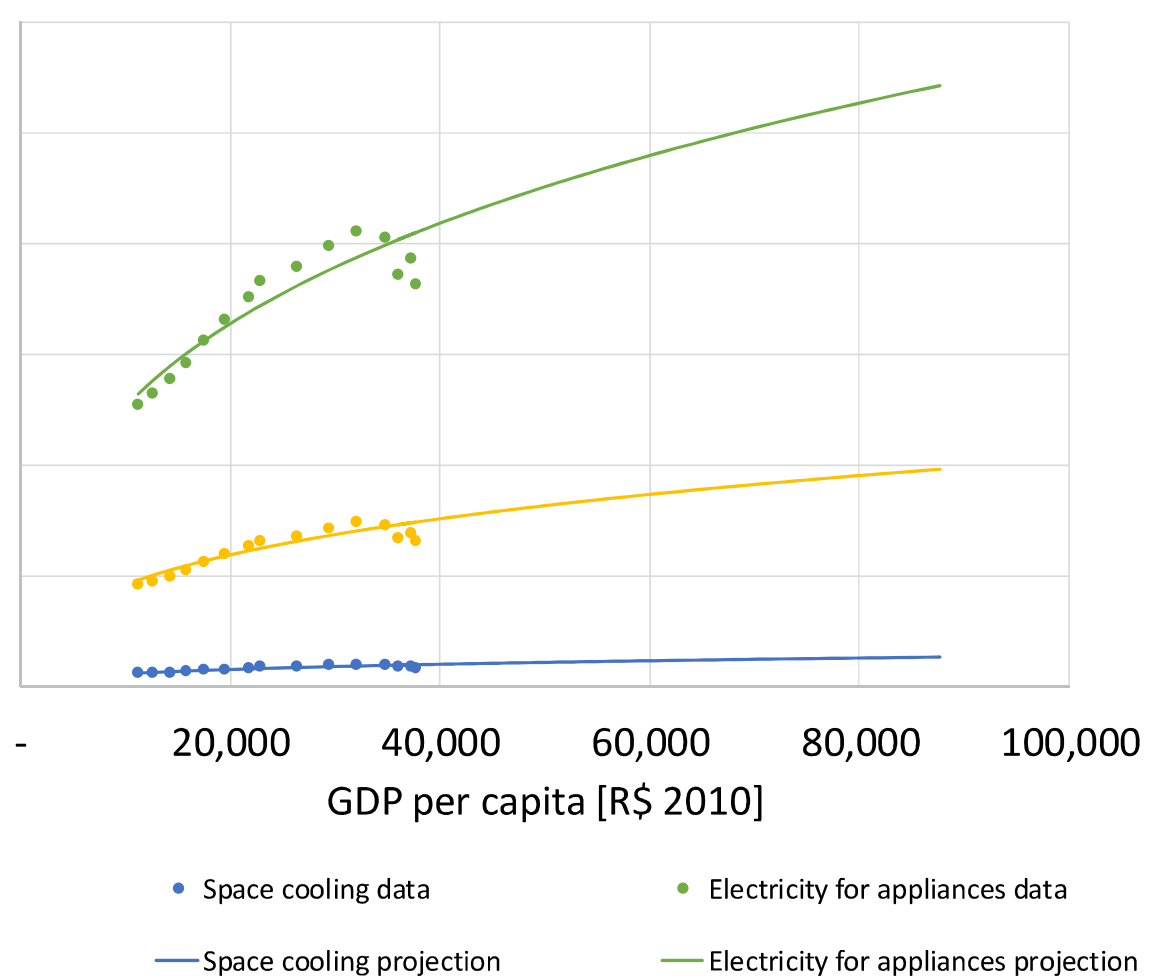

Figure 1: Residential service demand projections versus GDP per capita (R2=87\%)

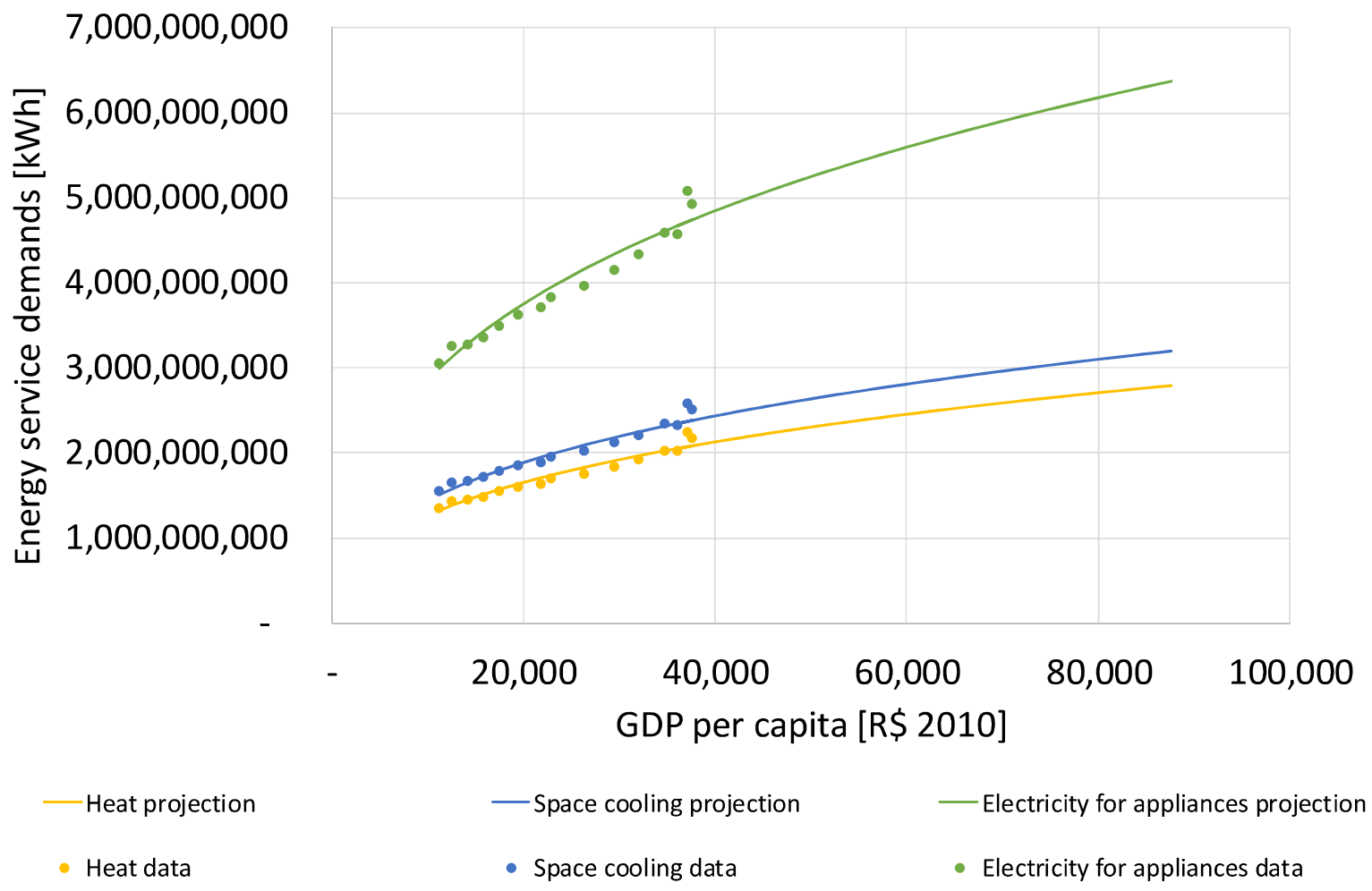

Figure 2: Commercial service demand projections versus GDP per capita (R2=95\%). 
The model takes energy service demands in time slices to account for seasonal and daily demand variations. For breaking down the annual energy service demands into time slices, different methodologies were used for the residential and commercial sectors. For the residential sector, the energy service demands were allocated into seasons (Winter/Summer) as described previously. To further break down seasonal demands into weekdays and weekend days, aggregated residential load curves simulated by Eletropaulo [71] - Sao Paulo's electricity distributor - were used. The profiles can be observed in Figure 3. Finally, to account for daily energy service demand variations PROCEL [72] data was used. Based on surveys and simulations, this research built consumption profiles for a typical house archetype in each of Brazil's regions. Figure 4 shows the archetypical consumption profile for the Southeast region used in this work. All electric appliances other than electric hot water and air-conditioning are here aggregated into one. Additionally, the same PROCEL study points out that only $7 \%$ of residential properties in Sao Paulo have air-conditioning units. Therefore, residential demands for air-cooling were distributed within zones among only $7 \%$ of the domestic customers.

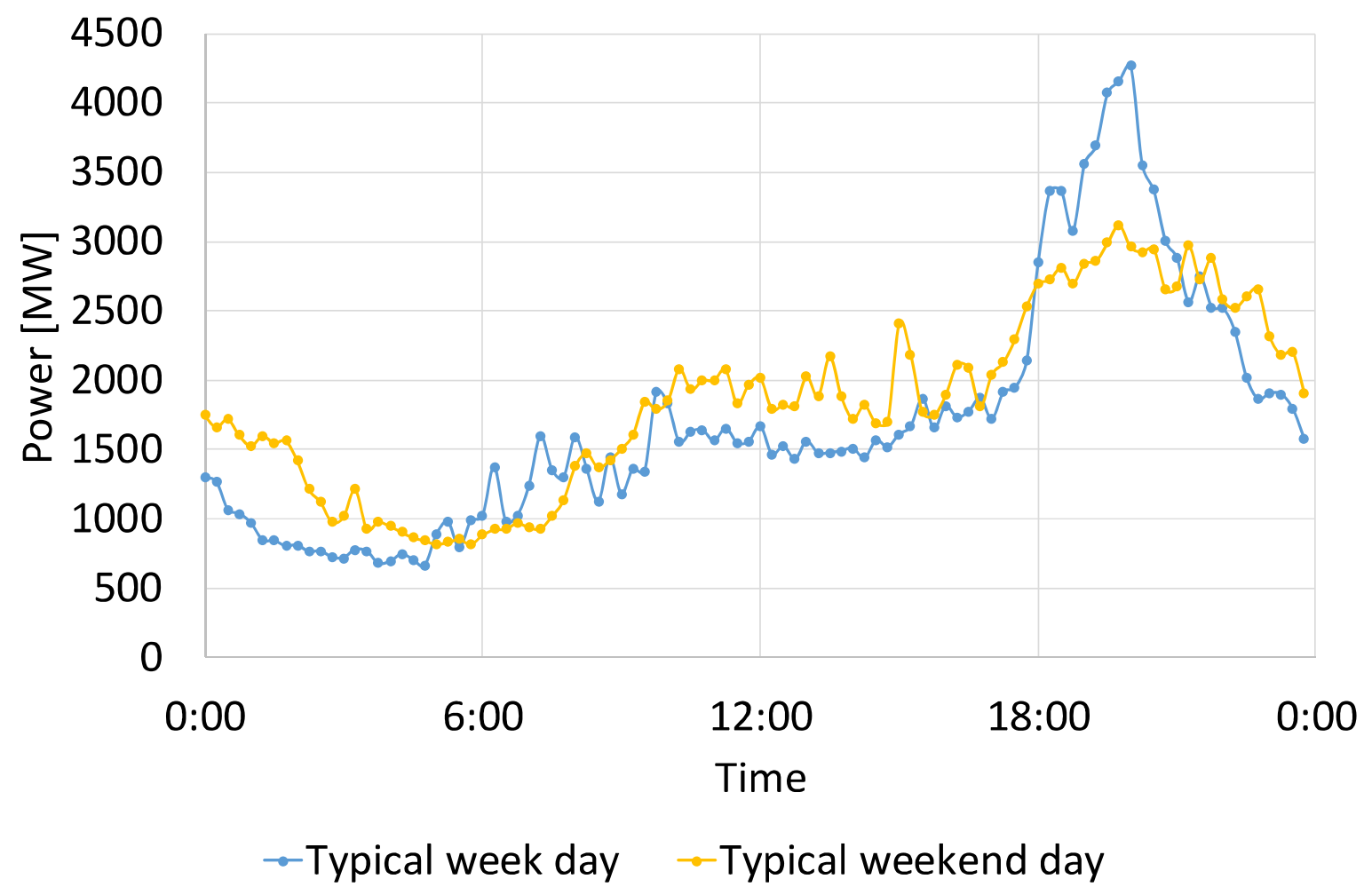

Figure 3: Load curves for Sao Paulo, simulated by Eletropaulo, residential sector. SOURCE: ANEEL/Eletropaulo data [71]. 


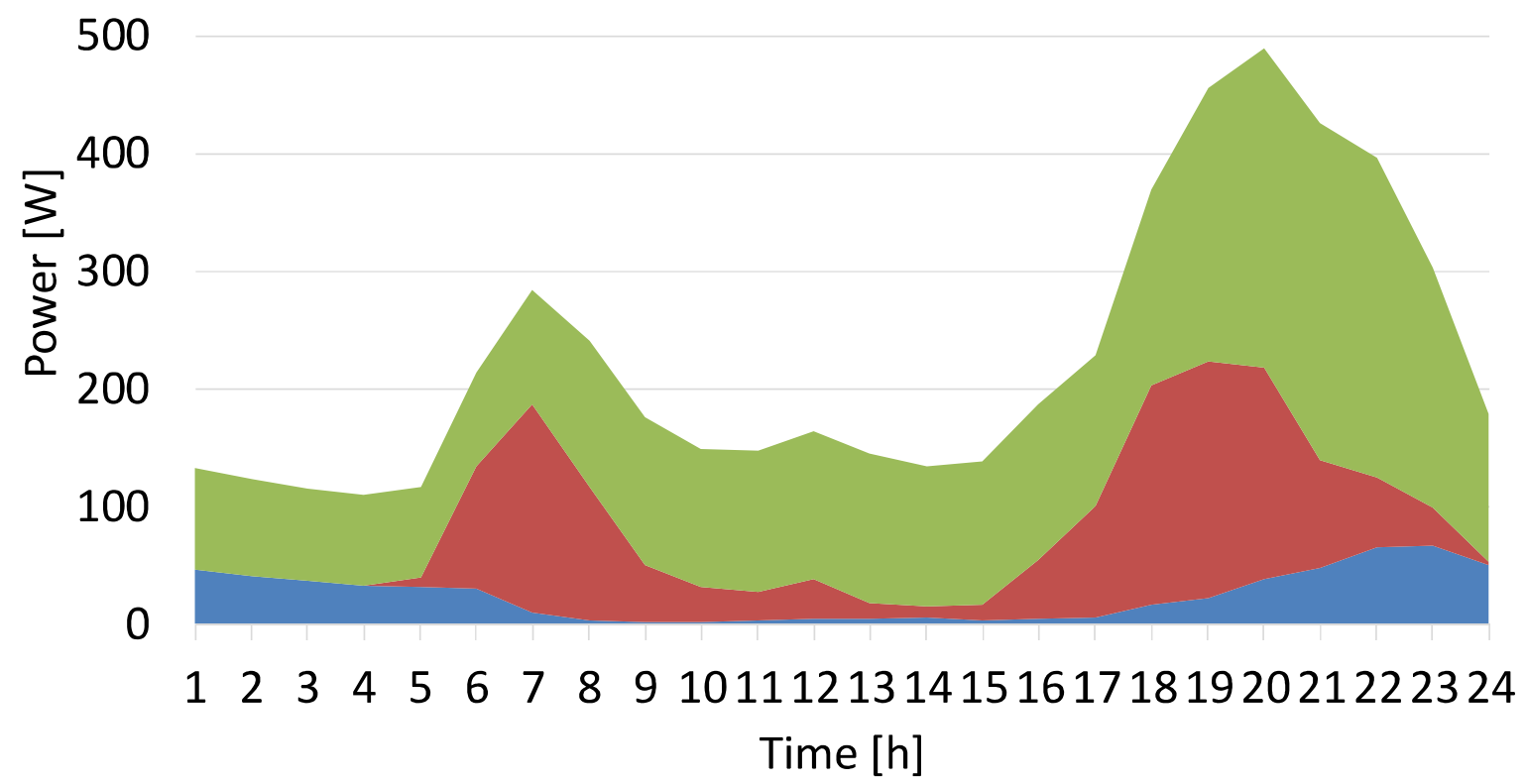

\section{Air-conditioner $\square$ Electric hot water $\square$ Other electric appliances}

Figure 4: Archetypical electricity consumption profile for appliances for the Southeast region. Based on [72].

As peak demand occurs in weekdays, these were further broken down into time slices to characterise operation profiles. Daily time slices were defined to characterise service demand variations in accordance to Figure 4. Considering the service demand for space cooling and hot water in winter and summer, the breakdown into weekday and weekend days, and the daily profiles in Figure 4, time slices were defined, and coefficients with respect to total annual service demands were obtained to allocate hot water and space cooling into time slices, as shown in Table 5. Taking into account the average efficiencies of these service demands and the seasonal metered electricity demand of the city of Sao Paulo for 2016 mentioned previously, the electricity service demand was obtained as the difference of total electricity demand and electricity demand for space cooling and water heating. It was then allocated into Weekdays/Weekend days and time slices using the daily average consumption profile (Figure 4). Table 5 shows the obtained coefficients and time allocation of time slices relative to a year. 
Table 5:Coefficients for energy service demand allocation into time slices, and fraction of year of time slices. Residential sector.

\begin{tabular}{|c|c|c|c|c|c|c|c|}
\hline Season & Day & Time of day & $\begin{array}{l}\text { Time slice } \\
\text { notation }\end{array}$ & $\begin{array}{l}\text { Space } \\
\text { cooling }\end{array}$ & Heating & $\begin{array}{l}\text { Electricity } \\
\text { service }\end{array}$ & $\begin{array}{l}\text { Fraction } \\
\text { of year }\end{array}$ \\
\hline \multirow[t]{6}{*}{$\begin{array}{l}\text { Winter } \\
\text { (W) }\end{array}$} & $\begin{array}{l}\text { Weekday } \\
\text { (Wd) }\end{array}$ & $\begin{array}{l}\text { 6:00-09:00 } \\
\text { Early morning }(E)\end{array}$ & WWdE & 0.003 & 0.132 & 0.038 & 0.045 \\
\hline & $\begin{array}{l}\text { Weekday } \\
\text { (Wd) }\end{array}$ & $\begin{array}{l}\text { 9:00-12:00 } \\
\text { Morning (M) }\end{array}$ & WWdM & 0.001 & 0.010 & 0.042 & 0.045 \\
\hline & $\begin{array}{l}\text { Weekday } \\
\text { (Wd) }\end{array}$ & $\begin{array}{l}\text { 12:00-18:30 } \\
\text { Afternoon }(A)\end{array}$ & WWdA & 0.005 & 0.061 & 0.092 & 0.097 \\
\hline & $\begin{array}{l}\text { Weekday } \\
\text { (Wd) }\end{array}$ & $\begin{array}{l}\text { 18:30-21:30 } \\
\text { Peak (P) }\end{array}$ & WWdP & 0.023 & 0.150 & 0.101 & 0.045 \\
\hline & $\begin{array}{l}\text { Weekday } \\
\text { (Wd) }\end{array}$ & $\begin{array}{l}\text { 21:30-6:00 } \\
\text { Night (N) }\end{array}$ & WWdN & 0.031 & 0.012 & 0.117 & 0.127 \\
\hline & $\begin{array}{l}\text { Weekend } \\
\text { (We) }\end{array}$ & Average (Av) & WWeAv & 0.027 & 0.157 & 0.168 & 0.142 \\
\hline \multirow[t]{6}{*}{$\begin{array}{l}\text { Summer } \\
\text { (S) }\end{array}$} & $\begin{array}{l}\text { Weekday } \\
\text { (Wd) }\end{array}$ & $\begin{array}{l}\text { 6:00-09:00 } \\
\text { Early morning (E) }\end{array}$ & SWdE & 0.034 & 0.120 & 0.030 & 0.045 \\
\hline & $\begin{array}{l}\text { Weekday } \\
\text { (Wd) }\end{array}$ & $\begin{array}{l}\text { 9:00-12:00 } \\
\text { Morning (M) }\end{array}$ & SWdM & 0.009 & 0.009 & 0.033 & 0.045 \\
\hline & $\begin{array}{l}\text { Weekday } \\
\text { (Wd) }\end{array}$ & $\begin{array}{l}\text { 12:00-18:30 } \\
\text { Afternoon }(\mathrm{A})\end{array}$ & SWdA & 0.051 & 0.056 & 0.073 & 0.096 \\
\hline & $\begin{array}{l}\text { Weekday } \\
\text { (Wd) }\end{array}$ & $\begin{array}{l}\text { 18:30-21:30 } \\
\text { Peak (P) }\end{array}$ & SWdP & 0.230 & 0.137 & 0.079 & 0.045 \\
\hline & $\begin{array}{l}\text { Weekday } \\
\text { (Wd) }\end{array}$ & $\begin{array}{l}\text { 21:30-6:00 } \\
\text { Night (N) }\end{array}$ & SWdN & 0.312 & 0.011 & 0.092 & 0.126 \\
\hline & $\begin{array}{l}\text { Weekend } \\
\text { (We) }\end{array}$ & Average (Av) & SWeAv & 0.274 & 0.144 & 0.133 & 0.142 \\
\hline
\end{tabular}

For allocating commercial energy service demands into time slices a different method was used due to data availability. Cooling profiles for different commercial building types in Sao Paulo (hospital, offices, schools, etc) were obtained from Arcuri, Spataru, and Barrett [73], per floor area of commercial building type. These were multiplied by the total floor area of each commercial building type in Sao Paulo [74], to obtain cooling demand profiles and allocation of seasonal cooling demands into time slices presented in Table 5 . Then, EnergyPlus [75], an energy performance simulation tool for buildings, was used to simulate archetype commercial buildings in Sao Paulo, considering average historical weather files. Summer/winter demand splits for heating and cooling were obtained, along with heating demand allocation into time slices. Seasonal electricity service demands for commercial buildings were then calculated as the difference between metered data for commercial buildings, and electricity consumed by heating and cooling, using efficiencies in Table 4. Finally, electricity service demands were further broken down into time slices by subtracting electricity consumed by space cooling and heating to the total electricity load curves for the commercial sector presented in Figure 5, simulated by Eletropaulo [71]. 


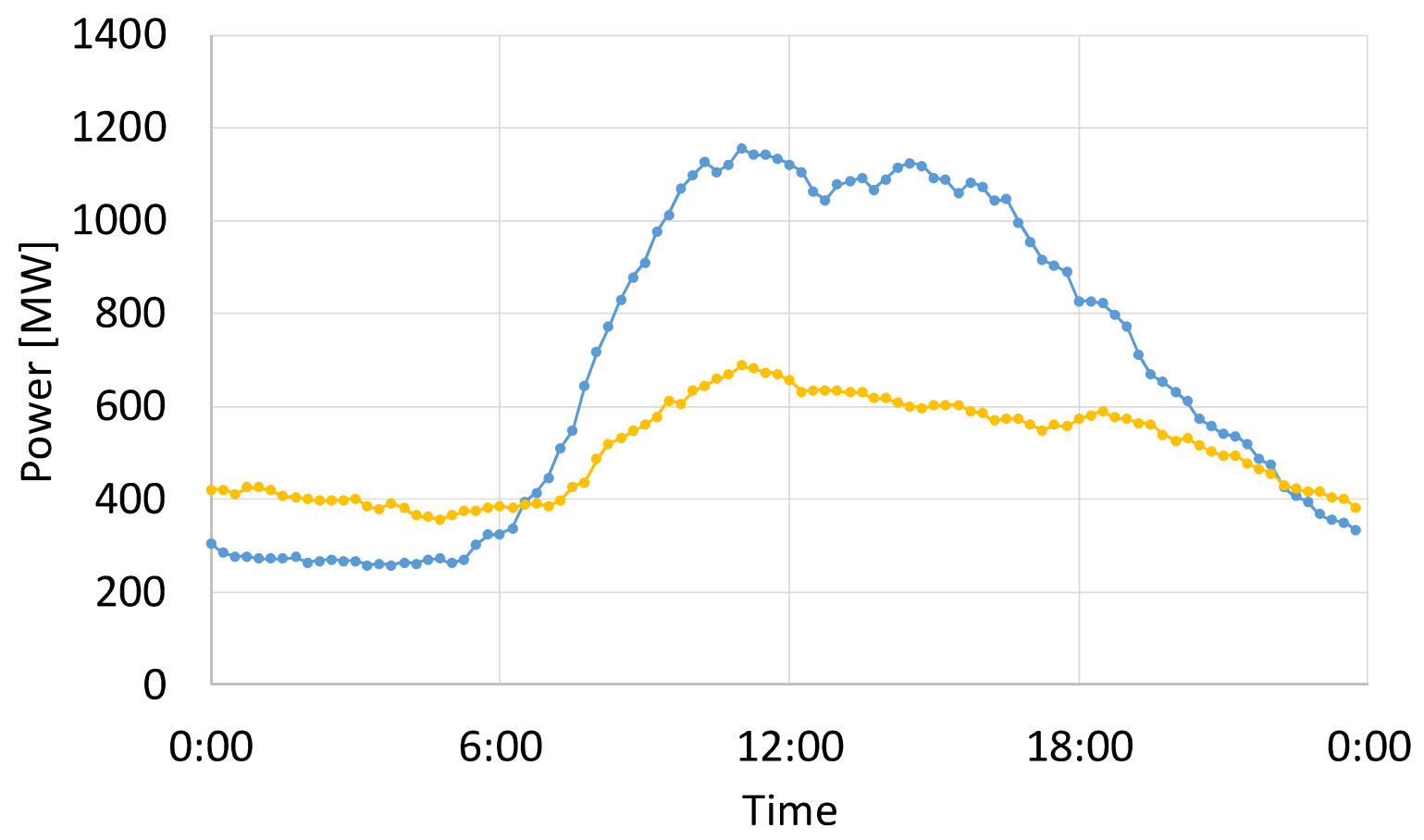

$\rightarrow$ Typical week day $\rightarrow$ Typical weekend day

Figure 5: Load curves for Sao Paulo, simulated by Eletropaulo, commercial sector. SOURCE: ANEEL/Eletropaulo data [71].

Table 6 shows the obtained coefficients for allocating energy service demands into time slices for the commercial sector.

Table 6: Coefficients for energy service demand allocation into time slices listed in Table 5. Commercial sector.

\begin{tabular}{llll}
\hline Time slice & Space cooling & Heating & Electricity service \\
\hline WWdE & 0.044 & 0.059 & 0.035 \\
WWdM & 0.068 & 0.082 & 0.089 \\
WWdA & 0.138 & 0.164 & 0.185 \\
WWdP & 0.029 & 0.042 & 0.065 \\
WWdN & 0.014 & 0.071 & 0.104 \\
WWeAv & 0.087 & 0.124 & 0.142 \\
SWdE & 0.072 & 0.038 & 0.015 \\
SWdM & 0.112 & 0.065 & 0.048 \\
SWdA & 0.226 & 0.146 & 0.093 \\
SWdP & 0.046 & 0.038 & 0.045 \\
SWdN & 0.021 & 0.065 & 0.092 \\
SWeAv & 0.143 & 0.105 & 0.087 \\
\hline
\end{tabular}

Finally, for estimating transport energy service demands, historical consumption of transport fuels were requested via Brazil's information access webpage [56] for the city of Sao Paulo. Average efficiencies for different road transport fuels were obtained using the ratio between useful energy and final energy for transport fuels from the Energy Balance of the State of Sao Paulo [76], and these were multiplied by annual consumptions. Using fuel consumption per litre data for average vehicle types [77], the energy service in kms was obtained for each transport fuel, and summed up to obtain the total transport energy service demand (in kms). Service demands were projected through 2050 using historical data. Finally, as it was not possible to obtain sub-city-resolution demand data for transport 
fuels, the total demand was allocated into zones in proportion to the number of fuel stations in each zone. A list of fuel stations for Sao Paulo was requested via Brazil's information access webpage [56], and their addresses were then processed using GIS to group fuel stations into zones. Note that the only transport technology for which the charging/fuelling time is relevant are electric vehicles. This will be addressed later in the formulation, so transport demands are obtained for a yearly time resolution.

\subsection{Model formulation}

This section presents the main equations for the COMET optimisation model. The full formulation can be found in Appendix B, while nomenclature can be found in Appendix A.

The objective function aims to minimise the total system's cost, which is the net present value of all the capital and operation costs over the modelled time horizon from 2015 to 2050. The cost components are shown in Equation (3.1).

$$
\min C O S T S=M N T+F E+C P T+D E C-S L V-E S
$$

The minimisation of the system's cost is subject to a number of constraints. First, there is a set of equations that relate vintage, new, decommissioned, and total capacities of technologies, considering their lifetimes. A similar set of equations are set for networks' infrastructure. These equations can be found in Appendix $B$ and meanings for abbreviations can be found in Appendix A. Then, operating capacities of technologies in a certain time slice can be at most equal to the installed capacity of the corresponding time period. Inequality (3.2) presents this constraint for individual heating end-use technologies. The same constraints apply for individual space-cooling end-use technologies, and for district cooling supply technologies. Equation (3.3) presents the constraint for transport technologies, where the total installed capacity (in km-passenger or km-tonne per year) is the sum of the operating capacity of each technology.

$$
\begin{aligned}
& \mathrm{OCHI}_{b h i_{\text {ind }} j y} \leq \mathrm{TCHI} \mathrm{I}_{\text {bind }} \mathrm{i} \quad \forall b h i_{\text {ind }} j \mathrm{y} \\
& \sum_{h} \text { OCTI }_{h i_{\text {trans }} j y}=\text { TCTI }_{i_{\text {trans }} j y} \quad \forall i_{\text {trans }} j y
\end{aligned}
$$

Demands for transport refer to demands for fuel and electricity for transport services. It is assumed that all transport fuels except hydrogen and electricity are supplied to fuelling stations via trucks. Therefore, time dependant demands (refuelling times) are less relevant. For electric vehicles however, charging schedules are important, as electric vehicle charging can overload the grid. Therefore, in this work it is assumed that electric vehicles' charging patterns follow the profiles for week and weekend days obtained in Flammini, Prettico, Julea, Fulli, Mazza, and Chicco [78]. This study presents a statistical analysis of 2900 charging points over four years, to obtain weekend/weekday electric vehicle charging profiles. The charging profile is imposed via Equation (3.4) with reference to the peak charging time slice. Additional constraints are imposed for heating and cooling technologies to follow demand load profiles, in order to ensure that each domestic or commercial property has one technology, and that there are no end-use technologies that are only used for aggregated peaks. These constraints have the same form as Equation (3.4). 


$$
T P_{h} \cdot \text { OCTI }_{h \text { itrans }_{\text {elec }} j y}=\text { OCTI }_{\text {peak }} \text { itrans }_{\text {elec }} j y \quad \forall \text { hjy }
$$

For the case of hydrogen vehicles, it is assumed that hydrogen is transported through the same distribution pipelines as if it were used for heat technologies, and purified and compressed in fuelling stations. Therefore, the scheduling problem becomes more flexible than for electric vehicles, and is addressed later together with hydrogen distribution.

In order to ensure that district cooling supply technologies are whole units, Equation (3.5) establishes that the new capacity is equivalent to multiples of the output capacity of district cooling units. An equivalent constraint is imposed for decommissioned units.

$$
N D_{i_{\text {dist }} j T y} \cdot \operatorname{Cap}_{i_{\text {dist }} T}^{D}=N C H D_{i_{\text {dist }} j T y} \quad \forall i_{\text {dist }} j T y
$$

Networks are defined in two ways; networks within zones and networks between zones. For networks between zones, the distance between neighbour zones is fixed. The decision variable is thus the capacity of the network, which relates to the energy flow between zones and ultimately translates into pipe or cable diameter. On the other hand, networks within zones are assumed to be built along roads, and the decision variable is the network length (of each type) built within a zone. The network length for each network type is proportional to the total road length within a zone and to the capacity met by each network for each service demand. For instance, constraint (3.6) states that the fraction of the road length in a given zone that is covered by the gas network is proportional to the ratio of installed capacity of heat end-use technologies that consume gas, over the peak heat demand. Inequalities (3.7) and (3.8) are equivalent regarding electricity networks for heating and cooling respectively; and Inequalities (3.9) and (3.10) are equivalent regarding cooling networks, and hydrogen networks for heat.

$$
\begin{aligned}
& \frac{\sum_{b, i_{\text {ind }}=\text { boilers, gas CHPS }} T C H I_{\text {bi ind } j y}}{D e m_{\text {dom peakdomjy }}^{H} \cdot N u m_{\text {domjy }}+\operatorname{Dem}_{\text {comm peakcomm jy }}^{H} \cdot N u m_{\text {commjy }}} \cdot R l_{j} \\
& \leq T L N_{j} \text { gasny } \quad \forall j y \\
& \sum_{b, i_{\text {ind }}=A S H P, G S H P, \text { eradiators }} T C H I_{b i_{\text {ind }} j y} \\
& \overline{\text { Dem }_{\text {dom peakdomjy }}^{H} \cdot \mathrm{Num}_{\text {domjy }}+\text { Dem }_{\text {comm peakcomm jy }}^{H} \cdot \mathrm{Num}_{\text {commjy }}} \\
& \leq T L N_{\text {jelecn } y} \forall j y \\
& \frac{\sum_{b, i_{\text {indc }}=A C d o m, A C c o m m} \operatorname{TCCI}_{b i_{\text {indc }} j y}}{\operatorname{Dem}_{\text {dom peakdomjy }}^{C} \cdot \mathrm{Num}_{\text {domjy }}+\operatorname{Dem}_{\text {comm peakcommjy }}^{C} \cdot \text { Num }_{\text {commjy }}} \\
& \leq T L N_{\text {jelecn } y} \forall j y \\
& \frac{\sum_{b, i_{\text {indc }}=H X T C \text { dom }, H X T C \text { comm }} T C C I_{b i_{\text {ind }} j y}}{\operatorname{Dem}_{\text {dom peakdomjy }}^{C} \cdot \mathrm{Num}_{\text {domjy }}+\operatorname{Dem}_{\text {comm peakcommjy }}^{C} \cdot N u m_{\text {commjy }}} \cdot R l_{j} \\
& \leq T L N_{j} \operatorname{cooln}\left(T C^{*}\right) y \quad \forall j T C^{*} y \\
& \frac{\sum_{b, i_{\text {ind }}=\text { hyd boilers, hyd CHPs }} \mathrm{TCHI}_{\text {bi ind }} \text { y }}{\operatorname{Dem}_{\text {dom peakdomjy }}^{H} \cdot \mathrm{Num}_{\text {domjy }}+\operatorname{Dem}_{\text {comm peakcomm jy }}^{H} \cdot N u m_{\text {commjy }}} \cdot R l_{j} \\
& \leq T L N_{j h y d n y} \quad \forall j y
\end{aligned}
$$


As mentioned before, hydrogen for transport is assumed to be supplied via pipelines to fuelling stations. However, networks that supply fuelling stations are assumed to run along main, and secondary roads in a zone. Therefore, the split of fuelling stations (and therefore networks connecting them) will be proportional to the total transport demand supplied by hydrogen vehicles in a zone, as shown in Inequality (3.11).

$$
\frac{T C T I_{H y d v} j y}{D e m_{j y}^{T}} \cdot M R l_{j} \leq T L N_{j h y d n y} \quad \forall j y
$$

Electricity networks are used to supply electricity for appliances, for heating, for cooling, and for transport. Inequalities (3.7) and (3.8) ensure that network lengths are enough to supply end-use heat and cooling technologies. Inequality (3.12) ensures that the network can supply all technologies that are operating simultaneously in a given time slice.

$$
\begin{aligned}
& \left(\frac{\sum_{b, i_{\text {ind }}=A S H P, G S H P, \text { eradiators }} \text { OCHI }_{\text {bhi }} \text { ind } j y}{} \frac{\text { Dem }_{\text {dom peakdomjy }}^{H} \cdot \text { Num }_{\text {domjy }}+\text { Dem }_{\text {comm peakcomm } j y}^{H} \cdot \text { Num }_{\text {commjy }}}{\sum_{\text {a }}}\right. \\
& +\frac{\sum_{b, i_{\text {indc }}=A C \text { dom }, A C c o m m} O C C I_{\text {bhi }} i_{\text {ind }} \text { jy }}{} \\
& \frac{\text { OCTI } I_{\text {helecvjy }}}{\eta_{\text {elecv }}^{\text {ThTr }} \cdot \text { Duration }} \\
& +\frac{\eta_{\text {elecv }} \cdot \text { Dem peakdomjy }_{\text {dom }}^{E} \cdot \mathrm{Num}_{\text {domm peakcommjy }} \cdot \mathrm{Num}_{\text {commjy }}}{\text { Eem }} \\
& \left.+\frac{\sum_{b} \text { Dem }_{\text {bhjy }}^{E} \cdot \mathrm{Num}_{\text {bjy }}}{\text { Dem }_{\text {dom peakdomjy }}^{E} \cdot \mathrm{Num}_{\text {domjy }}+\text { Dem }_{\text {comm peakcommjy }}^{E} \cdot \mathrm{Num}_{\text {commjy }}}\right) \cdot R l_{j} \\
& \leq T L N_{\text {jelecn } y} \quad \forall \text { hjy }
\end{aligned}
$$

The last constraint regarding network lengths (constraint (3.13)) ensures that all properties have a heat supply technology. It therefore ensures that all networks that supply heat are at least as long as the road length in each zone. This equation is not applicable for cooling, as only $7 \%$ of domestic properties have air conditioning units.

$$
\begin{aligned}
& +\left(\frac{T_{j} N_{j} \text { gasn y }}{\text { Dem }_{\text {dom peakdomjy }}^{H} \cdot \text { Num }_{\text {domjy }}+\text { Dem }_{\text {comm peakcomm } j y}^{H} \cdot \text { Num }_{\text {commjy }}}\right) \\
& \cdot R l_{j} \\
& +\left(\frac{\sum_{b, i_{\text {ind }}=\text { hyd boilers, hyd CHPs }} \text { TCHI }_{\text {bind }} \text { y }}{\text { Dem }_{\text {dom peakdomjy }}^{H} \cdot \text { Num }_{\text {domjy }}+\text { Dem }_{\text {comm peakcomm jy }}^{H} \cdot \text { Num }_{\text {commjy }}}\right) \\
& \cdot R l_{j} \geq R l_{j} \quad \forall j y
\end{aligned}
$$

An energy balance is implemented for each network and in each zone, as shown in Equation (3.14). 
The above energy balance is performed on a time slice basis, to ensure that building demands are met in each time slice. Regarding transport fuels other than hydrogen, it is assumed that fuelling stations are refilled by trucks. Therefore, as there are no networks in place and thus no need to ensure pipeline capacity for transport fuels (other than hydrogen), and it is assumed that fuels are stored in fuelling stations, time dependence of fuel consumption is not relevant for this work, and we focus on meeting annual demands. Nevertheless, it is assumed that hydrogen fuelling stations for hydrogen-fuelled vehicles are connected to the same network that feeds hydrogen to buildings. Fuel cell vehicles however require a higher purity than hydrogen for heat. Thus, it is assumed that purification is performed onsite at hydrogen fuelling stations. Because of this, Equation (3.14) is used for the flow balance of hydrogen for heat, and a separate annual flow balance is required to account for hydrogen for transport. These two flows are linked later to ensure a sufficient hydrogen network capacity. Equation (3.15) shows the annual energy balance for hydrogen for transport.

$$
F_{j y}^{I N T R H}-F_{j y}^{O U T T R H}+\sum_{j^{\prime}} F_{j^{\prime} j y}^{T R H}-\sum_{j^{\prime}} F_{j j^{\prime} y}^{T R H}-F_{j y}^{C O N S T R H}+F_{j y}^{G E N T R H}=0 \quad \forall j y
$$

The flow consumption and generation terms of Equations (3.14) and (3.15) for each network can be found in Appendix B. The energy balance for electricity ensures that electricity demand for appliances is met. Inequalities (3.16) and (3.17) ensure that cooling and transport demands are met. An equivalent equation to Equation (3.16) is also applied for heat demand. Finally, Inequality (3.18) ensures that the networks' capacity between zones is higher than the energy flow.

$$
\begin{array}{ll}
\sum_{i_{\text {indc }}} \text { OCCI }_{\text {bhi } i_{\text {ind } d y} \geq \text { Dem }_{\text {bhjy }}^{C} \cdot \text { Num }_{b j y}} & \forall b h j y \\
\sum_{i_{\text {trans }}, h} \text { OCTI }_{h_{\text {trans }} j y} \geq \operatorname{Dem}_{j y}^{T} & \forall j y \\
F_{h j j^{\prime} n y} \leq T C N_{j j^{\prime} n y} & \forall h j j^{\prime} n y
\end{array}
$$

Constraint (3.18) ensures the diameter of pipelines or cables connecting zones is enough for the flow in each time slice. For the hydrogen network, we also need to ensure capacity is enough to accommodate for transport demand, even if there is no network installed for heat. The total annual demand for hydrogen for transport and heat is divided by the number of hours in a year, to enable the capacity of pipelines to at least meet hydrogen demand if there was a permanent flow through them. This is ensured through Inequality (3.19).

$$
\frac{F_{j j^{\prime} y}^{T R H}+\sum_{h} F_{h j j^{\prime} h y d n y} \cdot \text { Duration }_{h}}{8760} \leq T C N_{j j^{\prime} \text { hydny }} \quad \forall j j^{\prime} y
$$

Finally, a carbon constraint profile -found in Appendix B- is imposed as described in the following section to account for different decarbonisation scenarios. 


\subsection{Scenario definition}

Two possible ways of considering carbon emissions in this model are either by pricing carbon, or by setting emission targets. For this work, the latter was performed. According to Brazil's intended Nationally Determined Contribution (iNDC) towards achieving the objective of the United Nations Framework Convention on Climate Change (UNCFCC), their targets are to reduce greenhouse gas (GHG) emissions by 37\% below 2005 levels in 2025, and reduce GHG emissions by 43\% below 2005 levels in 2030, in terms of 100 year Global Warming Potential (GWP-100), using IPCC AR5 values [79]. These values include the whole territory and are economy-wide. Although these values are not necessarily directly transferable to a city's emissions, they will be used as the baseline scenario studied in this work. First, economy-wide emissions for the State of Sao Paulo were obtained for the years 2005 and 2015 from [80]. Then, new iNDCs were calculated in relation to 2015, as this is the model's base year. With this, the baseline scenario with reference to 2015 as base year was obtained as shown in Table 7. These values were used in the model for carbon reduction targets. After 2030, the model was constrained to maintain the system's emissions at most at the previous period's levels.

Table 7: iNDCs recalculation for 2015 as base year

\begin{tabular}{lll}
\hline iNDC base year & $\begin{array}{l}\text { Intended carbon } \\
\text { by 2025 }\end{array}$ & $\begin{array}{l}\text { reductions } \\
\text { Intended carbon reductions } \\
\text { by 2030 }\end{array}$ \\
\hline 2005 & $37 \%$ & $43 \%$ \\
2015 & $46 \%$ & $51 \%$ \\
\hline
\end{tabular}

Three scenarios for the power sector, consistent with the World Energy Outlook (WEO) 2017 [81] scenarios for Brazil were studied: the Current Policies (CP) scenario, the New Policies (NP) scenario, and the Sustainable Development (SD) scenario. These three scenarios assume different policies for the power sector, and therefore produce different carbon emissions associated to the electricity consumed from the grid. For each of these scenarios, a business as usual (BAU) and a decarbonisation (DEC) case were studied, obtaining six scenarios studied in this research. The BAU scenarios do not impose carbon constraints, while decarbonisation scenarios impose the model to meet the carbon constraints defined in Table 7. The six scenarios are presented in Table 8.

Table 8: Scenario definition

\begin{tabular}{lll}
\hline WEO Scenario & $\begin{array}{l}\text { Business as usual (BAU), no } \\
\text { carbon constraint }\end{array}$ & $\begin{array}{l}\text { Meeting iNDC } \\
\text { (Decarbonisation-DEC) }\end{array}$ \\
\hline Current Policies (CP) & CP-BAU & CP-2/3DEC (CP-DEC ${ }^{3}$ ) \\
New Policies (NP) & NP-BAU & NP-DEC \\
Sustainable Development (SD) & SD-BAU & SD-DEC \\
\hline
\end{tabular}

The technoeconomic data of network infrastructure and end-use technologies, together with energy prices and emission factors are presented in Appendix $C$. The model was implemented in the General Algebraic Modeling System (GAMS) 25.0.3, a software for modelling and solving complex and large scale linear, non-linear, and mixed integer

\footnotetext{
${ }^{3}$ As explained in the Results section, this scenario was infeasible due to impossibility of meeting the carbon budget within the time horizon. Therefore, for Current Policies a new decarbonisation target was added, meeting $2 / 3$ of decarbonisation targets. This scenario is called CP-2/3DEC.
} 
optimisation applications [82]. It was first run for all scenarios for the base year only (2015), imposing initial technology mixes. Capacities of equipment, networks in place, and carbon emissions obtained for the base year were then imposed to calibrate initial starting points for the runs.

\section{Results and discussion}

The model was run for the 6 previously described scenarios. The CP-DEC scenario was infeasible. This means that intended decarbonisation cannot be met with the current policies for the power sector. A new decarbonisation target was thus added for the Current Policies scenarios, in which the decarbonisation target is relaxed to $2 / 3$ of the initially intended value (See Table 8).

Firstly, since all 3 BAU scenarios have the same costs and no restrictions for carbon emissions, the technology mixes are the same for all of them, although the total system's carbon emissions are different. Figure 6 shows the installed capacity of end-use technologies for space-cooling supply in domestic and commercial properties for the BAU scenarios. Figure 7 shows the share of district cooling in the total supply of space-cooling service demands for all scenarios.

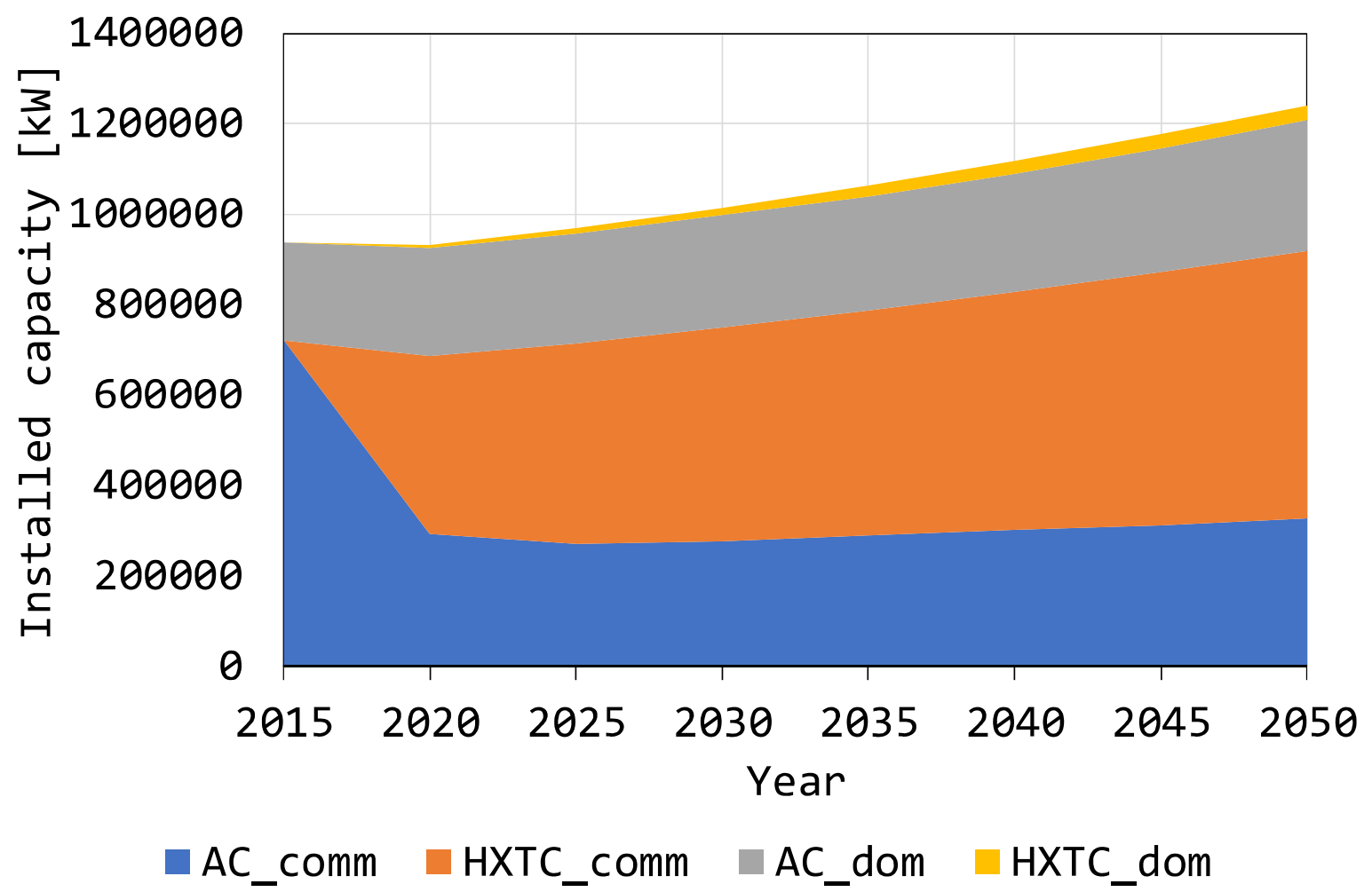

Figure 6: Total installed capacity of individual space-cooling technologies, all BAU scenarios. 

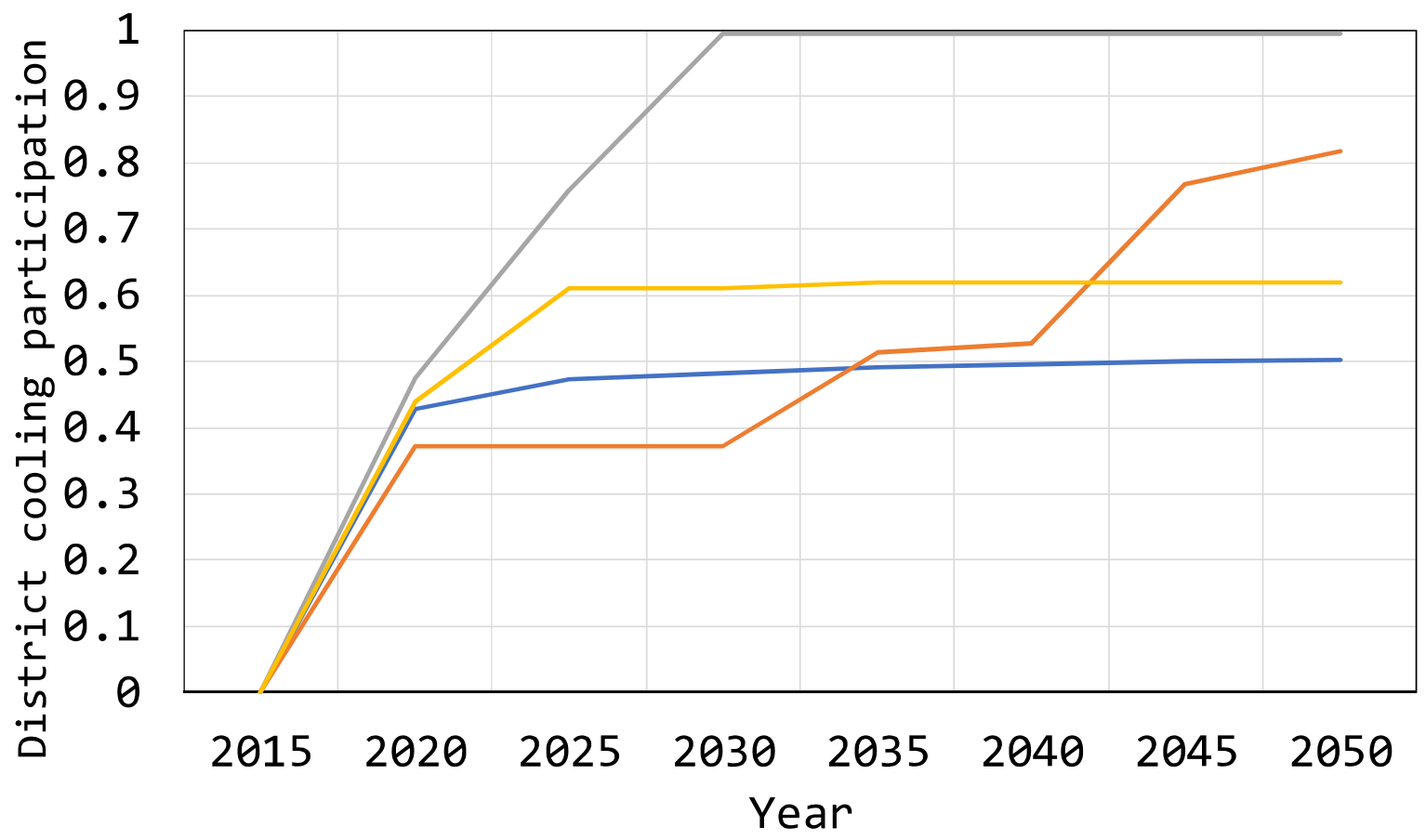

-All-BAU -CP_2/3DEC -NP_DEC -SD_DEC

Figure 7: Total district cooling participation in space cooling supply, all scenarios

The following figures present spatially-resolved heat exchanger penetration for supplying cooling demands, and the location and installed capacity of district cooling supply units. As shown in Figure 7, by 2030 all scenarios except from CP-2/3DEC have nearly reached the final percentage of participation of district cooling networks. Therefore, the spatial results are presented for the last modelled year, 2050, for all scenarios. Additionally, results for the CP-2/3DEC scenario are shown for the year 2030. Figure 8 to Figure 12 show the heat exchanger penetration as a percentage of total individual space cooling installed capacity for each zone. 


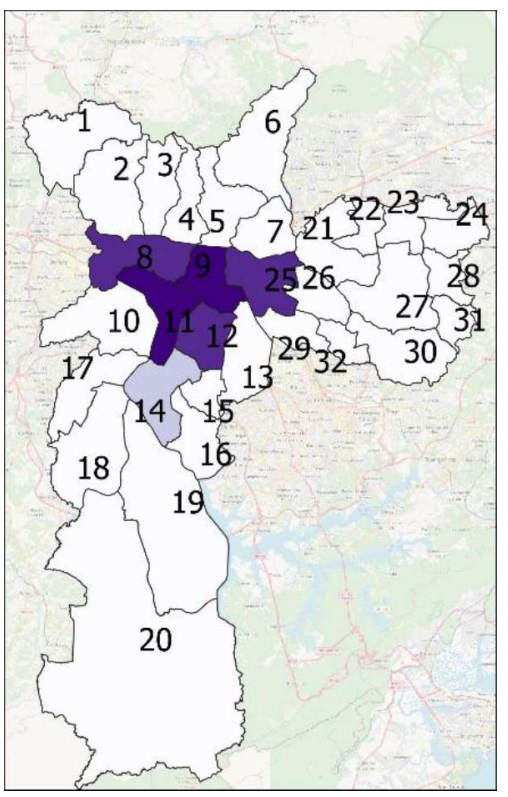

Figure 8: Heat exchanger penetration BAU scenarios, 2050.

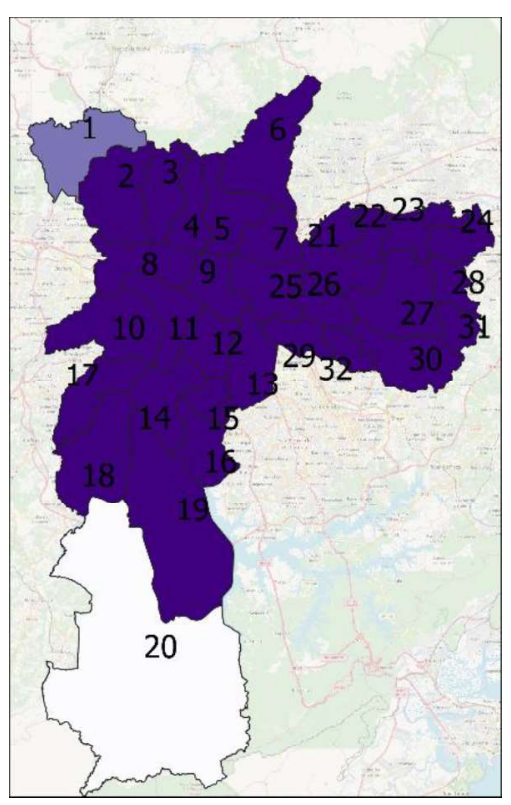

Figure 11: Heat exchanger penetration NP-DEC scenario, 2050.

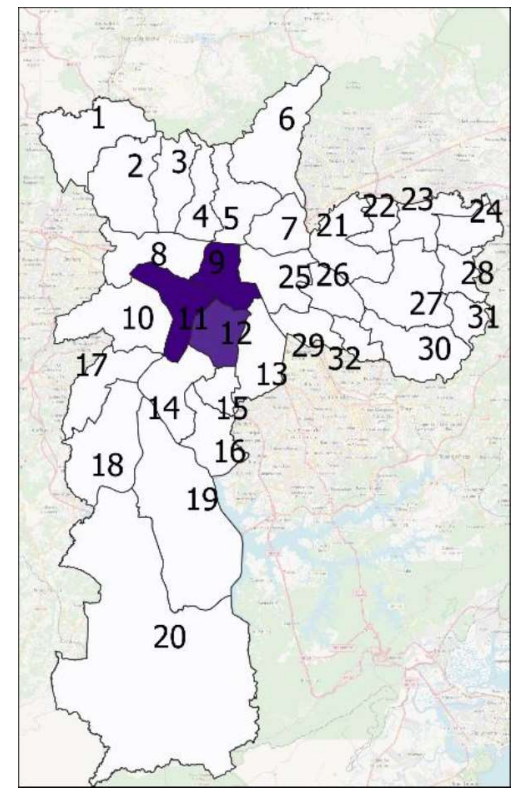

Figure 9: Heat exchanger penetration CP-2/3DEC scenario, 2030.

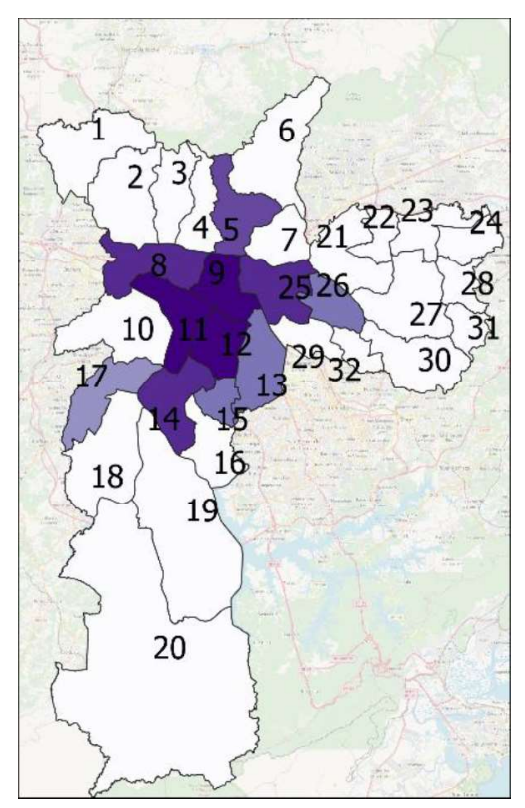

Figure 12: Heat exchanger penetration SD-DEC scenario, 2050.

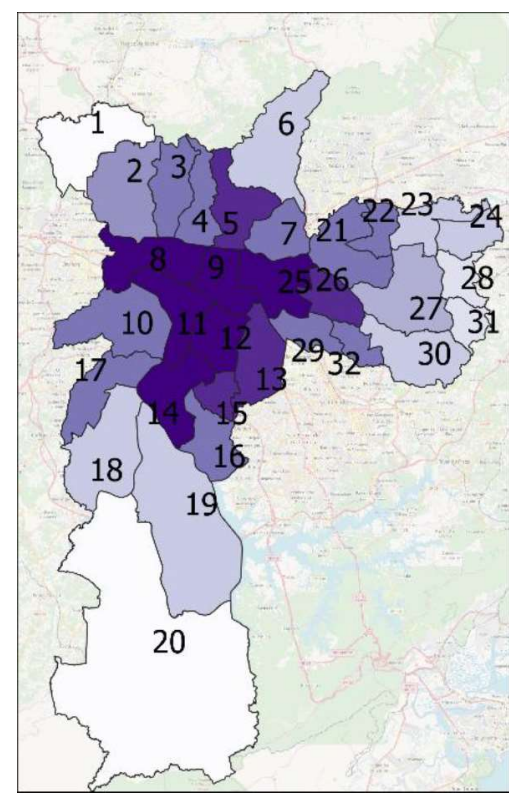

Figure 10: Heat exchanger penetration CP-2/3DEC scenario, 2050.

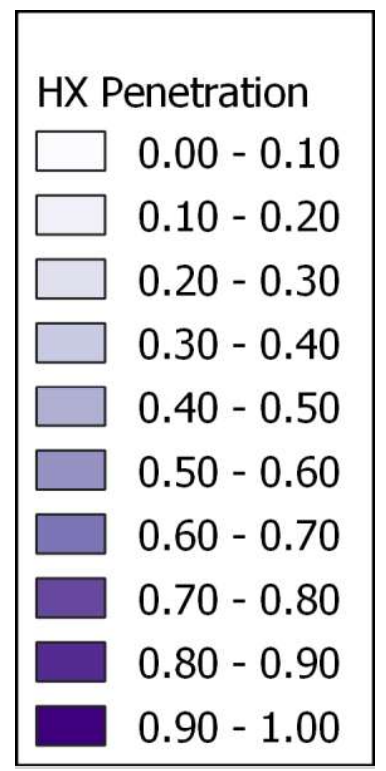

The BAU scenarios resulted in the lowest penetration of district cooling networks, as the capital costs of district cooling including networks and equipment are higher than for individual units, and no carbon constraint is in place. However, as there is a trade-off between network costs, energy supply costs, and end-use technology costs and efficiencies, when cooling demands are high enough, cooling networks become cost effective despite having higher capital costs, as the network costs are split over more customers and higher demands. An indicator of demands being high enough for enabling cost-effective deployment of cooling networks is the linear cooling density (LCD), which considers the total annual cooling demand over the road length. This indicator is equivalent to linear heat density discussed in [14], and normalises the demand by the length of the required network. 
Figure 13 and Figure 14 show the LCDs for the different zones in 2030 and 2050 respectively. For the $\mathrm{BAU}$ scenarios, a full penetration of district cooling networks is obtained by 2050 for LCDs over $1100 \mathrm{kWh} / \mathrm{m}$, and over $80 \%$ and $40 \%$ penetrations are obtained for zones with LCDs over $300 \mathrm{kWh} / \mathrm{m}$ and $200 \mathrm{kWh} / \mathrm{m}$ respectively. When decarbonisation targets are imposed, these thresholds decrease, enabling cost-effective deployment of cooling networks at lower LCDs. For the CP-2/3DEC scenario presented in Figure 10, for a LCD of over $270 \mathrm{kWh} / \mathrm{m}$, full penetration of cooling networks is obtained by 2050, and for LCDs above $160 \mathrm{kWh} / \mathrm{m}$, and $80 \mathrm{kWh} / \mathrm{m}$, penetrations of $80 \%$ and $60 \%$ are obtained respectively by 2050 .

The NP-DEC scenario (Figure 11), is the most constrained feasible scenario modelled. It has more demanding $\mathrm{CO}_{2}$ reduction targets than the $\mathrm{CP}-2 / 3 \mathrm{DEC}$ scenario, and its power sector has higher carbon emissions than for the SD-DEC scenario. This means that more efficient and expensive technologies are needed to meet the decarbonisation constraints. Therefore by 2050 all zones with over $50 \mathrm{kWh} / \mathrm{m}$ present full cooling network penetration by 2050 . This high penetration at low linear cooling densities- despite high capital costs of district cooling networks and equipment- is explained by the high efficiency of district cooling units. While the coefficient of performance of district cooling units is 5 , the efficiency of individual air-conditioning units is 0.56 . Thus, in scenario NP-DEC- a carbon constrained scenario with a relatively high carbon intensive electricity grid- the only way of meeting carbon constraints is consuming less electricity to supply cooling demands. This is the case with district cooling, as a result of the high coefficient of performance of the chillers, even when considering network and heat exchanger losses.

Finally, for scenario SD-DEC shown in Figure 12, an overall lower penetration of cooling networks is observed than for the other decarbonisation scenarios. This is because in this scenario the power sector has the lowest emission factors, therefore more efficient and expensive technologies are not as necessary for reaching the same decarbonisation targets. In this case, a full penetration of district cooling networks is obtained by 2050 with LCDs over $580 \mathrm{kWh} / \mathrm{m}$, while penetrations of over $80 \%$ and $60 \%$ are obtained for LCDs of over $270 \mathrm{kWh} / \mathrm{m}$ and $160 \mathrm{kWh} / \mathrm{m}$ respectively. 


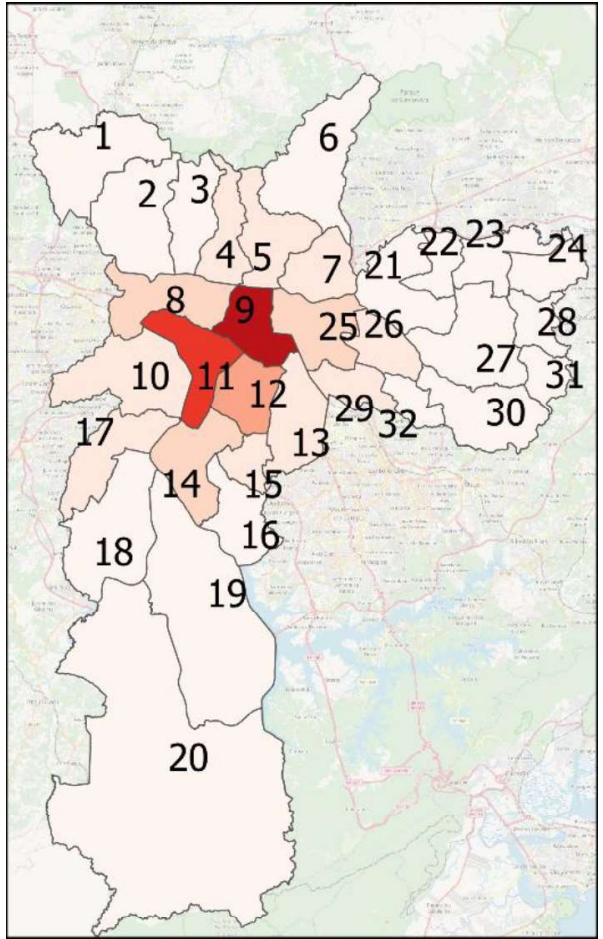

Figure 13: Linear cooling density 2030

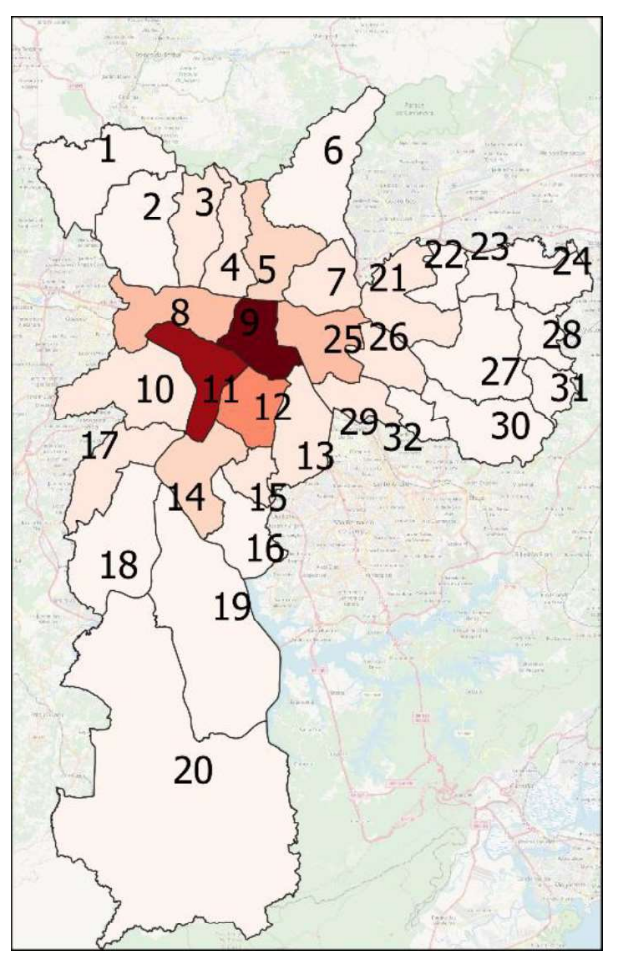

Figure 14: Linear cooling density 2050

Figure 15 to Figure 19 show the location of district cooling supply technologies for all modelled scenarios. As for the penetration of cooling networks, the location of district cooling technologies is also directly related to linear cooling density, as seen when comparing these results with Figure 13 and Figure 14. For the NP-DEC scenario (Figure 18) although by 2050 full penetration of district cooling networks is obtained for all zones, the major concentration of district cooling units is obtained in the densest cooling zones. 

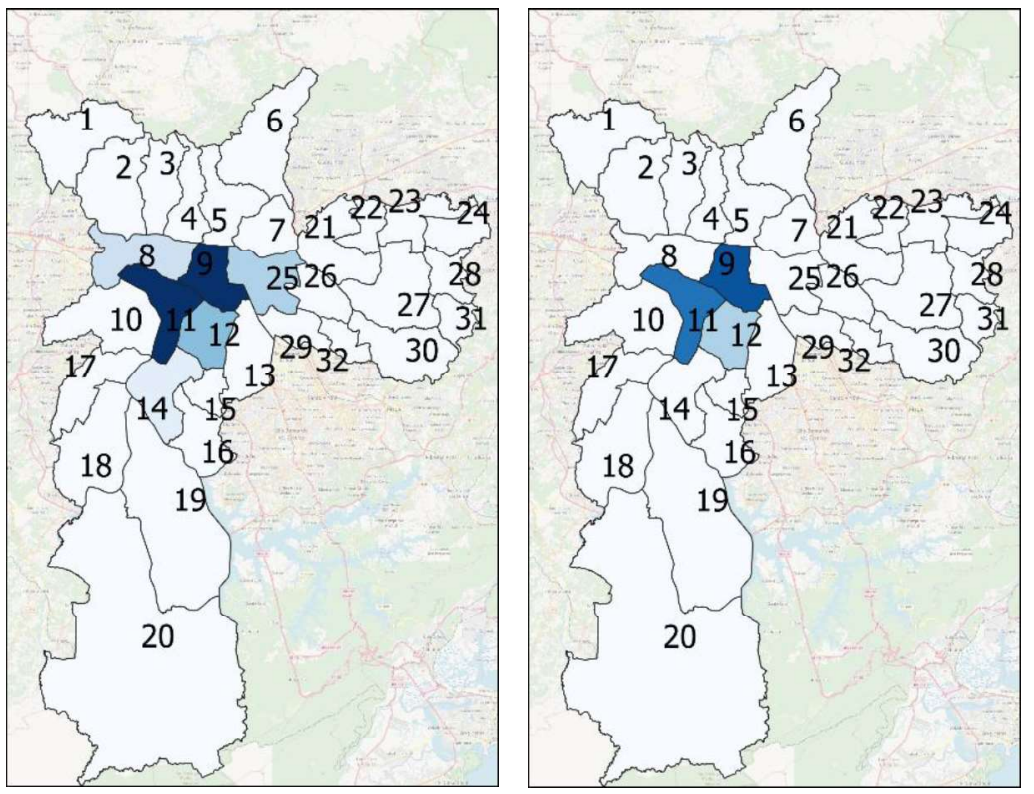

Figure 15: Installed capacity of district cooling chillers, BAU scenarios, 2050.

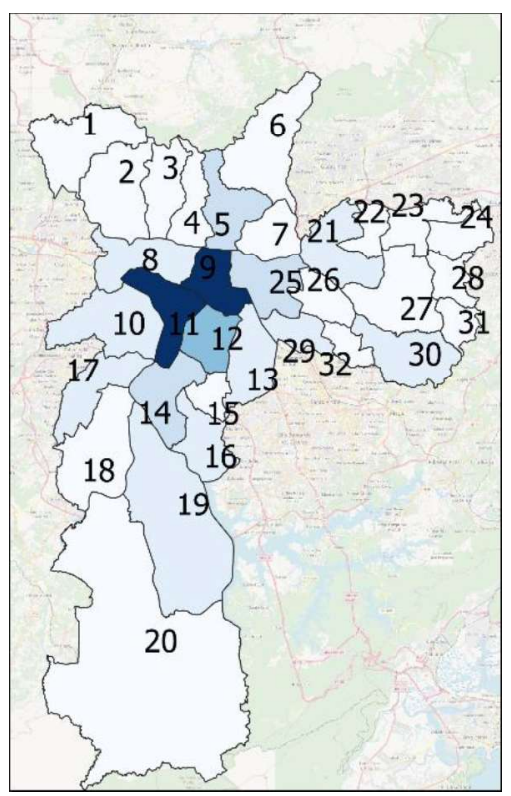

cooling chillers, CP-2/3DEC scenario, 2030.

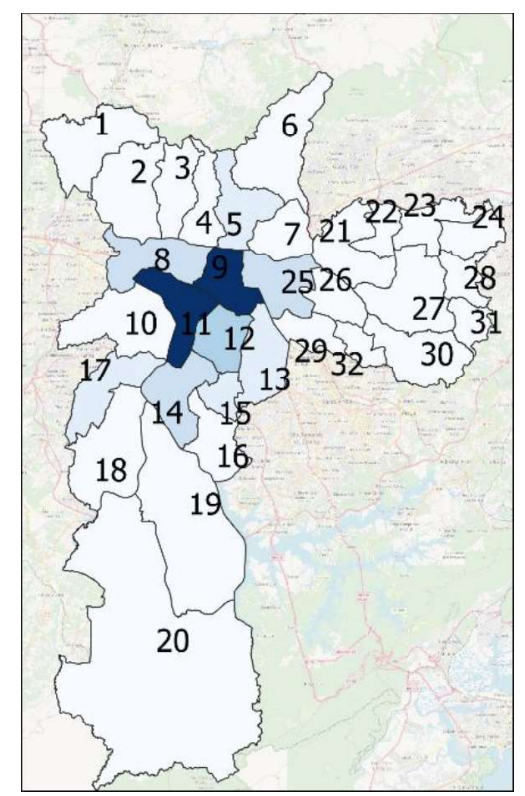

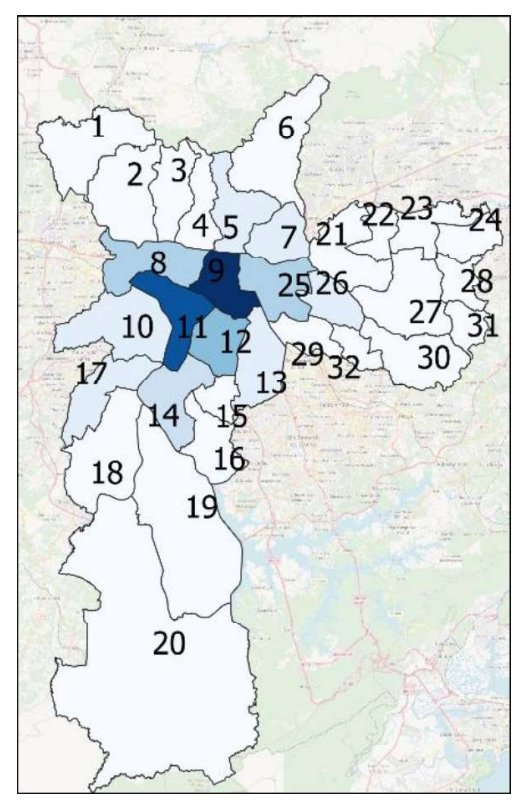

Installed capacity [kW]

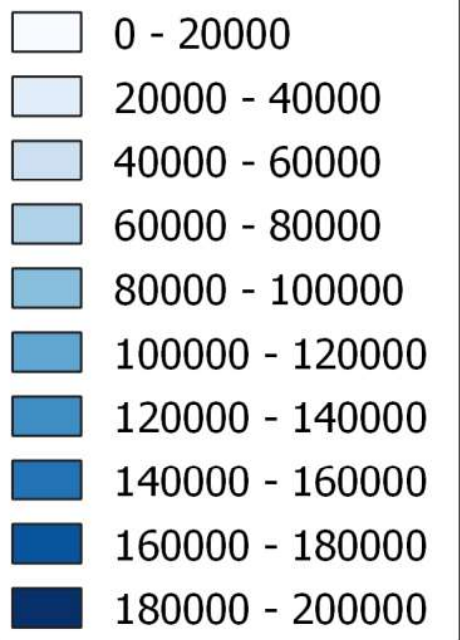

Figure 18: Installed capacity of district Figure 19: Installed capacity of district cooling chillers, NP-DEC scenario, 2050. cooling chillers, SD-DEC scenario, 2050.

Figure 20 shows the installed capacity of end-use technologies for heat supply in domestic and commercial properties, for the BAU scenarios. Figure 21, Figure 22 and Figure 23, present the total installed capacity of end-use technologies for heat supply for the three power sector decarbonisation scenarios. 


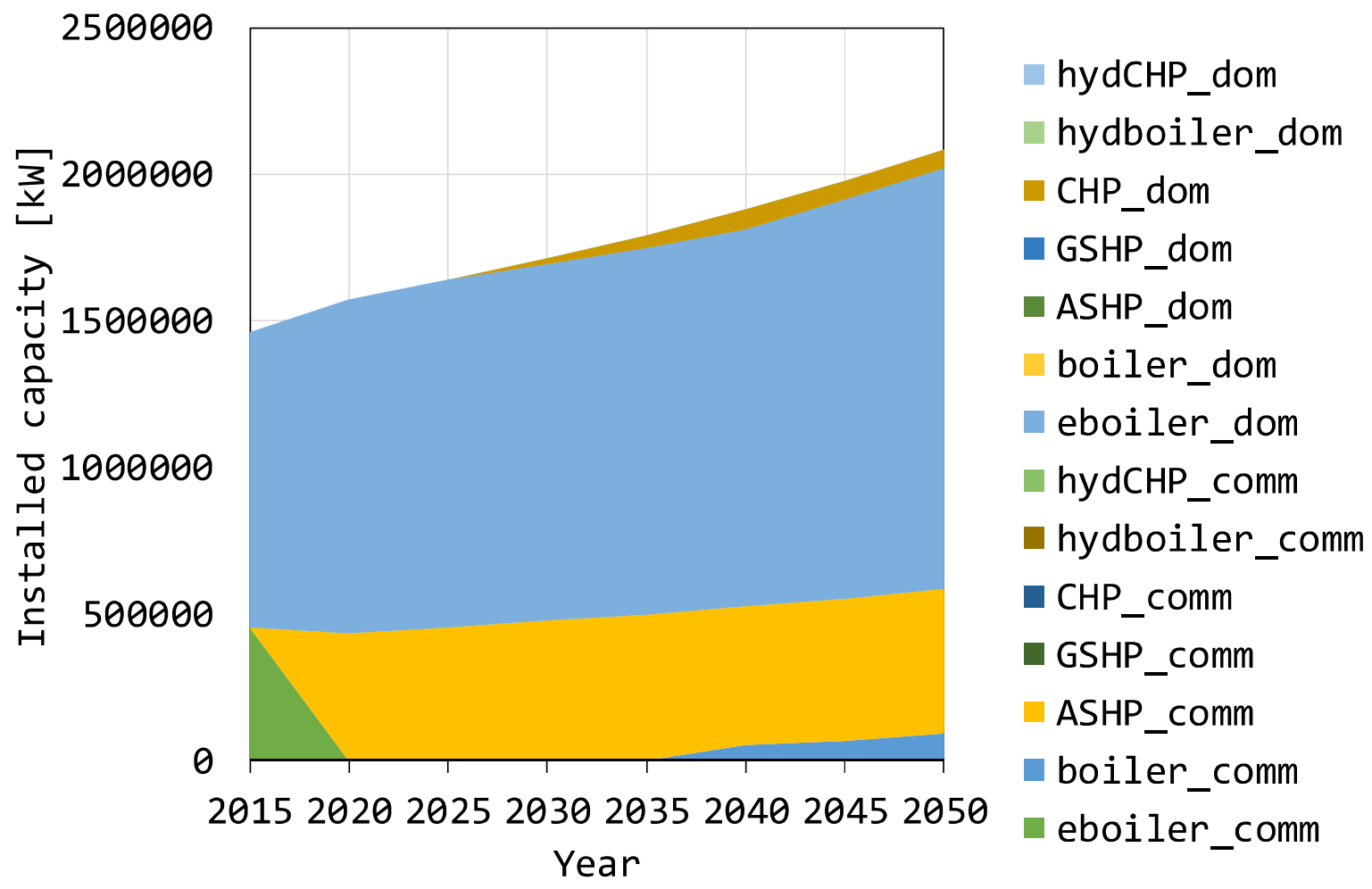

Figure 20: Total installed capacity of end-use heat supply technologies. All BAU scenarios.
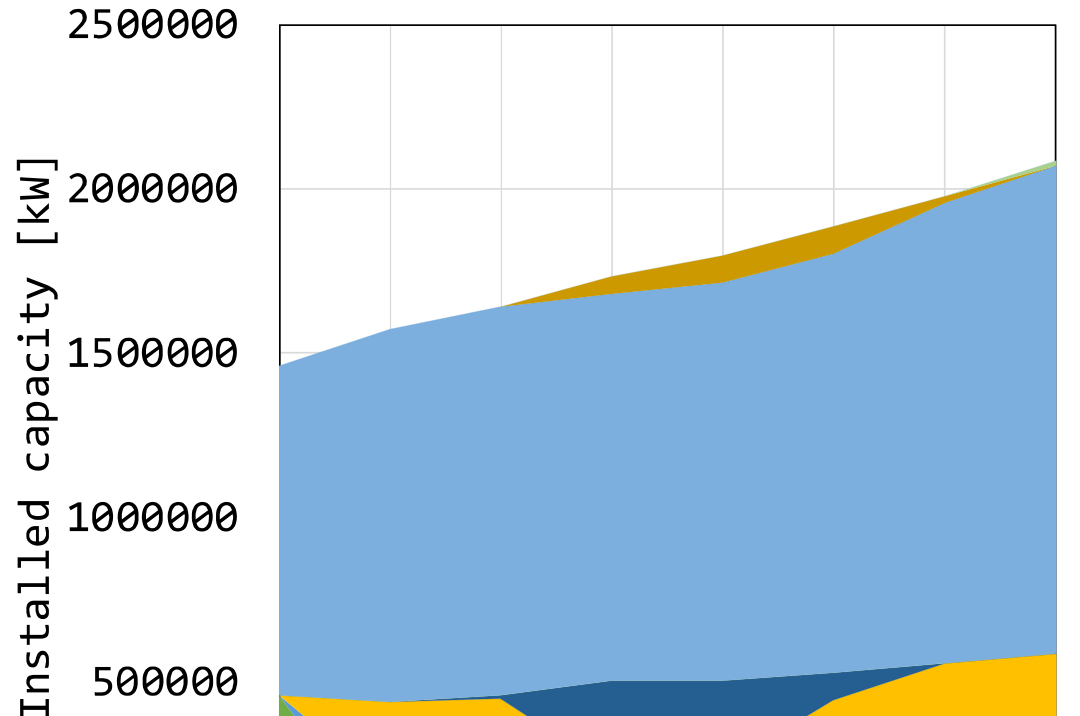

0

20152020202520302035204020452050 Year
hydCHP_dom

hydboiler_dom

CHP_dom

-GSHP_dom

ASHP_dom

boiler_dom

eboiler_dom

hydCHP_comm

nydboiler_comm

-CHP_comm

aSHP_comm

ASHP_comm

boiler_comm

- eboiler_comm

Figure 21: Total installed capacity of end-use heat supply technologies. CP-2/3DEC scenario. 


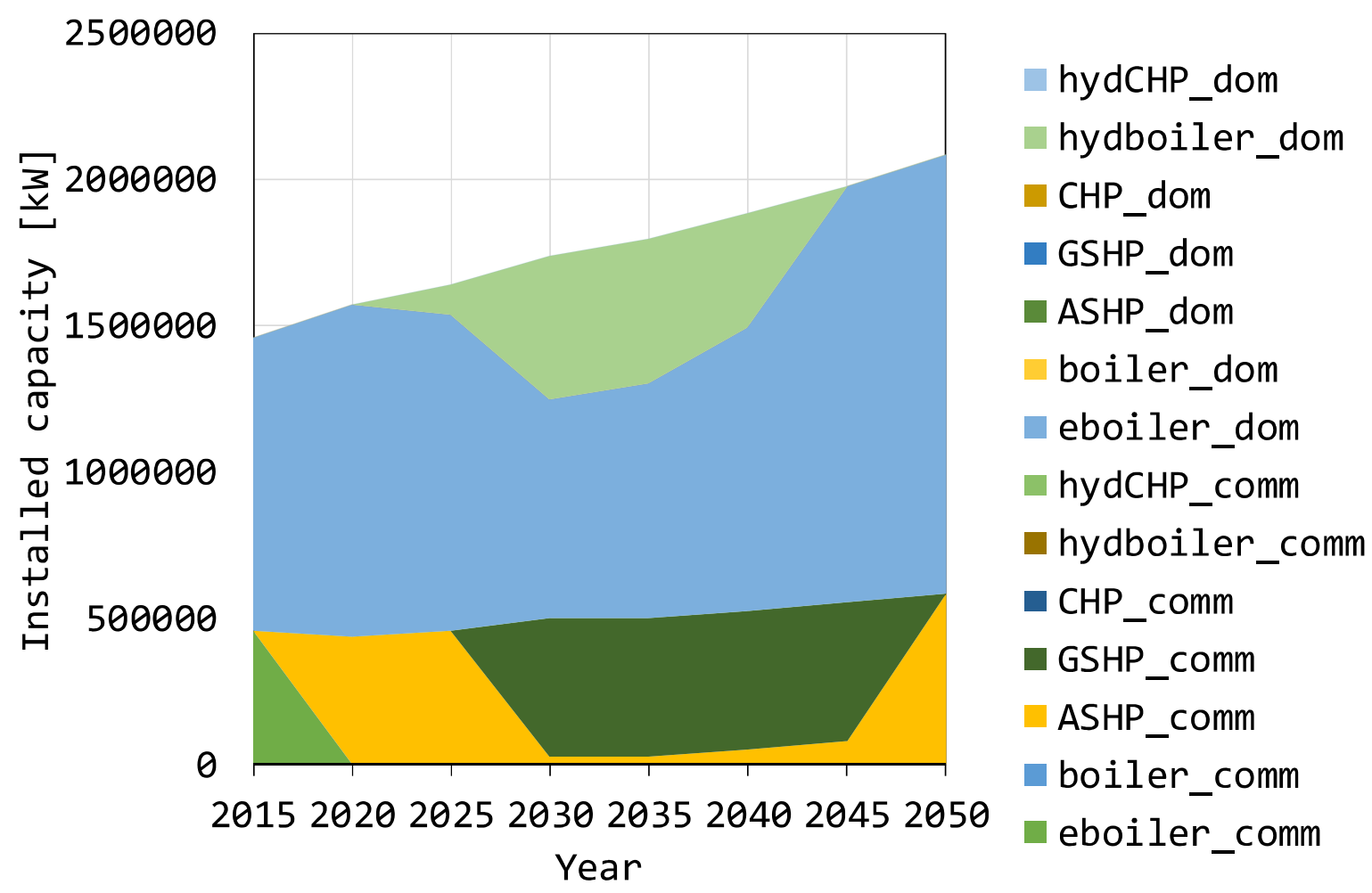

Figure 22: Total installed capacity of end-use heat supply technologies. NP-DEC scenario.

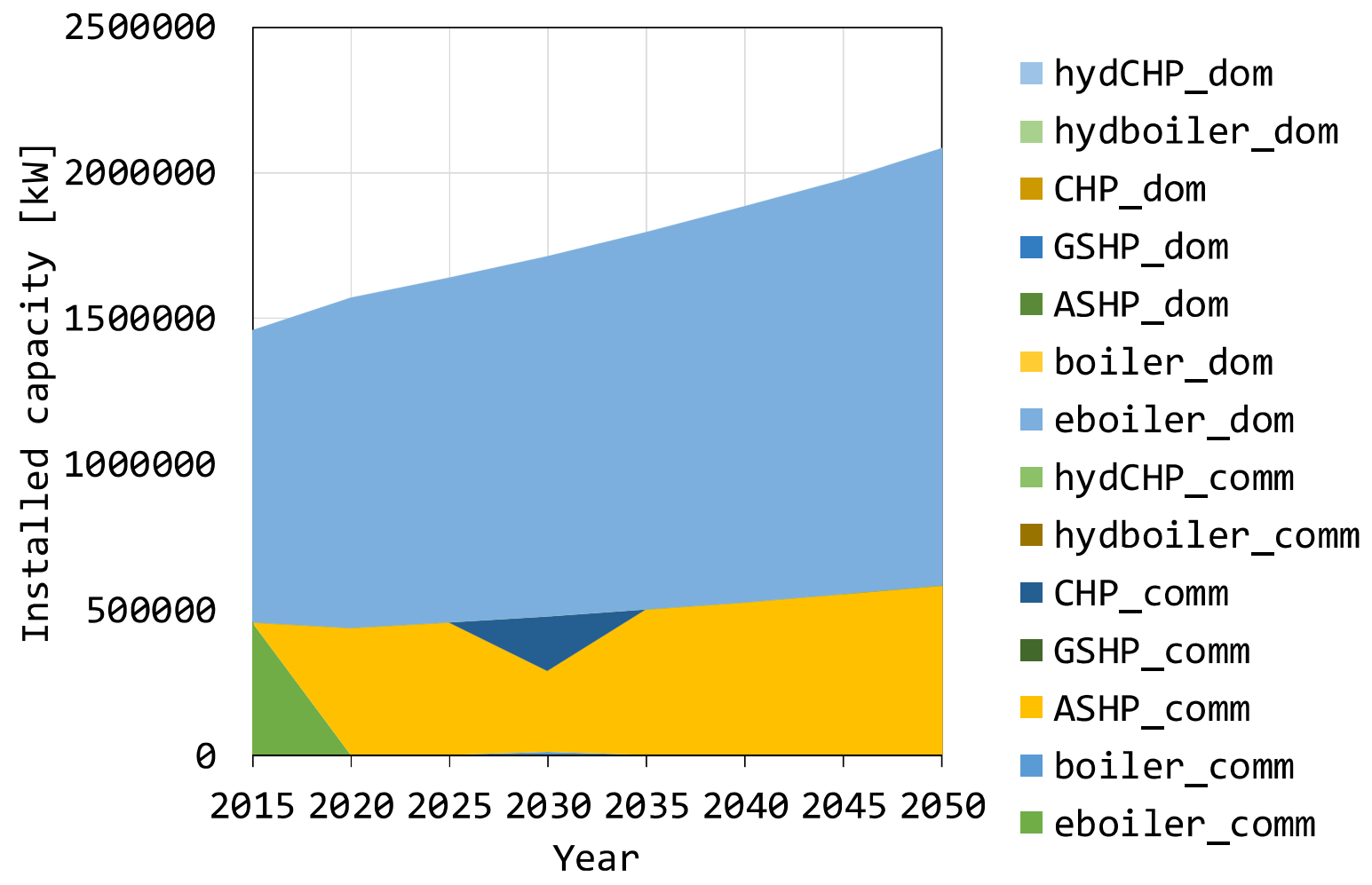

Figure 23: Total installed capacity of end-use heat supply technologies. SD-DEC scenario.

For the BAU scenarios shown in Figure 20, electric boilers in the commercial sector are replaced by air-source heat pumps, and some gas boilers from 2040 . Even though in the BAU scenarios there are no decarbonisation targets which would explain the introduction of 
heat pumps, the higher efficiencies of air-source heat pumps are able to offset their higher capital costs compared to electric boilers. This happens in the commercial sector and not in the domestic sector because of its higher demands per dwelling. Towards the end of the time horizon, some gas boilers are introduced in the commercial sector, as the price of gas is cheaper than for electricity. Conversely, for the domestic sector, electric boilers continue to be the most cost-effective solution, as heat demands are not high enough for lower gas prices to offset the lower capital costs of electric boilers compared to gas boilers. From 2030 on, some domestic gas CHP units are observed, reaching around $4 \%$ of the total heat installed capacity for the domestic sector by 2050.

For the CP-2/3DEC scenario presented in Figure 21, the initial electric boilers in the commercial sector are replaced in 2020 by a combination of gas boilers and air-source heatpumps. As this scenario imposes decarbonisation targets from 2030 on, gas boilers can be seen as a first low-cost transition technology. Gas CHPs can be seen as a second low-carbon transition technology, which serve the purpose of decarbonising heat supply while the transition to a lower carbon electricity grid is achieved. Towards the end of the modelled time horizon when decarbonisation of the power grid intensifies, air-source heat pumps reappear in the mix from 2040 on as the system's most cost-effective technology for supplying commercial heat while meeting decarbonisation targets. In the domestic sector, as for the BAU scenario, electric boilers are the most cost-effective solution that meets decarbonisation targets, with some gas CHP units covering around $6 \%$ of the domestic heat installed capacity in 2035. Additionally, around 1\% of hydrogen boilers are installed by 2050.

For the NP-DEC scenario (Figure 22), as the system is constrained to decarbonise more than in the previous scenarios (CP-2/3DEC), heat supply in the commercial sector switches from initial electric boilers to air-source heat pumps, and then to ground-source heat pumps, despite these being more capital expensive. This is due to the higher efficiencies of the latter. Then, after ground-source heat pumps meet their lifetimes, the system goes back to air-source heat pumps in 2050, as the electricity grid has reached deeper decarbonisation. For the domestic sector, electric boilers are partly replaced by hydrogen boilers, which appear in the mix as a transition technology and reach $40 \%$ of the domestic heat installed capacity in 2030. As for the commercial sector, as the power sector reaches its full final decarbonisation, electric boilers re-enter the mix. The most unexpected results regarding heating technologies occur in this scenario. As previously explained, as the system needs to reach decarbonisation targets with a power sector that takes longer to decarbonise than in the other scenarios, there is a transition period between 2030 and 2045 where hydrogen boilers appear in the domestic sector, and ground- source heat pumps are installed in the commercial sector as transition technologies. While in 2030 ground-source heat pumps cover around $95 \%$ of the installed heat supply capacity of the commercial sector, hydrogen boilers represent $40 \%$ of the domestic heat installed capacity, as previously stated. In order to understand how this $40 \%$ of total installed capacity of hydrogen boilers is distributed among zones, Figure 24 shows the linear heat density (total annual heat demand over road length) of all zones for 2030, while Figure 25 shows the penetration of hydrogen boilers with respect to the total installed capacity of heating technologies in 2030. While comparing these two figures there is an evident relation between linear heat density and hydrogen boiler penetration (specifically, at higher linear heat densities there is a higher penetration of hydrogen boilers), Figure 26 can aid to get a better understanding of this relationship. As the commercial sector has much higher individual heating demands that make ground- 
source heat pumps cost-effective, and therefore no hydrogen boilers are installed in the commercial sector, it is useful in this case to look at hydrogen boiler penetrations from the perspective of the domestic sector exclusively. Figure 26 shows the penetration of hydrogen boilers with respect to the domestic installed capacity of heating technologies only, for 2030. This figure shows that for linear heat densities over $300[\mathrm{kWh} / \mathrm{m}]$, penetrations of hydrogen boilers are over $30 \%$ of the domestic sector's installed capacity of heating technologies, and for linear heat densities over $400[\mathrm{kWh} / \mathrm{m}]$, penetrations of hydrogen boilers over $70 \%$ of the domestic sector's heat capacity is obtained. 


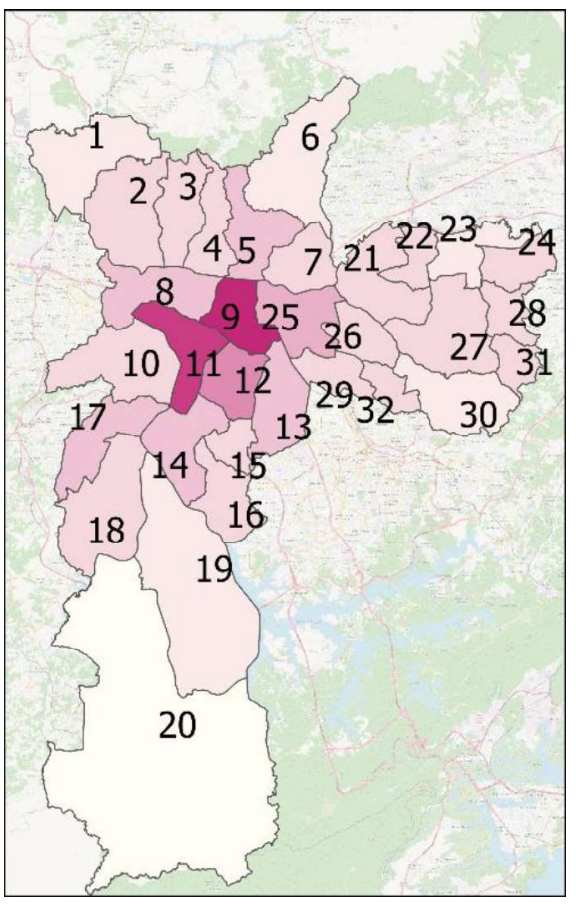

Linear heat density $[\mathrm{kWh} / \mathrm{m}]$

\begin{tabular}{|l}
$\square \quad 0-100$ \\
$\square \quad 100-200$ \\
$\square \quad 200-300$ \\
$300-400$ \\
$400-500$ \\
$500-600$ \\
$\square 00-700$ \\
$700-800$ \\
$800-900$ \\
$900-1000$ \\
$1000-1100$ \\
$1100-1200$ \\
\hline$\square$
\end{tabular}

Figure 24: Linear heat density, 2030.
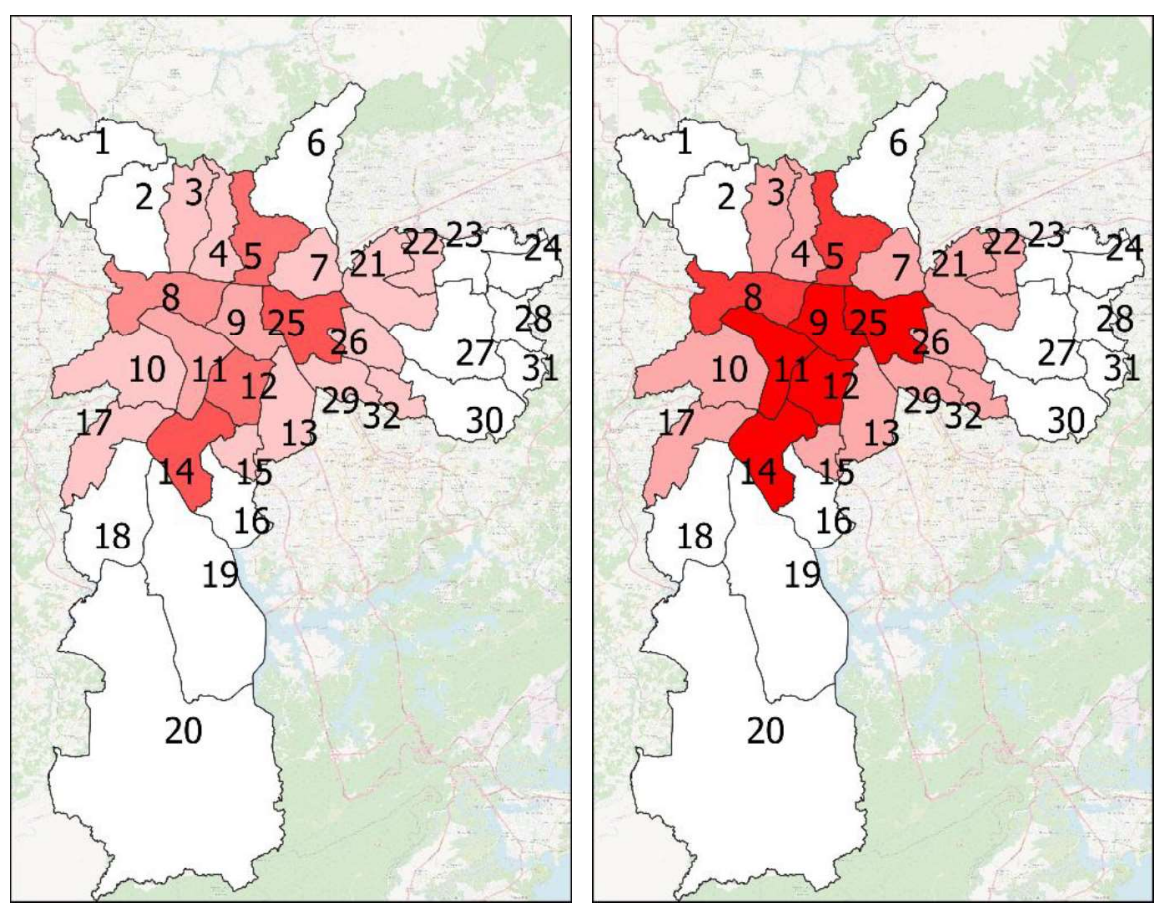

$\mathrm{H}$ boiler penetration

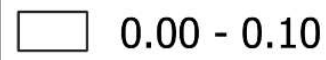

$0.10-0.20$

$0.20-0.30$

$0.30-0.40$

$0.40-0.50$

$0.50-0.60$

$0.60-0.70$

$0.70-0.80$

$0.80-0.90$

$0.90-1.00$

Figure 25: Domestic hydrogen boiler Figure 26: Domestic hydrogen boiler penetration with respect to all heating penetration with respect to domestic only Installed capacity, NP-DEC scenario, 2030. heating installed, NP-DEC scenario, 2030.

Finally, regarding heat supply in the SD-DEC scenario, air-source heat pumps replace electric boilers in the commercial sector, while electric boilers continue to be the main technology to supply domestic heat. This scenario has the most decarbonised power sector, and therefore emission targets are easily met with electric heat supply technologies. In this scenario, commercial CHP units appear as a transition technology in 2025. CHP units are only installed in zones, 9, 11, and 12. These three zones are the linear heat densest zones, as 
shown in Figure 24. In zones 9 and 11 where linear heat densities are between 1000 and $1200[\mathrm{kWh} / \mathrm{m}]$, penetration of commercial CHPs reaches $58 \%$ and $57 \%$ of the total installed capacity of heat technologies, respectively. In zone 12 , where the linear heat density is between 600 and $700[\mathrm{kWh} / \mathrm{m}]$, the penetration of commercial CHPs is around $5 \%$ of the total heat installed capacity. No CHP units are observed at lower linear heat densities in this scenario.

Figure 27 presents the transport sector total capacity for the three BAU scenarios, while Figure 28, Figure 29, and Figure 30 present the transport sector total capacity for the three power sector decarbonisation scenarios.

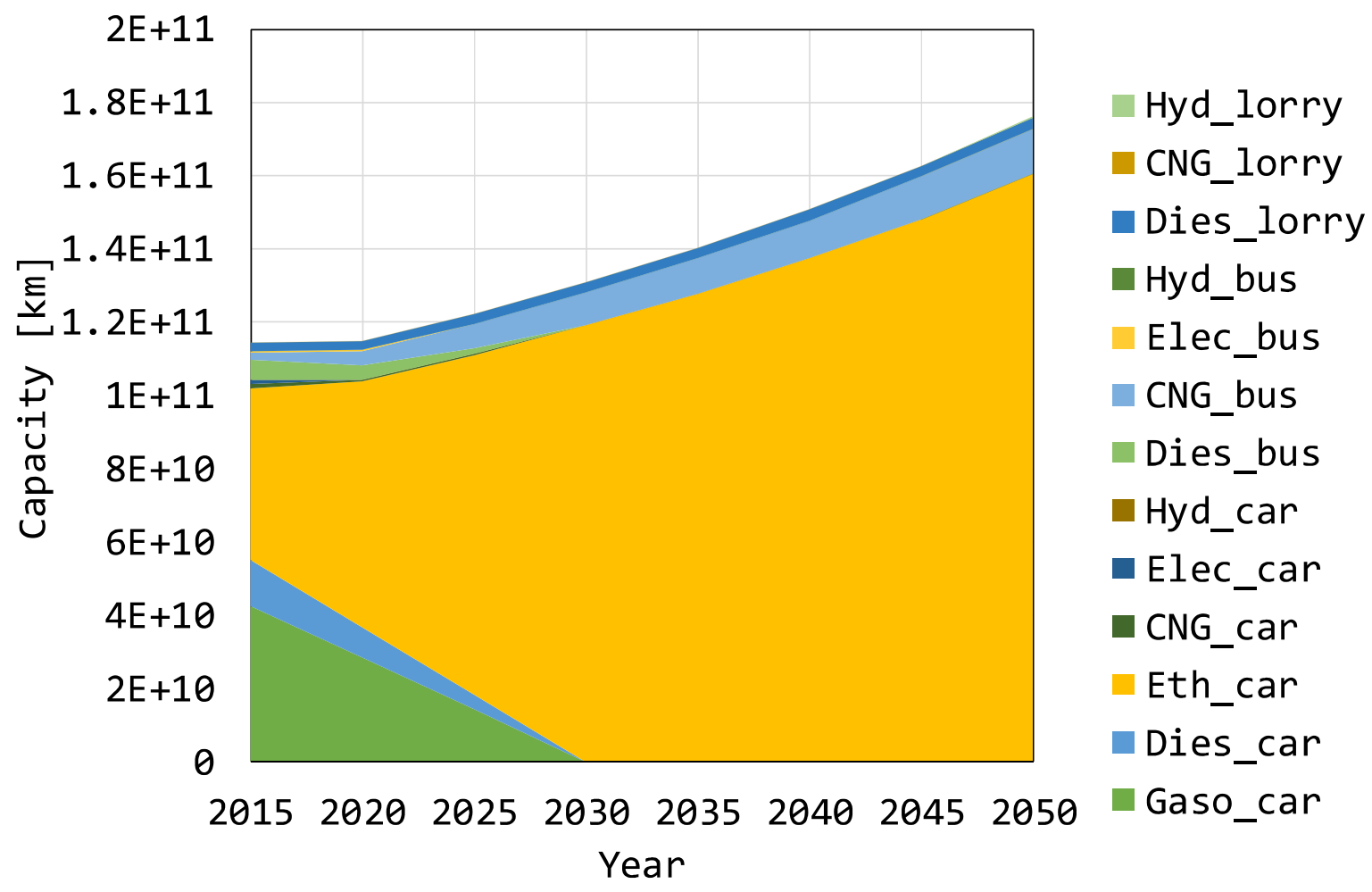

Figure 27: Total capacity transport sector. All BAU scenarios. 


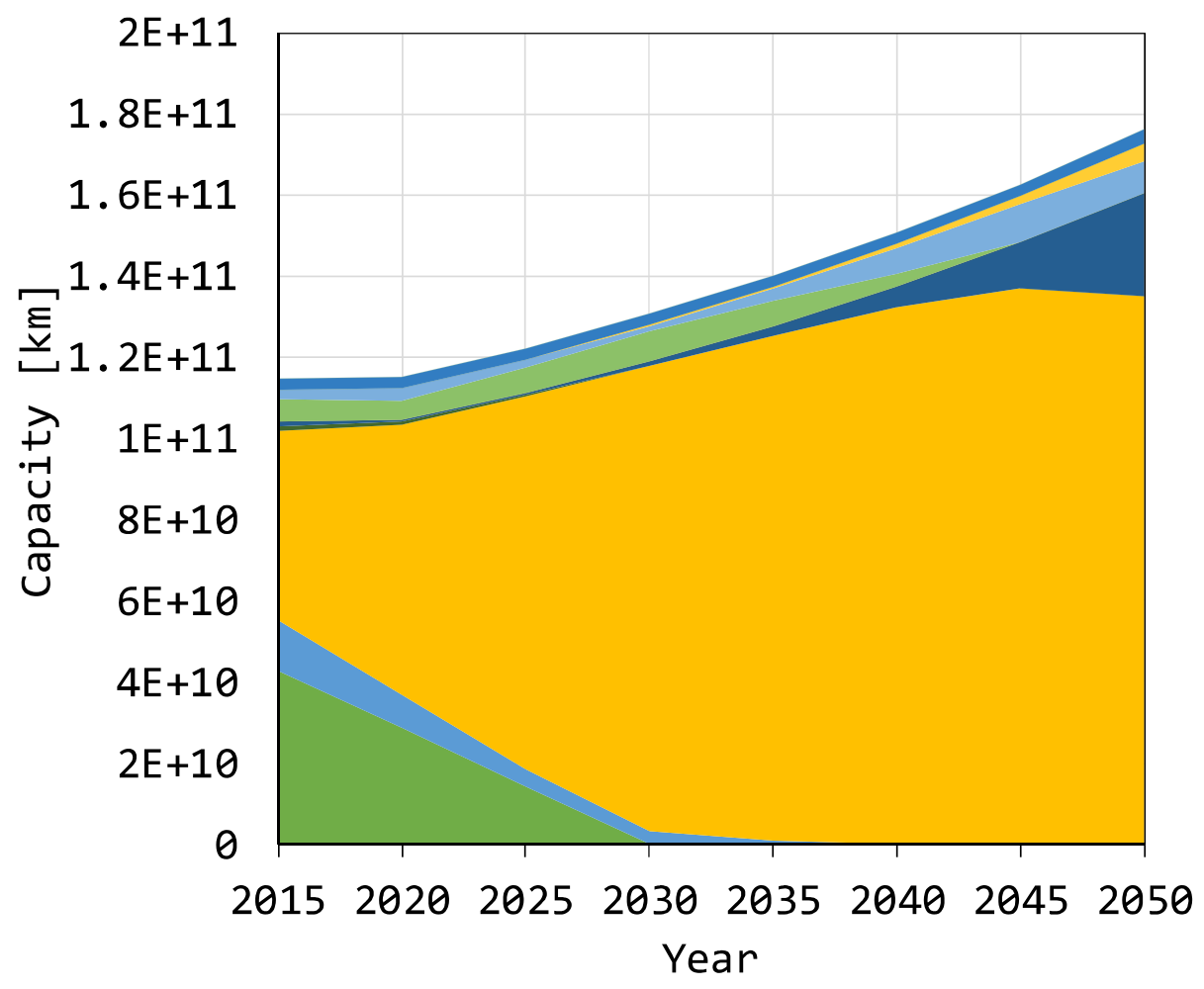

Hyd_lorry

- CNG_lorry

- Dies_lorry

- Hyd_bus

Elec_bus

- CNG_bus

- Dies_bus

- Hyd_car

- Elec_car

- CNG_car

Eth_car

- Dies_car

- Gaso_car

Figure 28: Total capacity transport sector. CP-2/3DEC scenario.

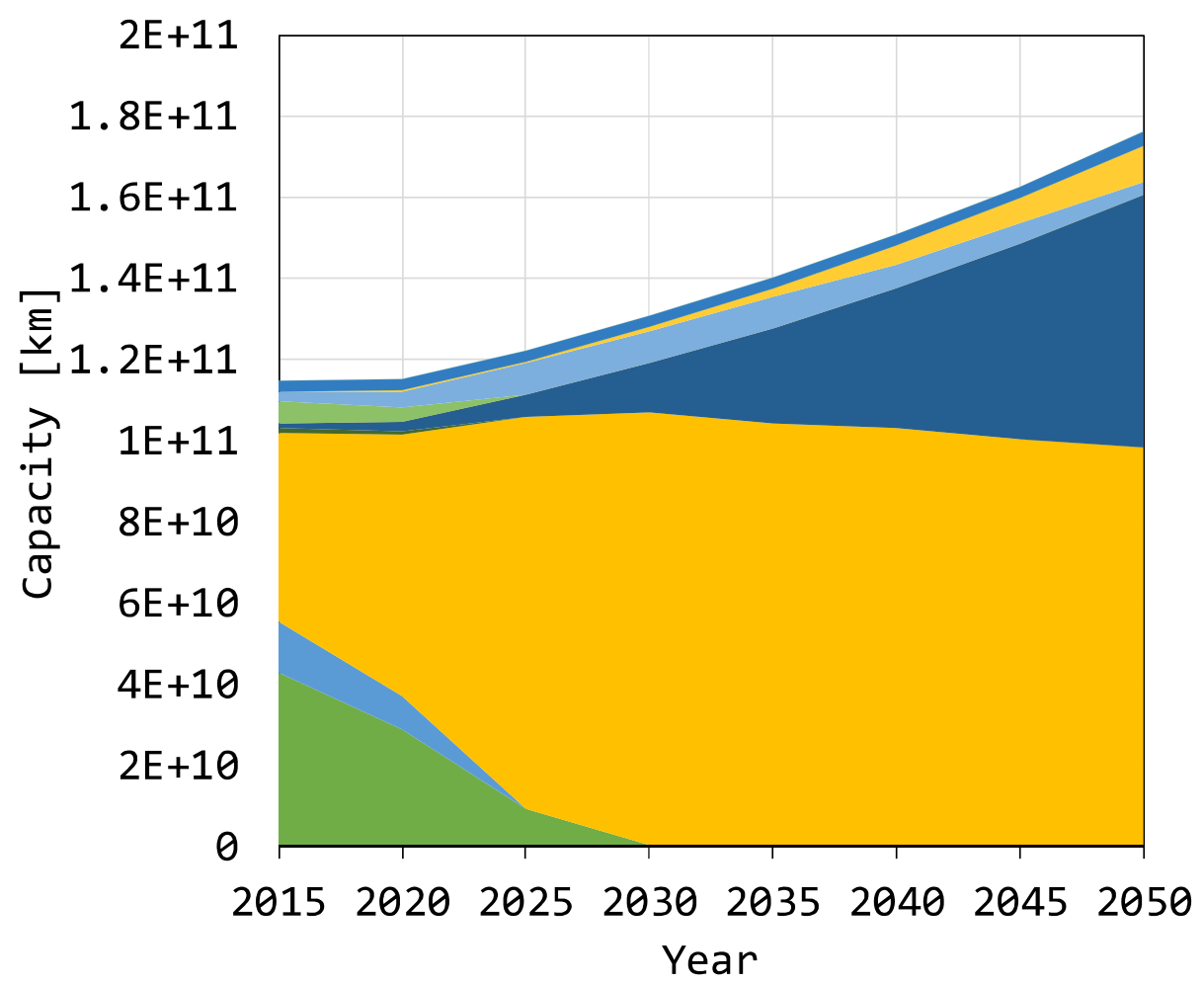

- Hyd_lorry

- CNG_lorry

- Dies_lorry

- Hyd_bus

Elec_bus

CNG_bus

- Dies_bus

- Hyd_car

- Elec_car

- CNG_car

Eth_car

- Dies_car

-Gaso_car

Year

Figure 29: Total capacity transport sector. NP-DEC scenario. 


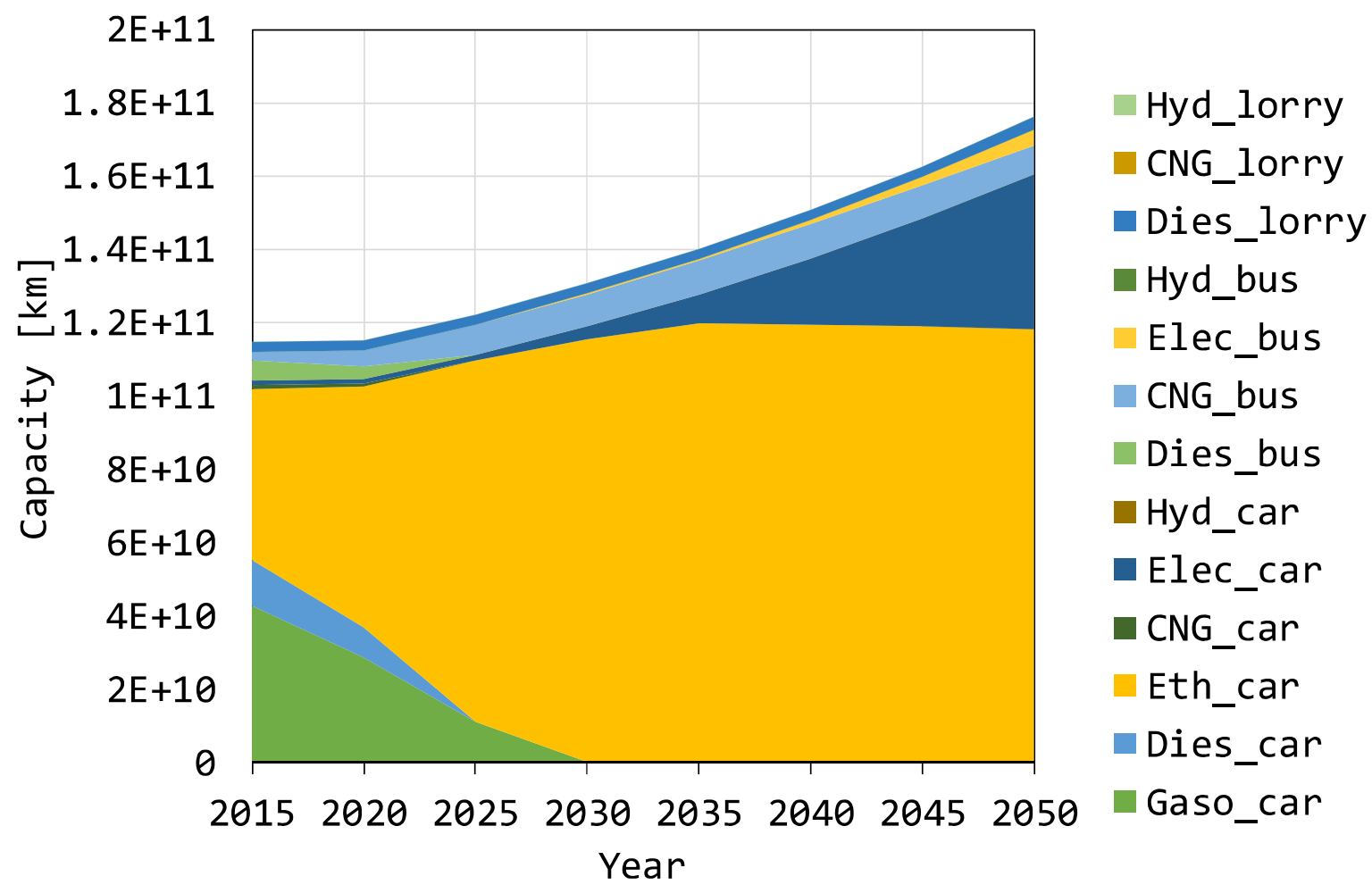

Figure 30: Total capacity transport sector. SD-DEC scenario.

For the BAU scenarios (Figure 27) the initial share of gasoline, diesel, and CNG cars are replaced mostly by ethanol cars through 2050. Initial diesel and electric buses are replaced by CNG buses, as higher CNG bus efficiencies offset the lower capital and fuel costs of diesel buses. For the case of lorries, diesel continues to be the main fuel/technology, and from 2035 on some participation (1\%) of hydrogen lorries is observed. For the decarbonisation scenarios, electric cars and buses broaden their participation, as although they have high costs, they allow to meet the carbon constraints because of decarbonised electricity grids and higher efficiencies. For CP-2/3DEC, NP-DEC, and SD-DEC scenarios, the participation of electric vehicles reaches $16 \%, 39 \%$, and $26 \%$ of cars by 2050 , and $36 \%, 76 \%$, and $37 \%$ of buses by 2050 , respectively. Additionally, for all decarbonisation scenarios diesel continues to be the main fuel/technology for lorries, with around $1 \%$ participation of hydrogen lorries from 2035 on. As discussed previously for the case of heat supply, the NP-DEC scenario is the most constrained scenario, as emissions from the electricity grid are higher than for the SD-DEC scenario. Therefore, more electric vehicles than for the other decarbonisation scenarios are required to meet carbon targets, despite the higher investment costs.

Finally, Figure 31 and Figure 32 compare the results for $\mathrm{CO}_{2}$ emissions and total system costs for all scenarios. As discussed previously, all BAU scenarios are unconstrained in terms of carbon emissions. Therefore, the same equipment is purchased, and the system operates in the same way for all the scenarios, obtaining the same cost and the lowest system's cost compared to the decarbonisation scenarios. However, as the power grid has different emission factors in the three $\mathrm{BAU}$ scenarios, the $\mathrm{CO}_{2}$ emissions are different between them, as observed in Figure 31. As also discussed previously, the most constrained scenario is the NP-DEC scenario, which results also in the one that achieves the highest system cost, as it is the costliest to decarbonise, though still only $6 \%$ higher than the business as usual case. As the SD-DEC scenario has lower power sector emissions, it is not necessary to purchase the 
most expensive or efficient technologies, as cheaper electric technologies are available and can reach decarbonisation targets with a decarbonised electricity grid.

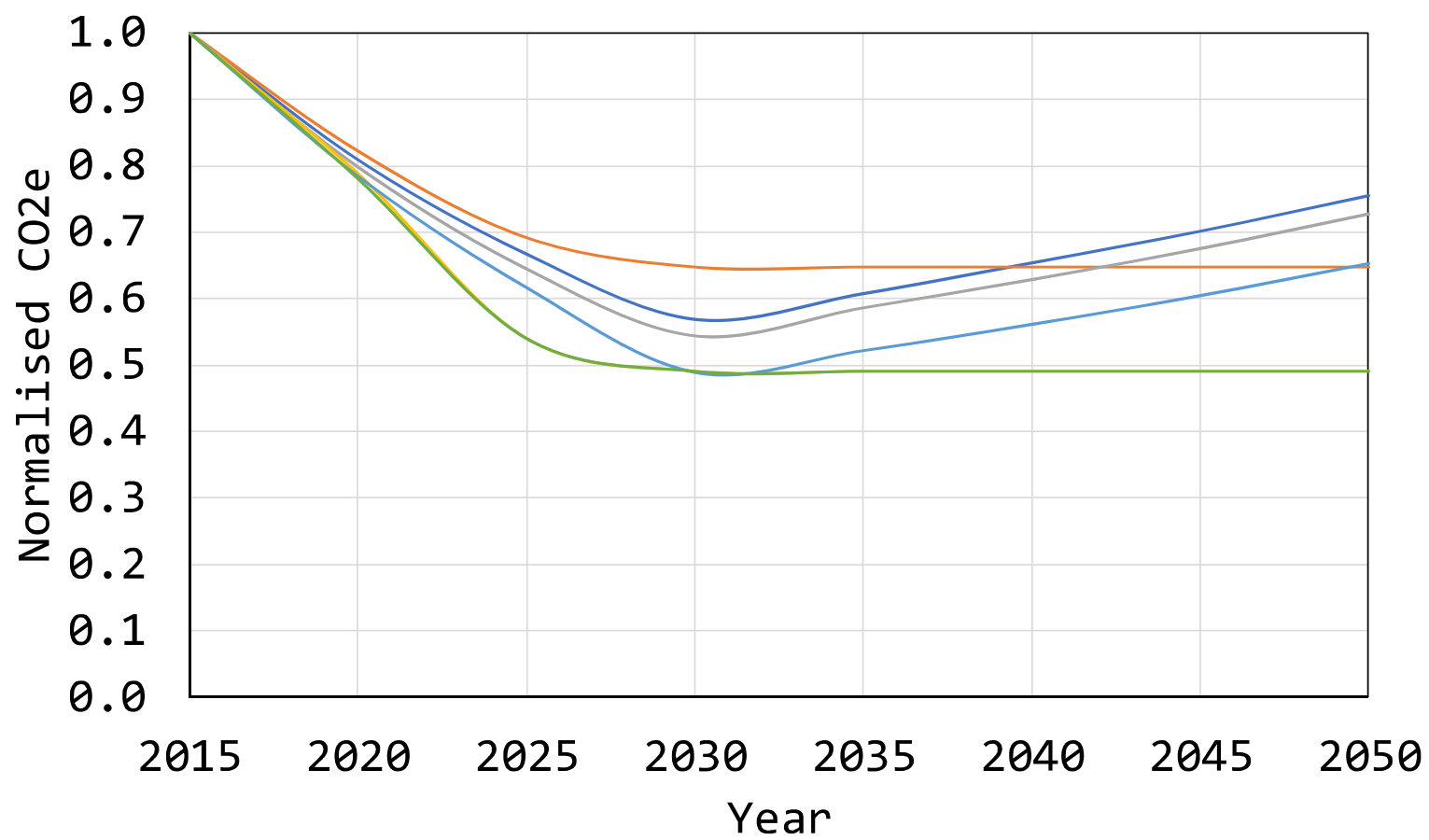

-CP_BAU-CP_2/3DEC-NP_BAU-NP_DEC - SD_BAU - SD_DEC

Figure 31: $\mathrm{CO}_{2}$ e emissions for all scenarios, normalised to 2015.

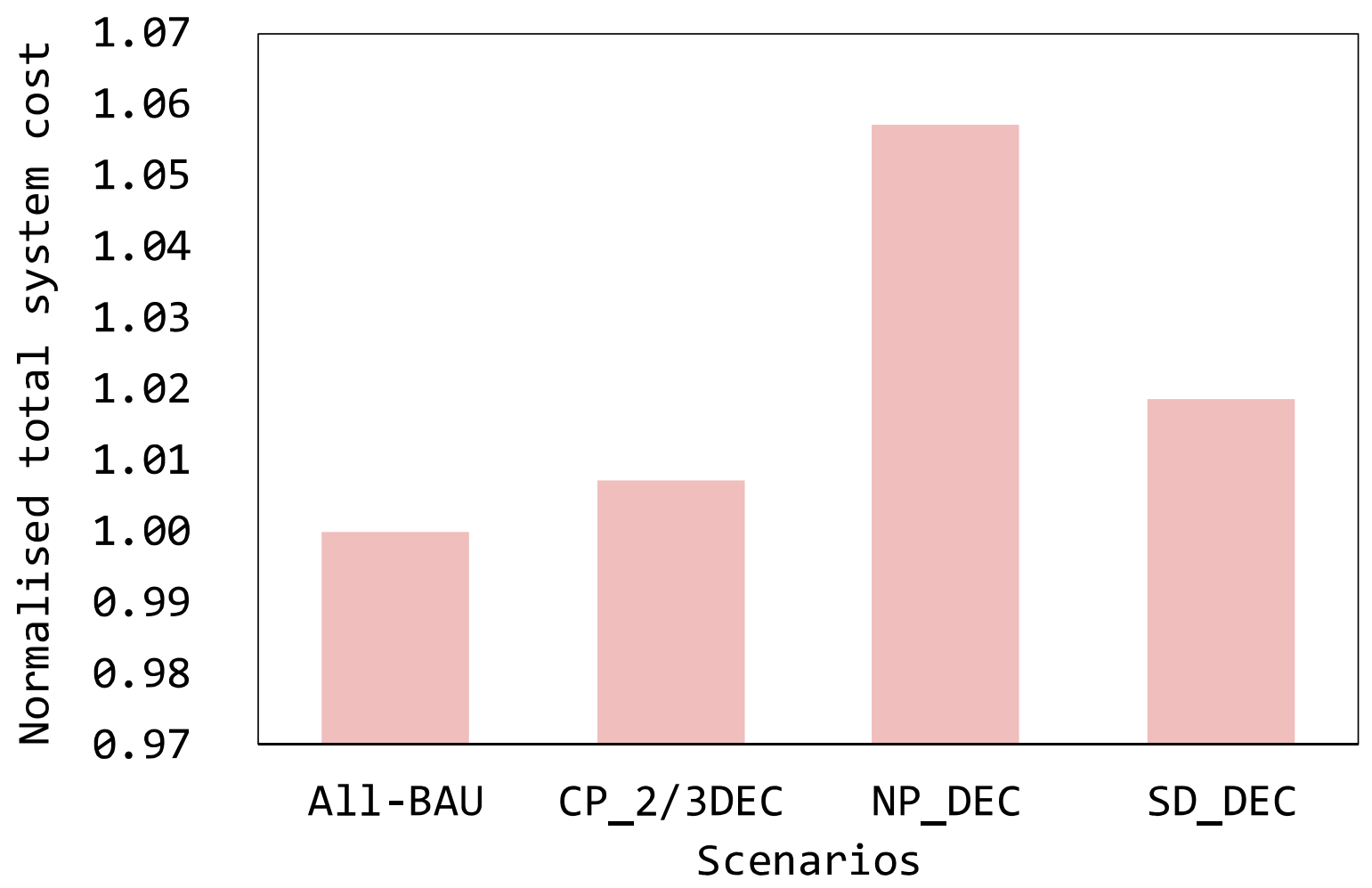

Figure 32: Total system's cost, normalised to BAU scenarios. 
Results are validated comparing them with previous literature. Regarding district cooling, Eveloy and Ayou [83] report that cost-effective adoption of district cooling occurs at linear heat densities of around $4000[\mathrm{kWh} / \mathrm{m}]$. This is a higher threshold than the one found for the BAU scenarios, which don't have carbon constraints and are therefore comparable in terms of a solely economic perspective. For the BAU scenario, around $40 \%$ adoption by 2020 is found in zones with linear cooling densities over $1100[\mathrm{kWh} / \mathrm{m}]$. Differences in adoption thresholds can be explained by three factors: First, the COMET model is an integrated model that considers synergies with other service demands, and also trades-off cost of infrastructure with other technologies. Therefore, the reported linear heat density threshold of $4000[\mathrm{kWh} / \mathrm{m}]$, may not be taking into account the counter alternative: that if demand is supplied by individual AC units, the electricity network also needs to be reinforced. It also does not consider the cost of end-use technologies. The second factor influencing this threshold is that, as stated by Eveloy and Ayou [83], the distribution network represents around $50-75 \%$ of the initial investment which is highly affected by local labour costs. Brazil has much lower labour costs than the region studied in [83]. The third factor is that Eveloy and Ayou [83] report a value for full heat network deployment, but this work allows a partial penetration: in 2020, around $40 \%$ of district cooling penetration is obtained, which would possibly be at a lower linear cooling density thresholds than the one reported by Eveloy and Ayou [83].

In terms of heating, it is more complex to validate these results with existing literature. Most literature around heating is based on Europe. Conditions are not comparable due to the different heat loads between European case studies and a Brazilian case study. Also, in this model district heating was not included, given the low heat demands. However, a general trend regarding the electrification of heat can be observed. The results showed that by 2050 , the commercial sector is mostly supplied by heat pumps, and the domestic sector is mostly supplied by electric boilers, for all scenarios. This is in line with several European studies which show that for lower heat densities, heat pumps [11] and electric resistance boilers [84] in the domestic sector are cost-effective alternatives .

Results from the transport sector can be validated with findings from Pye and Daly [25], who use the ESME energy systems model study transport modal shift in the UK under a carbon budget. They obtain that by 2050 , around $60 \%$ of the car fleet is composed by electric vehicles. Besides different modelling inputs in terms of costs and fuel prices in Sao Paulo and the UK, the difference of the ESME model results with the COMET's NP-DEC scenario ( $40 \%$ participation of electric vehicles by 2050 ) can be explained by ethanol cars. For the case of the UK, internal combustion engines are composed mainly by gasoline or diesel cars. This means that for the UK, lower shares of internal combustion engines and a higher participation of electric vehicles would be needed to meet the same carbon emission targets. Ethanol vehicles, which by 2050 represent the rest of cars' capacity for the Sao Paulo case study, have lower carbon emissions than diesel or gasoline internal combustion engines, and therefore can have a higher share in the transport mix to reach decarbonisation targets.

As set out by the Sao Paulo Statement on Urban Sustainability [85], cities around the world concentrate resource use and greenhouse gas emissions, but they are also acknowledged as a part of the solutions to climate change. Recognising that each city is unique, the Statement identifies different types of efforts to develop integrated solutions, such as setting low emission targets and integrating climate aspects "into spatial planning while 
investing in compact and connected urban development". This work presents a useful tool for analysing the most cost-effective decarbonisation pathways in cities (and in particular in the City of Sao Paulo), under defined carbon targets, that can aid-policy and decision makers to plan and implement measures throughout an extended time horizon. Among others, for example, the spatially-resolved nature of this model can inform in which areas it is cost effective to install district cooling, or where to install the district cooling supply units, together with a temporal pathway for its deployment. This can be used for energy policy planning, and cost-effective implementation of different measures.

\section{Conclusion}

This work presents the COMET (Cities Optimisation Model for Energy Technologies) model, a spatially-resolved optimisation model for finding cost effective technology pathways for decarbonising energy services in urban areas. The novelty of this work is that it presents an energy systems model that takes into account energy service demands for heating, cooling, electricity, and transport, and finds cost-effective pathways for supplying these demands under carbon constraints, at a high spatial resolution, considering trade-offs between energy supply, network infrastructure, and end-use technologies. Current energy systems models found in the literature either represent a subset of these energy service demands in a spatially-resolved manner; or include all these service demands in an aggregated way, without spatial representation of network infrastructure and end-use technologies. This work shows how spatial resolution is important in energy systems models in order to gain insights on the optimal distribution of networks infrastructure and end-use technologies in areas with varying demand densities. The first part of this work explains how spatiallyresolved energy service demands were obtained for the residential and commercial sectors. The model was then implemented for the city of Sao Paulo, for a range of 6 scenarios. The first 3 scenarios (Business As Usual or BAU) minimised the total cost for supplying energy service demands for the three World Energy Outlook power sector emission factor scenarios. The other 3 scenarios imposed a carbon constraint to reach carbon emission targets under the same World Energy Outlooks power sector emission factor scenarios.

For all scenarios a relation between penetration of district cooling networks and linear cooling density was observed. Results show that the Business As Usual (BAU) scenarios resulted in the lowest penetration of district cooling networks, as individual air-conditioning units resulted to be more cost-effective when trading-off network infrastructure, end-use technologies, and energy supply costs. For the Business As Usual (BAU) scenarios, full penetration of district cooling networks was obtained for linear cooling densities over 1100 $\mathrm{kWh} / \mathrm{m}$ by 2050 , and over $40 \%$ penetration was observed for linear cooling densities greater than $200 \mathrm{kWh} / \mathrm{m}$. When carbon constraints are imposed, linear cooling densities thresholds for full penetration of district cooling vary between $50 \mathrm{kWh} / \mathrm{m}$ and $580 \mathrm{kWh} / \mathrm{m}$ for the scenarios studied, while $80 \%$ and $60 \%$ penetration thresholds vary in the ranges of $160-270$ $\mathrm{kWh} / \mathrm{m}$ and 80-160 kWh/m, respectively. For the Sustainable Development Decarbonisation (SD-DEC) scenario, an overall lower penetration of cooling networks is observed than for the other decarbonisation scenarios. This is because in this scenario the power sector has the lowest emission factors, therefore more efficient and expensive technologies are not as necessary for reaching the same decarbonisation targets. The district cooling supply plants were found to be located at the linear cooling densest zones as well, suggesting that if a 
progressive deployment of a district cooling network were installed in the city, it would be cost-effective to start by subprefectures Sé, Pinheiros, and Vila Mariana.

Regarding heating technologies, in the Business As Usual (BAU) scenarios the domestic sector continues to be supplied by electric boilers, with a small participation of combined heat and power units towards the end of the modelled time horizon. Air-source heat pumps appear as the most cost-effective solution for the commercial sector, with a small participation of gas boilers at from 2040. For the decarbonisation scenarios, the technology mix varies depending on the power sector emissions in each case. In the Current Policies with $2 / 3$ decarbonisation (CP-2/3DEC) scenario, the commercial sector switches its heat supply from electric boilers to air-source heat pumps at the end of the period. However, as this scenario has a more relaxed carbon constraint, gas boilers and gas combined heating and power appear between 2030 and 2040, which serve the purpose of decarbonising heat supply while the transition to a lower carbon electricity grid is achieved. When decarbonisation of the power grid intensifies towards 2045 air-source heat pumps reappear as the most cost-effective technology for supplying commercial heat while meeting decarbonisation targets. The domestic sector continues to be supplied by electric boilers, with a small participation of combined heating and power and hydrogen boilers towards the end of the period. In the New Policies Decarbonisation (NP-DEC) scenario the commercial sector switches its heating technologies from electric boilers to air and ground-source heat pumps, with a full penetration of air-source heat pumps by 2050. In the domestic sector, electric boilers continue to be the main heat supply technology. An unexpected behaviour is observed in this scenario, as the system needs to reach decarbonisation targets with a power sector that takes longer to decarbonise than in the other scenarios. A transition period between 2030 and 2045 is observed, where hydrogen boilers reach $40 \%$ of the domestic sector capacity, and ground- source heat pumps cover around $95 \%$ of the commercial sector's capacity. In the Sustainable Development Decarbonisation (SD-DEC) scenario, air-source heat pumps replace electric boilers in the commercial sector, while the domestic sector continues to be supplied by electric boilers.

For the transport sector, in the Business As Usual (BAU) scenarios the main technology replacing the initial gasoline, diesel, and compressed natural gas cars are ethanol cars. Diesel and electric buses are replaced by compressed natural gas buses, while diesel continues to be the dominant technologies for lorries, with a small participation of hydrogen lorries. In the decarbonisation scenarios, higher penetrations of electric vehicles appeared in the mix to meet carbon constraints, reaching $16 \%, 39 \%$, and $26 \%$ of cars by 2050 , and $36 \%$, $76 \%$, and $37 \%$ of buses by 2050 , for the Current Policies with $2 / 3$ decarbonisation (CP2/3DEC), New Policies Decarbonisation (NP-DEC), and Sustainable Development Decarbonisation (SD-DEC) scenarios respectively. Lorries continue with the same trend as in the Business As Usual (BAU) scenarios. As opposed to most research in European contexts, a high participation of ethanol cars are found complementing electric cars, due to costeffectivity for reaching carbon targets in all scenarios.

Finally, the most constrained scenario is the New Policies Decarbonisation (NP-DEC) scenario, which results in it being the costliest to decarbonise. However, the total system's cost is only $6 \%$ higher than the business as usual case with these techno-economic assumptions. This means that from a system-wide perspective achieving decarbonisation targets is not as costly even in the most constrained scenarios. 
This paper has presented a novel spatially-resolved model that supplies transport, heating, cooling, and electric appliances energy services in urban areas, and the model was implemented for the city of Sao Paulo. This work shows the importance of using spatiallyresolved energy systems models for planning technology deployment in urban areas, as depending on specific demand densities different results can be found cost-effective among zones. This model also shows the importance of considering trade-offs between end-use technologies, network infrastructure, and energy supply, for supporting potential policy decisions to inform cost-effective investments.

\section{Acknowledgements}

This research was supported by Newton/NERC Sustainable Gas Pathways (NE/N018656/1). 


\section{Appendix A. Nomenclature}

Sets

\begin{tabular}{|c|c|c|}
\hline Index & Description & Set elements \\
\hline$a$ & Fuel type & gas, hyd, eth, gaso, dies, CNG \\
\hline$b$ & Demand type & dom, comm \\
\hline$h$ & Time slice [Hours] & $h_{1}, h_{2}, \ldots h_{12}$ \\
\hline$i_{\text {distc }}$ & $\begin{array}{l}\text { District cooling supply } \\
\text { technologies }\end{array}$ & ChillerDC \\
\hline$i_{\text {ind }}$ & $\begin{array}{l}\text { Individual heat supply } \\
\text { technologies }\end{array}$ & $\begin{array}{c}\text { CHP } P_{\text {dom }}, C H P_{\text {comm }}, \text { Boiler }_{\text {dom }}, \text { Boiler }_{\text {comm }}, \text { EBoiler } \\
\text { dom } \\
\text { EBoiler }_{\text {comm }}, A S H P_{\text {dom }}, A S H P_{\text {comm }}, G S H P_{\text {dom }}, G S H P_{\text {comm }}, \\
\text { HydBoiler }_{\text {dom }}, H y d B o i l e r_{\text {comm }}, H y d C H P_{\text {dom }}, H y d C H P_{\text {comm }}, H\end{array}$ \\
\hline$i_{\text {indc }}$ & $\begin{array}{l}\text { Individual cooling } \\
\text { supply technologies }\end{array}$ & $A C_{\text {dom }}, A C_{\text {comm }}, H X T C_{\text {dom }}, H X T C_{\text {comm }}$ \\
\hline$i_{\text {trans }}$ & $\begin{array}{ll}\text { Transport } & \text { supply } \\
\text { technologies } & \end{array}$ & 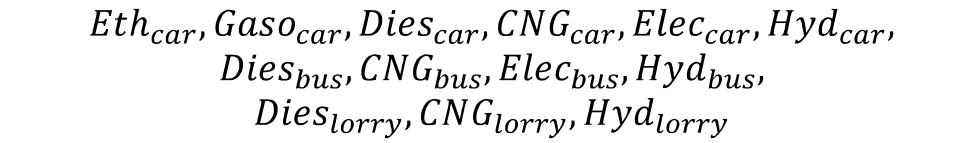 \\
\hline $\begin{array}{l}i_{\text {trans }} \text { bus } \\
\in i_{\text {trans }}\end{array}$ & $\begin{array}{l}\text { Subset of transport } \\
\text { technologies that are } \\
\text { buses }\end{array}$ & Dies $_{\text {bus }}, C N G_{\text {bus }}$, Elec $_{\text {bus }}, H y d_{\text {bus }}$, \\
\hline $\begin{array}{l}i_{\text {trans }} \text { car } \\
\in i_{\text {trans }}\end{array}$ & $\begin{array}{l}\text { Subset of transport } \\
\text { technologies that are } \\
\text { cars }\end{array}$ & Eth $_{\text {car }}$, Gaso $_{\text {car }}$, Dies $_{\text {car }}, C N G_{\text {car }}$, Elec $_{\text {car }}, H y d_{c a r}$, \\
\hline $\begin{array}{l}i_{\text {trans }} \text { diesel } \\
\in i_{\text {trans }}\end{array}$ & $\begin{array}{l}\text { Subset of diesel } \\
\text { consuming transport } \\
\text { technologies }\end{array}$ & Dies $_{\text {car }}$, Dies $_{\text {bus }}$, Dies $_{\text {lorry }}$ \\
\hline $\begin{array}{l}i_{\text {trans }_{\text {elec }}} \\
\in i_{\text {trans }}\end{array}$ & $\begin{array}{l}\text { Subset of electricity } \\
\text { consuming transport } \\
\text { technologies }\end{array}$ & Elec $_{\text {car }}$, Elec $_{\text {bus }}$ \\
\hline $\begin{array}{l}i_{\text {trans }} \text { gas } \\
\in i_{\text {trans }}\end{array}$ & $\begin{array}{l}\text { Subset of gas } \\
\text { consuming transport } \\
\text { technologies }\end{array}$ & $C N G_{\text {car }}, C N G_{\text {bus }}, C N G_{\text {lorry }}$ \\
\hline $\begin{array}{l}i_{\text {trans }} \text { hydl } \\
\in i_{\text {trans }}\end{array}$ & $\begin{array}{l}\text { Subset of hydrogen } \\
\text { consuming transport } \\
\text { technologies }\end{array}$ & Hyd $d_{\text {car }}, H y d_{\text {bus }}, H y d_{\text {lorry }}$ \\
\hline $\begin{array}{l}i_{\text {trans }} \text { lorry } \\
\in i_{\text {trans }}\end{array}$ & $\begin{array}{l}\text { Subset of transport } \\
\text { technologies that are } \\
\text { lorries }\end{array}$ & Dies $_{\text {lorry }}, C N G_{\text {lorry }}, H y d_{\text {lorry }}$ \\
\hline$j$ & Zones & $1,2, \ldots, 32$ \\
\hline$n$ & Network type & gasn, elecn, hydn, cooln \\
\hline$T C$ & $\begin{array}{l}\text { Supply temperature } \\
\text { district } \\
\text { network [K] }\end{array}$ & $T C$ \\
\hline$y$ & Time period [Years] & $2015,2020,2025,2030,2035,2040,2045,2050$ \\
\hline
\end{tabular}

Decision variables

\begin{tabular}{clc}
\hline Variable & Description & Units \\
\hline$C C N_{j j \prime n y y \prime}$ & $\begin{array}{l}\text { Continuous variable. Capacity of network type } \mathrm{n} \text { that connects zones jkW } \\
\text { and } \mathrm{j}^{\prime} \text { installed in year y remaining in year } \mathrm{y}^{\prime}\end{array}$ \\
\hline
\end{tabular}




\begin{tabular}{|c|c|}
\hline ariable & Description \\
\hline $\operatorname{TCTI}_{i_{\text {trans }} j y}$ & $\begin{array}{l}\text { Continuous variable. Total capacity of individual transport supplykm } \\
\text { technology } i_{\text {trans }} \text { in zone } j \text { remaining in year } y\end{array}$ \\
\hline$T L N_{\text {jny }}$ & $\begin{array}{l}\text { Continuous variable. Total network length of network type } n \text { within zonekm } \\
\mathrm{j} \text { in year } \mathrm{y}\end{array}$ \\
\hline$C D_{i_{d i s}}$ & $\begin{array}{l}\text { Continuous variable. Vintage capacity of district cooling supplykW } \\
\text { technology } i_{\text {distc }} \text { of temperature level } T C \text { in zone } j \text { installed in year } y \\
\text { remaining in year } y^{\prime}\end{array}$ \\
\hline$V C C I_{b i_{i n d c} j y y \prime}$ & $\begin{array}{l}\text { Continuous variable. Vintage capacity of individual cooling supplykW } \\
\text { technology } i_{\text {indc }} \text { for demand type } b \text { in zone } j \text { installed in year } y \\
\text { remaining in year } y^{\prime}\end{array}$ \\
\hline$V C H I_{b i_{i n d} j y y \prime}$ & $\begin{array}{l}\text { Continuous variable. Vintage capacity of individual heat supplykW } \\
\text { technology } i_{\text {ind }} \text { for demand type } b \text { in zone } j \text { installed in year } y \text { remaining } \\
\text { in year } y^{\prime}\end{array}$ \\
\hline$V C T I_{i_{\text {trans }} j y y \prime}$ & $\begin{array}{l}\text { Continuous variable. Vintage capacity of individual transport supplykm } \\
\text { technology } i_{\text {trans }} \text { in zone } j \text { installed in year } y \text { remaining in year } y^{\prime}\end{array}$ \\
\hline$V L N_{\text {jnyy }}$ & $\begin{array}{l}\text { Continuous variable. Vintage network length of network type } n \text { installedkm } \\
\text { within zone } \mathrm{j} \text { in year } \mathrm{y} \text { remaining in year } \mathrm{y}^{\prime}\end{array}$ \\
\hline$Y C O 2_{y}$ & Continuous variable. Yearly $\mathrm{CO} 2$ equivalent emissions \\
\hline
\end{tabular}

Scalars

\begin{tabular}{lll}
\hline Scalar & Description & Value \\
\hline$c$ & Specific heat capacity of water & $4.1813 \mathrm{~kJ} / \mathrm{kg} \mathrm{K}$ \\
$M, M 1$ & Big numbers & \\
$r$ & Discount rate & $7 \%$ \\
\multicolumn{1}{c}{$y_{\text {final }}$} & Final modelling year & 2051 \\
\hline
\end{tabular}

Parameters

\begin{tabular}{|c|c|c|}
\hline Parameter & Description & Units \\
\hline$\eta_{C H P}^{E I}$ & Electric efficiency of individual CHP & - \\
\hline$\eta_{i_{\text {distc }}^{T h D C}}^{T h C}$ & $\begin{array}{l}\text { Thermal efficiency of cooling technology } i_{\text {distc }} \text { of temperature level } \\
T C\end{array}$ & - \\
\hline$\eta_{i_{\text {ind }}^{T h I}}^{T h}$ & Thermal efficiency of heat technology $i_{\text {ind }}$ & - \\
\hline$\eta_{i_{\text {indc }}}^{T h I C}$ & Thermal efficiency of cooling technology $i_{\text {indc }}$ & - \\
\hline$\eta_{i_{\text {trans }}}^{T h T r}$ & Thermal efficiency of transport technology $i_{\text {trans }}$ & $\mathrm{km} / \mathrm{kWh}$ \\
\hline $\operatorname{Cap}_{i_{\text {distc }} T C}^{D C}$ & $\begin{array}{l}\text { Maximum thermal capacity of cooling technology } i_{\text {distc }} \text { at } \\
\text { temperature level } T C\end{array}$ & $\mathrm{~kW}$ \\
\hline$C b_{j}$ & 1 if zone $j$ is a city boundary, 0 if not. & - \\
\hline $\operatorname{Cost}_{b i_{i n d} j y}^{C I}$ & $\begin{array}{l}\text { After diversity capital cost for demand type } b \text { of individual heat supply } \\
\text { technology } i_{\text {ind }} \text { in zone } j \text { and year } y\end{array}$ & $\mathrm{f} / \mathrm{kW}$ \\
\hline $\operatorname{Cost}_{b i_{i n d c} j y}^{C I C}$ & $\begin{array}{l}\text { After diversity capital cost for demand type } b \text { of individual cooling } \\
\text { supply technology } i_{\text {indc }} \text { in zone } j \text { and year } y\end{array}$ & $f / k W$ \\
\hline $\operatorname{Cost}_{i_{\text {distc }}^{C D C} T C}$ & $\begin{array}{l}\text { Capital cost for district cooling supply technology } i_{\text {distc }} \text { in zone } j \text { for } \\
\text { temperature level } T C \text { in year } y\end{array}$ & $f / k W$ \\
\hline $\operatorname{Cost}_{\text {bi trans }}^{C T y}$ & $\begin{array}{l}\text { After diversity capital cost of individual transport supply technology } \\
i_{\text {trans }} \text { in zone } j \text { and year } y\end{array}$ & $\mathrm{f} / \mathrm{km}$ \\
\hline $\operatorname{Cost}_{i_{\text {dist } T y}^{D D}}^{D}$ & $\begin{array}{l}\text { Decommission cost of district heat supply technology } i_{d i s t} \text { of } \\
\text { temperature level } T \text { in year } y\end{array}$ & $f / k W$ \\
\hline $\operatorname{Cost}_{i_{\text {distc }}^{D D C} y}^{D D C}$ & Decommission cost of district cooling supply technology $i_{\text {distc }}$ of & $f / k W$ \\
\hline
\end{tabular}




\begin{tabular}{|c|c|c|}
\hline Parameter & Description & Units \\
\hline & temperature level $T C$ in year $y$ & \\
\hline $\operatorname{Cost}_{i_{\text {ind }} y}^{D I}$ & Decommission cost of individual heat supply technology $i_{\text {ind }}$ in year $y$ & $\mathrm{f} / \mathrm{kW}$ \\
\hline $\operatorname{Cost}_{i_{\text {ind }} \text { DIC }}$ & $\begin{array}{l}\text { Decommission cost of individual cooling supply technology } i_{\text {indc }} \text { in } \\
\text { year } y\end{array}$ & $f / k W$ \\
\hline $\operatorname{Cost}_{i_{\text {trans }} \boldsymbol{D T}}$ & Decommission cost of transport supply technology $i_{\text {trans }}$ in year $y$ & $\mathrm{f} / \mathrm{km}$ \\
\hline Cost $t_{b y}^{E}$ & Electricity price for demand type $b$ in year $y$ & $\mathrm{f} / \mathrm{kWh}$ \\
\hline $\operatorname{Cost}_{y}^{E D}$ & Electricity price for district technologies in year $y$ & $\mathrm{f} / \mathrm{kWh}$ \\
\hline $\operatorname{Cost}_{y}^{E T R}$ & Electricity price for transport technologies in year $y$ & $\mathrm{f} / \mathrm{kWh}$ \\
\hline Cost $t_{a b y}^{F}$ & Fuel price of fuel $a$ for demand type $b$ in year $y$ & $\mathrm{f} / \mathrm{kWh}$ \\
\hline $\operatorname{Cost}_{a y}^{F D}$ & Fuel price of fuel $a$ for district technologies in year $y$ & $\mathrm{f} / \mathrm{kWh}$ \\
\hline $\operatorname{Cost}_{a y}^{F T R}$ & Fuel price of fuel $a$ for transport technologies in year $y$ & $\mathrm{f} / \mathrm{kWh}$ \\
\hline $\operatorname{Cost}_{i_{\text {distc }}^{M D C} y}$ & $\begin{array}{l}\text { Annual maintenance cost of district cooling supply technology } i_{\text {distc }} \text { in } \\
\text { year } y\end{array}$ & $\mathrm{f} / \mathrm{kW}$ \\
\hline $\operatorname{Cost}_{b i_{i n d} j y}^{M I}$ & $\begin{array}{l}\text { Annual maintenance cost after diversity in zone } j \text { for demand type } b \\
\text { of individual heat supply technology } i_{\text {ind }} \text { in year } y\end{array}$ & $\mathrm{f} / \mathrm{kW}$ \\
\hline $\operatorname{Cost}_{b i_{\text {ind }} j y}^{M I C}$ & $\begin{array}{l}\text { Annual maintenance cost after diversity in zone } j \text { for demand type } b \\
\text { of individual cooling supply technology } i_{\text {indc }} \text { in year } y\end{array}$ & $\mathrm{f} / \mathrm{kW}$ \\
\hline $\operatorname{Cost}_{i_{\text {trans }} j y}^{M T r}$ & $\begin{array}{l}\text { Annual maintenance cost in zone } j \text { of transport supply technology } \\
i_{\text {trans }} \text { in year } y\end{array}$ & $\mathrm{f} / \mathrm{km}$ \\
\hline $\operatorname{Cost}_{n y}^{N D}$ & Average capital cost of distribution network $n$ in year $y$ & $\mathrm{f} / \mathrm{km}$ \\
\hline $\operatorname{Cost}_{n y}^{N T}$ & Diameter dependent capital cost of network $n$ in year $y$ & $\mathrm{f} / \mathrm{kW} \mathrm{km}$ \\
\hline $\operatorname{Cost}_{i_{\text {trans }} y}^{\text {OTr }}$ & $\begin{array}{l}\text { Variable operation cost for transport supply technology } i_{\text {trans }} \text { in year } \\
y\end{array}$ & $\mathrm{f} / \mathrm{km}$ \\
\hline$d_{j j}$ & Linear distance between zone $j$ and zone $j^{\prime}$ & $\mathrm{km}$ \\
\hline Dem $_{\text {bhjy }}^{C}$ & $\begin{array}{l}\text { After diversity individual cooling demand of customer type } b \text { in } \\
\text { timeslice } h \text { in zone } j \text { and year } y\end{array}$ & $\mathrm{~kW}$ \\
\hline $\operatorname{Dem}_{\text {bhjy }}^{E}$ & $\begin{array}{l}\text { After diversity individual electricity demand of customer type } b \text { in } \\
\text { timeslice } h \text { in zone } j \text { and year } y\end{array}$ & $\mathrm{~kW}$ \\
\hline$D_{e} m_{\text {bhjy }}^{H}$ & $\begin{array}{l}\text { After diversity individual heat demand of customer type } b \text { in timeslice } \\
h \text { in zone } j \text { and year } y\end{array}$ & kW \\
\hline $\operatorname{Dem}_{j y}^{T C}$ & Total annual transport demand for cars in zone $j$ and year $y$ & $\mathrm{~km}$ \\
\hline $\operatorname{Dem}_{j y}^{T B}$ & Total annual transport demand for buses in zone $j$ and year $y$ & $\mathrm{~km}$ \\
\hline $\operatorname{Dem}_{j y}^{T L}$ & Total annual transport demand for lorries in zone $j$ and year $y$ & $\mathrm{~km}$ \\
\hline Dur $_{h}$ & Duration of time slice $h$ & hours \\
\hline$E m_{b y}^{E}$ & $\begin{array}{l}\text { Consumption based emission factor of electricity grid for demand type } \\
b \text { in year } y\end{array}$ & $\begin{array}{l}\text { tonCO2e/kW } \\
\mathrm{h}\end{array}$ \\
\hline$E m_{y}^{E D}$ & $\begin{array}{l}\text { Consumption based emission factor of electricity grid for district } \\
\text { technologies in year } y\end{array}$ & $\begin{array}{l}\text { tonCO2e/kW } \\
\mathrm{h}\end{array}$ \\
\hline$E m_{y}^{E T R}$ & $\begin{array}{l}\text { Consumption based emission factor of electricity grid for transport } \\
\text { technologies in year } y\end{array}$ & $\begin{array}{l}\text { tonCO2e/kW } \\
\mathrm{h}\end{array}$ \\
\hline$E m_{a b y}^{F}$ & Emission factor of fuel $a$ for demand type $b$ in year $y$ & $\begin{array}{l}\text { tonCO2e/kW } \\
\mathrm{h}\end{array}$ \\
\hline$E m_{a y}^{F D}$ & Emission factor of fuel $a$ for district technologies in year $y$ & $\begin{array}{l}\text { tonCO2e/kW } \\
\mathrm{h}\end{array}$ \\
\hline$E m_{a y}^{F T R}$ & Emission factor of fuel $a$ for transport technologies in year $y$ & $\begin{array}{l}\text { tonCO2e/kW } \\
\mathrm{h}\end{array}$ \\
\hline$H P_{h}$ & $\begin{array}{l}\text { Heat profile parameter in time slice } h \text {, expressed as a fraction of peak } \\
\text { heat demand. }\end{array}$ & - \\
\hline $\operatorname{Loss}_{T C}$ & Average loss (\% of heat generated) of cooling distribution network of & - \\
\hline
\end{tabular}




\begin{tabular}{lll}
\hline Parameter & Description & Units \\
\hline & supply temperature $T C$ & \\
$L t_{i_{\text {distc }} T C}^{D C}$ & Lifetime of cooling supply technology $i_{\text {distc }}$ at temperature level $T C$ & Years \\
$L t_{i_{\text {ind }}}^{I C}$ & Lifetime of heat supply technology $i_{\text {ind }}$ & Years \\
$L t_{i_{\text {ind }}}^{I C}$ & Lifetime of cooling supply technology $i_{\text {indc }}$ & Years \\
$L t_{n}^{N}$ & Lifetime of network $n$ & Years \\
$L t_{i_{\text {trans }}}^{T r}$ & Lifetime of transport supply technology $i_{\text {trans }}$ & Years \\
$M R l_{j}$ & Main road length within zone $j:$ Motorway, trunk, primary, secondary. & $\mathrm{km}$ \\
$N b_{j j r}$ & 1 if zones $j$ and $j$ 'are neighbours, 0 if not. & - \\
$N d c_{y}$ & Intended nationally determined contribution: carbon reduction \\
& targets for year $y$, with base on the first year modelled (2015 in this \\
$N u m_{b j y}$ & case). & \\
$R l_{j}$ & Number of customers of demand type $b$ in zone $j$ in year $y$ & - \\
$S e l l$ & Road length within zone $j$ & $\mathrm{~km}$ \\
$T C_{T C}^{R}$ & Electricity price for selling electricity to the grid in year $y$ & $\mathrm{f} / \mathrm{kWh}$ \\
& Return temperature of cooling network of supply temperature level & $\mathrm{K}$
\end{tabular}

\section{Appendix B. Model formulation}

\section{Minimise total system's costs}

Minimise net present value of the total system's costs.

$$
\min C O S T S=M N T+F E+C P T+D E C-S L V-E S
$$

\section{Cost components}

Annual maintenance costs:

$$
\begin{array}{rl}
M N T=\sum_{b i_{\text {ind }} j y} & T C H I_{b i_{\text {ind }} j y} \cdot \operatorname{Cost}_{b i_{\text {ind }} j y}^{M I} \cdot \frac{1}{(1+r)^{y}} \\
& +\sum_{b i_{\text {indc } j y}} T C C I_{b i_{i n d} j y} \cdot \operatorname{Cost}_{b i_{\text {ind }} j y}^{M I C} \cdot \frac{1}{(1+r)^{y}} \\
& +\sum_{i_{\text {distc } j} T C y} T C C D_{i_{\text {dist }} j T C y} \cdot \operatorname{Cost}_{i_{\text {distc }} y}^{M D C} \cdot \frac{1}{(1+r)^{y}} \\
& +\sum_{i_{\text {trans }} j y} T C T I_{i_{\text {trans }} j y} \cdot \operatorname{Cost}_{i_{\text {trans }}^{M T} j y} \cdot \frac{1}{(1+r)^{y}}
\end{array}
$$


Purchase fuel and electricity from networks

$$
\begin{aligned}
& F E=\sum_{a b y} F U E L_{a b y}^{T O T} \cdot \operatorname{Cos} t_{a b y}^{F} \cdot \frac{1}{(1+r)^{y}}+\sum_{a y} F U E L D_{a y}^{T O T} \cdot \operatorname{Cost}_{a y}^{F D} \cdot \frac{1}{(1+r)^{y}} \\
&+\sum_{a y} F U E L T R_{a y}^{T O T} \cdot \operatorname{Cost}_{a y}^{F T R} \cdot \frac{1}{(1+r)^{y}}+\sum_{b y} E L E C_{b y}^{T O T} \cdot \operatorname{Cost}_{b y}^{E} \\
& \cdot \frac{1}{(1+r)^{y}}+\sum_{y} E L E C D_{y}^{T O T} \cdot \operatorname{Cost}_{y}^{E D} \cdot \frac{1}{(1+r)^{y}} \\
&+\sum_{y} E L E C T R_{y}^{T O T} \cdot \operatorname{Cost}_{y}^{E T R} \cdot \frac{1}{(1+r)^{y}}
\end{aligned}
$$

Capital cost

$$
C P T=E Q+N T W
$$

Where capital cost of equipment and networks is respectively:

$$
\begin{aligned}
& C E Q=\sum_{b i_{\text {ind }} j y} N C H I_{b i_{\text {ind }} j y} \cdot \operatorname{Cost}_{b i_{\text {ind }} j y}^{C I} \cdot \frac{1}{(1+r)^{y}} \\
& +\sum_{b i_{\text {indc }} j y} N C C I_{b i_{\text {indc }} j y} \cdot \operatorname{Cost}_{b i_{\text {indc }} j y}^{C I C} \cdot \frac{1}{(1+r)^{y}} \\
& +\sum_{i_{\text {distc } j T C} y} N C C D_{i_{\text {distc }} j T C y} \cdot \operatorname{Cost}_{i_{\text {distc }}^{C D C} T C y} \cdot \frac{1}{(1+r)^{y}} \\
& +\sum_{i_{\text {trans }} j y} N C T I_{i_{\text {trans }} j y} \cdot \operatorname{Cost}_{i_{\text {trans }} j y}^{C T r} \cdot \frac{1}{(1+r)^{y}} \\
& N T W=\sum_{j j^{\prime} n y} \frac{I C N_{j j^{\prime} n y}}{2} \cdot d_{j j^{\prime}} \cdot \operatorname{Cos}_{n y}^{N T} \cdot \frac{1}{(1+r)^{y}}+\sum_{j n y} N L N_{j n y} \cdot \operatorname{Cos}_{n y}^{N D} \cdot \frac{1}{(1+r)^{y}} \\
& C P T=E Q+N T W
\end{aligned}
$$


Salvage value

$$
\begin{aligned}
& S L V=\sum_{b i_{\text {ind }} j y} V C H I_{b i_{\text {ind }} j y y_{\text {final }}} \cdot \operatorname{Cost}_{b i_{\text {ind }} j y}^{C I} \cdot \frac{L t_{i_{\text {ind }}}^{I}-\left(y_{\text {final }}-y\right)}{L t_{i_{\text {ind }}}^{I}} \cdot \frac{1}{(1+r)^{y_{\text {final }}}} \\
& +\sum_{b i_{\text {indc }} j y} V C C I_{b i_{\text {indc }} j y y_{\text {final }}} \cdot \operatorname{Cost}_{b i_{\text {indc }} j y}^{C I C} \cdot \frac{L t_{i_{\text {indc }}^{I C}}^{I C}-\left(y_{\text {final }}-y\right)}{L t_{i_{\text {indc }}^{I C}}^{I C}} \\
& \cdot \frac{1}{(1+r)^{y_{\text {final }}}}
\end{aligned}
$$

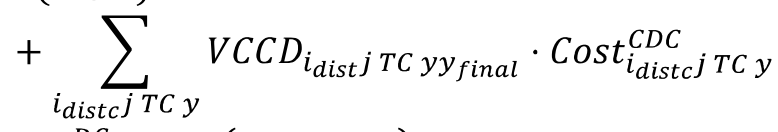

$$
\begin{aligned}
& \cdot \frac{L t_{i_{\text {distct } T C}^{D C}}-\left(y_{\text {final }}-y\right)}{L t_{i_{\text {distc }}^{D C} T C}^{D}} \cdot \frac{1}{(1+r)^{y_{\text {final }}}} \\
& +\sum_{i_{\text {trans }} j y} V C T I_{i_{\text {trans }} j y y_{\text {final }}} \cdot \operatorname{Cost}_{i_{\text {trans }} j y}^{C T r} \cdot \frac{L t_{i_{\text {trans }}^{T r}}^{T r}-\left(y_{\text {final }}-y\right)}{L t_{i_{\text {trans }}^{T r}}^{T}} \\
& \cdot \frac{1}{(1+r)^{y_{\text {final }}}} \\
& +\sum_{j j^{\prime} n y} \frac{C C N_{j j^{\prime} n y y_{f i n a l}}}{2} \cdot d_{j j^{\prime}} \cdot \operatorname{Cos}_{n y}^{N T} \cdot \frac{L t_{n}^{N}-\left(y_{f i n a l}-y\right)}{L t_{n}^{N}} \\
& \frac{1}{(1+r)^{y_{\text {final }}}} \\
& +\sum_{j n y} V L N_{\text {jnyy }} y_{\text {final }} \cdot \operatorname{Cost}_{n y}^{N D} \cdot \frac{L t_{n}^{N}-\left(y_{\text {final }}-y\right)}{L t_{n}^{N}} \cdot \frac{1}{(1+r)^{y_{\text {final }}}}
\end{aligned}
$$

Electricity sold to the grid

$$
E S=\sum_{h j y} F_{h j \text { elecn } y}^{G E N} \cdot \operatorname{Dur}_{h} \cdot \operatorname{Sell}_{y}^{E} \cdot \frac{1}{(1+r)^{y}}
$$

\section{Constraints}

\section{Capacity constraints}

Vintage capacity

Vintage capacity is the new capacity minus what has been decommissioned previously:

$$
\begin{array}{cc}
V C H I_{b i_{\text {ind }} j y y^{\prime *}}=N C H I_{b i_{\text {ind }} j y}-\sum_{y^{\prime}=0}^{y^{\prime *}} D C H I_{b i_{\text {ind }} j y y^{\prime}} & \forall b i_{\text {ind }} j, y \leq y^{\prime *} \\
V C C I_{b i_{\text {indc }} j y y^{\prime *}}=N C C I_{b i_{\text {indc }} j y}-\sum_{y^{\prime}=0}^{y^{\prime *}} D C C I_{b i_{\text {indc }} j y y^{\prime}} & \forall b i_{\text {indc }} j, y \leq y^{\prime *}
\end{array}
$$




$$
\begin{aligned}
& V C C D_{i_{\text {distc }} j T C y y^{\prime *}}=N C C D_{i_{\text {distc } j T C y}}-\sum_{y^{\prime}=0}^{y^{\prime *}} D C C D_{i_{d i s t c} j T C y y^{\prime}} \quad \forall i_{d i s t c} j T C, \\
& y \leq y^{\prime *} \\
& V C T I_{i_{\text {trans }} j y y^{\prime *}}=N C T I_{i_{\text {trans }} j y}-\sum_{y^{\prime}=0}^{y^{\prime *}} D C T I_{i_{\text {trans }} j y y^{\prime}} \quad \forall i_{\text {trans }} j, y \leq y^{\prime *}
\end{aligned}
$$

Total installed capacity

Total installed capacity is all vintage capacity independently of when it was installed:

$$
\begin{aligned}
T C H I_{b i_{\text {ind }} j y^{\prime}} & =\sum_{y=0}^{y^{\prime}} V C H I_{b i_{\text {ind }} j y y^{\prime}} & & \forall b i_{\text {ind }} j y^{\prime} \\
T C C I_{b i_{\text {indc }} j y^{\prime}} & =\sum_{y=0}^{y^{\prime}} V C C I_{b i_{\text {ind }} j y y^{\prime}} & & \forall b i_{\text {indc }} j y^{\prime} \\
T C C D_{i_{\text {distc }} j T C y^{\prime}} & =\sum_{y=0}^{y^{\prime}} V C C D_{i_{\text {distc }} j T C y y^{\prime}} & & \forall i_{\text {distc }} j T C y^{\prime} \\
T C T I_{i_{\text {trans }} j y^{\prime}} & =\sum_{y=0}^{y^{\prime}} V C T I_{i_{\text {trans }} j y y^{\prime}} & & \forall i_{\text {trans }} j y^{\prime}
\end{aligned}
$$

Lifetime decommissioning

Equipment must be decommissioned at most when it reaches its lifetime:

$$
\begin{aligned}
& N C H I_{b i_{\text {ind }} j y}=\sum_{y^{\prime}=0}^{y+L t_{i_{\text {ind }}}^{I}} D C H I_{b i_{\text {ind }} j y y^{\prime}} \quad \forall b i_{\text {ind }} j y \\
& N C C I_{b i_{\text {indc }} j y}=\sum_{y^{\prime}=0}^{y+L t_{i_{\text {indc }}^{I C}}^{I C}} D C C I_{b i_{\text {indc }} j y y^{\prime}} \quad \forall b i_{\text {indc }} j y \\
& N C C D_{i_{\text {distc } j T C y}}=\sum_{y^{\prime}=0}^{y+L t_{i_{\text {distc }}^{D C} T C}} D C C D_{i_{\text {distc }} j T C y y^{\prime}} \quad \forall i_{\text {distc }} j T C y
\end{aligned}
$$

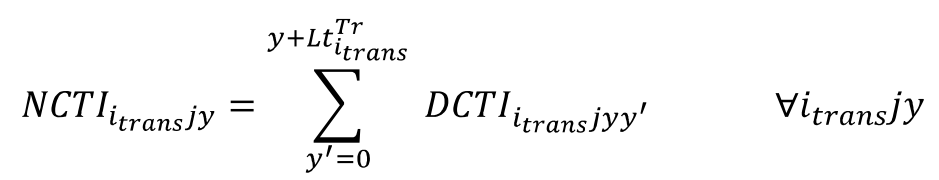

Boundary conditions

$$
\begin{array}{ll}
V C H I_{b i_{\text {ind } j y y y^{\prime}}=0} & \forall b i_{\text {ind }} j, y>y^{\prime} \\
V C C I_{b i_{\text {indc }} j y y^{\prime}}=0 & \forall b i_{\text {indc }} j, y>y^{\prime}
\end{array}
$$




$$
\begin{aligned}
& V C C D_{i_{\text {distc }} j T C y y^{\prime}}=0 \\
& \forall i_{\text {distc }} j T C, y>y^{\prime} \\
& V C T I_{i_{\text {trans }} j y y y^{\prime}}=0 \\
& \forall i_{\text {trans }} j, y>y^{\prime} \\
& D_{C H} I_{b i_{\text {ind }} j y y^{\prime}}=0 \\
& \forall b i_{\text {ind }} j, y \geq y^{\prime} \\
& D C C I_{b i_{i n d c} j y y^{\prime}}=0 \\
& \forall b i_{\text {indc }} j, y \geq y^{\prime} \\
& D C C D_{i_{\text {distc }} j T C y y^{\prime}}=0 \\
& \forall i_{\text {distc }} j T C, y \geq y^{\prime} \\
& D C T I_{i_{\text {trans }} j y y y^{\prime}}=0 \\
& \forall i_{\text {trans }} j, y \geq y^{\prime}
\end{aligned}
$$

Installed and operating capacities

Operating capacities are constrained by the installed capacity:

$$
\begin{array}{cc}
O C H I_{b h i_{i n d} j y} \leq T C H I_{b i_{\text {ind }} j y} & \forall b h i_{\text {ind }} j y \\
O C C I_{b h i_{i n d c} j y} \leq T C C I_{b i_{i n d c} j y} & \forall b h i_{\text {indc }} j y \\
O C C D_{h i_{\text {distc }} j T C y} \leq T C C D_{i_{\text {distc }} j T C y} & \forall h i_{\text {distc }} j T C y \\
\sum_{h} O C T I_{h i_{\text {trans }} j y}=T C T I_{i_{\text {trans }} j y} & \forall i_{\text {trans }} j y
\end{array}
$$

Following demand load profiles:

$$
\begin{array}{lr}
H P_{h} \cdot O C H I_{\text {b peak } i_{\text {ind }} j y} \leq O C H I_{b h i_{\text {ind }} j y} & \forall b h i_{\text {ind }} j y \\
C P_{h} \cdot O C C I_{\text {b peak } i_{\text {ind }} j y} \leq O C C I_{\text {bhi }} \text { indc } j y & \forall b h i_{\text {indc }} j y
\end{array}
$$

Charging patterns for electric vehicles:

$$
\text { TP }_{h} \cdot \text { OCTI }_{\text {hitrans }_{\text {elec }} j y}=\text { OCTI }_{\text {peak }} \text { itrans }_{\text {elec }} j y \quad \forall \text { ijy }
$$

Integer district technologies:

$$
\begin{array}{cc}
N D C_{i_{\text {distc } j T C y}} \cdot C a p_{i_{d i s t c}^{D C} C}^{D C}=N C C D_{i_{\text {distc } j T C y}} & \forall i_{d i s t c} j T C y \\
N D C D_{i_{\text {distc }} j T C y} \cdot C a p_{i_{d i s t c}^{D C}}^{D C}=\sum_{y^{\prime}<y} D C C D_{i_{\text {distc }} j T C y^{\prime} y} & \forall i_{d i s t c} j T C y \\
N D C_{i_{\text {distc } j T C y}, N D C D_{i_{\text {distc }} j T C y} \in \mathbb{Z}^{+}}
\end{array}
$$

Non-negative capacities: 


$$
\begin{aligned}
& N C H I_{b i_{i n d} j y}, V C H I_{b i_{i n d} j y y^{\prime}}, \quad D C H I_{b i_{\text {ind }} j y y^{\prime}}, \quad T C H I_{b i_{\text {ind }} j y,} \\
& O C H I_{b h i_{i n d} j y}, N C C I_{b i_{\text {indc }} j y}, V C C I_{b i_{\text {indc }} j y y^{\prime},}, \quad D C C I_{b i_{\text {indc }} j y y^{\prime}} \text {, } \\
& T C C I_{b i_{\text {indc }} j y}, \quad O C C I_{b h i_{\text {indc }} j y}, \quad N C C D_{i_{\text {distc }} j T C y} \text {, } \\
& V C C D_{i_{\text {distc }} j T C y y \prime}, \quad D C C D_{i_{\text {distc }} j T C y y \prime}, \quad T C C D_{i_{\text {distc }} j T C y}, \\
& \text { OCCD } D_{\text {histc }} j \text { TCy, } \quad N C T i_{i_{\text {trans }} j y,}, V C T I_{i_{\text {trans }} j y y^{\prime}}, \\
& \text { DCTI } i_{i_{\text {trans }} j y y^{\prime}}, \quad \text { TCTI } i_{i_{\text {trans }} j y,} \text { OCTI } I_{i_{\text {trans }} j y} \geq 0
\end{aligned}
$$

\section{Networks}

Infrastructure between zones

\section{Connected networks:}

$$
C C N_{j j^{\prime} n y y^{\prime *}}=I C N_{j j^{\prime} n y}-\sum_{y^{\prime}=0}^{y^{\prime *}} D C N_{j j^{\prime} n y y^{\prime}} \quad \forall j j^{\prime} n, \forall y \leq y^{\prime *}
$$

Total capacity:

$$
T C N_{j j^{\prime} n y}=\sum_{y^{\prime} \leq y} C C N_{j j^{\prime} n y^{\prime} y} \quad \forall j j^{\prime} n y
$$

Decommissioning initial networks and lifetimes:

$$
\begin{aligned}
D C N_{j j^{\prime} n y_{0} y} & =\frac{I C N_{j j^{\prime} n y_{0}}}{8} & \forall j j^{\prime}, y_{0}<y, n=\text { gasn, elecn } \\
I C N_{j j^{\prime} n y} & =\sum_{y^{\prime}=0}^{y+L t_{n}^{N}} D C N_{j j^{\prime} n y y^{\prime}} & \forall j j^{\prime} n y
\end{aligned}
$$

Non-negative capacities and border conditions:

$$
\begin{array}{rr}
I C N_{j j^{\prime} n y}, \quad C C N_{j j^{\prime} n y y^{\prime}}, \quad D C N_{j j^{\prime} n y y^{\prime}} \geq 0 & \forall j j^{\prime} n y y^{\prime} \\
C C N_{j j^{\prime} n y y^{\prime}}=0 & \forall j j^{\prime} n, \quad \forall y>y^{\prime} \\
D C N_{j j^{\prime} n y y^{\prime}}=0 & \forall j j^{\prime} n, \quad \forall y \geq y^{\prime}
\end{array}
$$

Symmetric networks:

$$
\begin{array}{cc}
I C N_{j j^{\prime} n y}=I C N_{j^{\prime} j n y} & \forall j j^{\prime} n y \\
C C N_{j j^{\prime} n y y^{\prime}}=C C N_{j^{\prime} j n y y^{\prime}} & \forall j j^{\prime} n y y^{\prime} \\
D C N_{j j^{\prime} n y y^{\prime}}=D C N_{j^{\prime} j n y y^{\prime}} & \forall j j^{\prime} n y y^{\prime}
\end{array}
$$

Infrastructure within zones

Vintage capacity for networks: 


$$
V L N_{j n y y^{\prime *}}=N L N_{j n y}-\sum_{y^{\prime}=0}^{y^{\prime *}} D L N_{j n y y^{\prime}} \quad \forall j n, \forall y \leq y^{\prime *}
$$

Total network length:

$$
T L N_{j n y}=\sum_{y^{\prime} \leq y} V L N_{j n y^{\prime} y} \quad \forall j n y
$$

Decommissioning initial networks and lifetimes:

$$
\begin{array}{cc}
D L N_{j n y_{0} y}=\frac{N L N_{j j^{\prime} n y_{0}}}{8} & \forall j, y_{0}<y n=\text { gasn, elecn } \\
N L N_{j n y}=\sum_{y^{\prime}=0}^{y+L t_{n}^{N}} D L N_{j n y y^{\prime}} & \forall j n y
\end{array}
$$

Non-negative lengths and border conditions:

$$
\begin{array}{rll}
N L N_{\text {jny }}, \quad V L N_{\text {jny }}, \quad & D L N_{\text {jny }}, \geq 0 & \forall j n y y^{\prime} \\
V L N_{j n y y^{\prime}}=0 & & \forall j n, \forall y>y^{\prime} \\
D L N_{j n y y^{\prime}}=0 & & \forall j n, \forall y \geq y^{\prime}
\end{array}
$$

Gas network length:

$$
\frac{\sum_{b, i_{\text {ind }}=\text { boilers, gas CHPs }} T C H I_{b i_{\text {ind }} j y}}{\text { Dem }_{\text {dom peakdomjy }}^{H} \cdot \mathrm{Num}_{\text {domjy }}+\text { Dem }_{\text {comm peakcomm jy }}^{H} \cdot \mathrm{Num}_{\text {commjy }}} \cdot R l_{j}
$$

Electricity network length:

$$
\begin{aligned}
& \frac{\sum_{b, i_{\text {ind }}=A S H P, G S H P, \text { eradiators }} T_{C H} \text { bi }_{\text {ind }} j y}{\text { Dem }_{\text {dom peakdomjy }} \cdot \text { Num }_{\text {domjy }}+\text { Dem }_{\text {comm peakcomm jy }}^{H} \cdot \text { Num }_{\text {commjy }}} \\
& \leq T_{L} N_{\text {elecn }} \quad \forall j y
\end{aligned}
$$

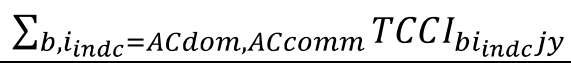

$$
\begin{aligned}
& \overline{\text { Dem }_{\text {dom peakdomjy }}^{C} \cdot \mathrm{Num}_{\text {domjy }} \cdot 0.07+\text { Dem }_{\text {comm peakcommjy }}^{C} \cdot \mathrm{Num}_{\text {commjy }}} \\
& \leq T L N_{j \text { elecn }} \quad \forall j y
\end{aligned}
$$




$$
\begin{aligned}
& \text { ( } \\
& \sum_{b, i_{\text {ind }}=A S H P, G S H P, \text { eradiators }} \text { OCHI }_{\text {bhind }} j y \\
& \overline{\text { Dem }_{\text {dom peakdomjy }}^{H} \cdot \mathrm{Num}_{\text {domjy }}+\text { Dem }_{\text {comm peakcomm jy }}^{H} \cdot \mathrm{Num}_{\text {commjy }}} \\
& +\frac{\sum_{b, i_{\text {indc }}=A C d o m, A C c o m m} \text { OCCI }_{\text {bhi }} \text { indc } j y}{\text { Dem }_{\text {dom peakdomjy }}^{C} \cdot \text { Num }_{\text {domjy }}+\text { Dem }_{\text {comm peakcommjy }}^{C} \cdot N u m_{\text {commjy }}} \\
& \text { OCTI } I_{\text {elecvjy }}[\mathrm{km}] \\
& +\frac{\overline{\eta_{\text {elecv }}^{T h T r}\left[\frac{\mathrm{km}}{\mathrm{kWh}}\right] \cdot \operatorname{Duration}(\mathrm{h})}}{\operatorname{Dem}_{\text {dom peakdomjy }}^{E} \cdot \mathrm{Num}_{\text {domjy }}+\text { Dem }_{\text {comm peakcommjy }}^{E} \cdot \mathrm{Num}_{\text {commjy }}} \\
& \left.+\frac{\sum_{b} \operatorname{Dem}_{\text {bhjy }}^{E} \cdot \mathrm{Num}_{\text {bjy }}}{\operatorname{Dem}_{\text {dom peakdomjy }}^{E} \cdot \mathrm{Num}_{\text {domjy }}+\operatorname{Dem}_{\text {comm peakcommjy }}^{E} \cdot \mathrm{Num}_{\text {commjy }}}\right) \cdot R l_{j} \\
& \leq T_{L} N_{\text {elecn }} \quad \forall \text { ijy }
\end{aligned}
$$

Hydrogen network length:

For heat:

$$
\begin{aligned}
& \frac{\sum_{b, i_{\text {ind }}=\text { hyd boilers, hyd CHPs }} \text { TCHI }_{\text {bi ind }} \text { jy }}{\text { Dem }_{\text {dom peakdomjy }}^{H} \cdot \text { Num }_{\text {domjy }}+\text { Dem }_{\text {comm peakcomm jy }}^{H} \cdot N u m_{\text {commjy }}} \cdot R l_{j} \\
& \leq T L N_{j h y d n y} \quad \forall j y
\end{aligned}
$$

For transport:

$$
\frac{T C T I_{H y d v j y}}{D e m_{j y}^{T}} \cdot M R l_{j} \leq T L N_{j h y d n y} \quad \forall j y
$$

Cooling network length:

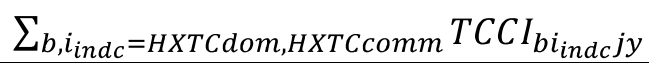

$$
\begin{aligned}
& \frac{D_{\text {dom peakdomjy }} \cdot N u m_{\text {domjy }}+\text { Dem }_{\text {comm peakcommjy }}^{C} \cdot N u m_{\text {commjy }}}{D e l_{\text {ind }}} \cdot R l_{j} \\
& \leq T L N_{j} \operatorname{cooln}\left(T C^{*}\right) y \quad \forall j T C^{*} y
\end{aligned}
$$

All network lengths for heat: 
$+\left(\frac{\sum_{b, i_{\text {ind }}=A S H P, G S H P, \text { eradiators }} T C H I_{b i_{\text {ind }} j y}}{\text { Dem }_{\text {dom peakdom jy }}^{H} \cdot N u m_{\text {domjy }}+\operatorname{Dem}_{\text {comm peakcomm jy }}^{H} \cdot N u m_{\text {commjy }}}\right)$

$\cdot R l_{j}$

$+\left(\frac{\sum_{b, i_{\text {ind }}=\text { hyd boilers, } h y d \text { CHPs }} T C H I_{b i_{\text {ind }} j y}}{\text { Dem }_{\text {dom peakdomjy }}^{H} \cdot N u m_{\text {domjy }}+\operatorname{Dem}_{\text {comm peakcomm jy }}^{H} \cdot N u m_{\text {commjy }}}\right)$

$\cdot R l_{j} \geq R l_{j} \quad \forall j y$

\section{Energy balances}

In each zone, for all networks:

$$
F_{h j n y}^{I N}-F_{h j n y}^{O U T}+\sum_{j^{\prime}} F_{h j^{\prime} j n y}-\sum_{j^{\prime}} F_{h j j^{\prime} n y}-F_{h j n y}^{C O N S}+F_{h j n y}^{G E N}=0 \quad \forall \text { inny }
$$

Annual energy balance for hydrogen for transport:

$$
F_{j y}^{I N T R H}-F_{j y}^{O U T T R H}+\sum_{j^{\prime}} F_{j^{\prime} j y}^{T R H}-\sum_{j^{\prime}} F_{j j^{\prime} y}^{T R H}-F_{j y}^{C O N S T R H}+F_{j y}^{G E N T R H}=0 \quad \forall j y
$$

Gas network energy consumption and generation:

$$
\begin{aligned}
& F_{h j \text { gasn } y}^{\text {CONS }}=\sum_{b,} \frac{O C H I_{\text {bhi }} i_{\text {ind }} j y}{\eta_{i_{\text {ind }}}^{T h I}} \quad \forall h j y \\
& i_{\text {ind }}= \\
& \text { boilers, } \\
& \text { CHPS } \\
& F_{h j \text { gasn } y}^{G E N}=0 \\
& \forall h j y
\end{aligned}
$$

Electricity network energy consumption and generation:

$$
\begin{aligned}
& F_{h j \text { elecn } y}^{\text {CONS }}=\sum_{b} D_{e m}^{E} m_{b h y}^{E} \cdot N u m_{b j y}+\sum_{b,} \frac{O C H I_{b h i_{i n d} j y}}{\eta_{i_{\text {ind }}^{T h I}}^{h}} \\
& i_{\text {ind }}= \\
& \text { ASHP, } \\
& \text { GSHP, } \\
& \text { eradiator } \\
& +\sum_{b,} \frac{O C C I_{\text {bhi }} i_{\text {indc }} j y}{\eta_{i_{\text {indc }}^{T C}}^{T h C}}+\frac{\text { OCTI } I_{\text {elecv } j y}}{\eta_{\text {elecv }}^{T h T r} \cdot \text { Dur }_{h}} \quad \forall \text { hjy } \\
& i_{\text {indc }}= \\
& \text { ACdom, } \\
& F_{\text {hj elecn } y}^{G E N}=\sum_{b} O_{C H I_{\text {bh CHPind } j y}} \cdot \frac{\eta_{C H P_{\text {ind }}}^{E I}}{\eta_{C H P_{\text {ind }}}^{T h I}} \quad \forall \text { ijy }
\end{aligned}
$$

Hydrogen network energy consumption and generation: 


$$
\begin{aligned}
& F_{\text {hj hydny }}^{\text {CONS }}=\sum_{\begin{array}{c}
b, \\
i_{\text {ind }}= \\
\text { hyd boiler, } \\
\text { hyd microcHP, }
\end{array}} \frac{O C H I_{b h i_{\text {ind }} j y}}{\eta_{i_{\text {ind }}^{T h I}}} \quad \forall \text { my } \\
& F_{h j h y d n y}^{G E N}=0 \quad \forall h j y \\
& F_{j y}^{\text {CONSTRH }}=\sum_{h} \frac{\text { OCTI } I_{h \text { Hydv jy }}}{\eta_{H y d v}^{T h r}} \\
& F_{j y}^{G E N T R H}=0 \quad \forall j y
\end{aligned}
$$

Cooling network energy consumption and generation:

$$
\begin{aligned}
& F_{h j \operatorname{cooln}\left(T C^{*}\right) y}^{\operatorname{CONS}}=\sum_{b,} \frac{O C C I_{b h i_{\text {indc }} j y}}{\eta_{i_{\text {ind }}^{T h I C}}} \quad \forall h j T C^{*} y \\
& F_{h j \operatorname{cooln}\left(T C^{*}\right) y}^{G E N}=\sum_{i_{\text {distc }}}\left(1-\operatorname{Loss}_{T C^{*}}\right) \cdot O C C D_{h i_{d i s t c} j T C^{*} y} \quad \forall h j T C^{*} y
\end{aligned}
$$

Further energy flows, networks, and demand constraints

Meeting heat, cooling, and transport demands:

$$
\begin{array}{cc}
\sum_{i_{\text {ind }}} \text { OCHI }_{\text {bhi } i_{\text {ind }} j y} \geq \operatorname{Dem}_{\text {bhjy }}^{H} \cdot \text { Num }_{\text {bjy }} & \forall b h j y \\
\sum_{i_{\text {indc }}} \text { OCCI }_{\text {bhi } i_{\text {indc }} j y} \geq \operatorname{Dem}_{\text {bhjy }}^{C} \cdot \text { Num }_{\text {bjy }} & \\
\sum_{i_{\text {trans }}, h} \text { OCTI }_{h i_{\text {trans }} j y} \geq \operatorname{Dem}_{j y}^{T} & \forall b h j y
\end{array}
$$

Cooling network water mass flow:

$$
\dot{m} c_{h j j^{\prime} T C^{*} y} \cdot\left(T C^{*}-T C_{T C}^{R}\right) \cdot c=F_{h j j^{\prime}} \operatorname{cooln}\left(T^{*}\right) y \quad \forall h j j^{\prime} T C^{*} y
$$

Network capacity enough to meet flow:

$$
F_{h j j^{\prime} n y} \leq T C N_{j j^{\prime} n y} \quad \forall h j j^{\prime} n y
$$

Capacity for hydrogen demand if there was a permanent flow through them:

$$
\frac{F_{j j^{\prime} y}^{T R H}+\sum_{h} F_{h j j^{\prime} h y d n y} \cdot \text { Duration }_{h}}{8760} \leq T C N_{j j^{\prime} \text { hydn } y} \quad \forall j j^{\prime} y
$$

Networks can be installed between neighbour zones:

$$
\begin{array}{ll}
I C N_{j j^{\prime} n y} \leq N b_{j j} \cdot M & \forall h j j^{\prime} n y \\
C C N_{j j^{\prime} n y y^{\prime}} \leq N b_{j j^{\prime}} \cdot M & \forall h j j^{\prime} n y y^{\prime}
\end{array}
$$




$$
\begin{array}{lr}
F_{h j j^{\prime} n y}=0 & \forall h n y, j=j^{\prime} \\
F_{j j^{\prime} y}^{T R H}=0 & \forall y, j=j^{\prime} \\
\dot{m} c_{h j j^{\prime} T C y}=0 & \forall h T C y, j=j^{\prime}
\end{array}
$$

Energy flows from and to outside the city boundaries:

$$
\begin{array}{lr}
F_{h j n y}^{I N} \leq C b_{j} \cdot M & \forall \text { ingy } \\
F_{h j n y}^{\text {OUT }} \leq C b_{j} \cdot M & \forall \text { hjny } \\
F_{j y}^{I N T R H} \leq C b_{j} \cdot M & \forall j y \\
F_{j y}^{\text {OUTTRH }} \leq C b_{j} \cdot M & \forall j y
\end{array}
$$

Non-negative variables:

$$
\begin{aligned}
& F_{h j n y}^{I N}, \quad F_{h j n y}^{\text {OUT }}, \quad F_{\text {hjj'ny }}, \quad F_{\text {hjny }}^{\text {CONS }}, \quad F_{\text {hiny }}^{\text {GEN }} \quad F_{j y}^{I N T R H}, \quad F_{j y}^{\text {OUTTRH }} \text {, } \\
& F_{j j^{\prime} y}^{T R H}, \quad F_{j y}^{C O N S T R H}, \quad F_{j y}^{G E N T R H}, \quad \dot{m} c_{h j j^{\prime} T C y} \geq 0 \quad \forall h, j, j^{\prime}, n, \\
& T C, y
\end{aligned}
$$

\section{Fuel and electricity consumption and $\mathrm{CO}_{2}$ emissions}

Hourly fuel consumption of individual and district level heat and cooling supply technologies:

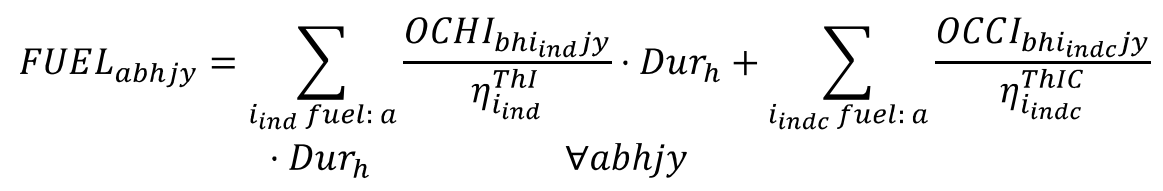

$$
\begin{aligned}
& F U E L D_{\text {ahjy }}=\sum_{\substack{T C, i_{\text {distc }} \text { fuel: } a}} \frac{O C C D_{h i_{\text {distc }} j T C y}}{\eta_{i_{\text {distc }}^{T h D C}} T C} \cdot \text { Dur }_{h} \quad \forall \text { ahjy }
\end{aligned}
$$

Total annual fuel consumption by demand type, not including transport:

$$
F U E L_{\text {aby }}^{T O T}=\sum_{h j} F U E L_{a b h j y} \quad \forall a b y
$$

Annual transport fuel consumption:

$$
\begin{array}{cl}
\text { FUELTR }_{a j y}=\sum_{h, i_{\text {trans fuel: } a} \frac{O C T I_{h j i_{\text {trans }} y}}{\eta_{i_{\text {trans }}^{T h T}}}} & \forall a j y \\
\text { FUELTR } R_{a y}^{T O T}=\sum_{j} F U E L T R_{\text {ajy }} & \forall a y
\end{array}
$$


Electricity consumption from the grid for heating and cooling:

$$
\begin{aligned}
& E L E C_{b y}^{T O T}=\sum_{h j} D m_{b h j y}^{E} \cdot N u m_{b j y} \cdot D_{h}+\sum_{\substack{h j \\
i_{\text {ind }}=\\
A S H P, G S H P, \\
\text { eradiator }}} \frac{O C H I_{b h i_{\text {ind }} j y}}{\eta_{i_{\text {ind }}^{T h}}^{T h}} \cdot \operatorname{Dur}_{h} \\
& +\sum_{\substack{h j \\
i_{\text {indc }}=\\
\text { AC_dom, } \\
A C_{-} \text {comm }}} \frac{O C C I_{\text {bhi }}}{\eta_{i_{\text {ind }} \text { ind }}^{\text {ThIC }}} \cdot \text { Dur }_{h} \quad \forall b y \\
& E L E C D_{y}^{T O T}=\sum_{\substack{h j T C \\
\text { idistc }}} \frac{O C C D_{h i_{\text {distc }} j T C y}}{\eta_{i_{\text {distc } T C}^{T h D C}}^{\text {S }_{\text {ist }}}} \cdot \operatorname{Dur}_{h} \forall y
\end{aligned}
$$

Electricity from the grid for transport:

$$
\operatorname{ELECTR}_{y}^{T O T}=\sum_{\substack{h j \\ i_{\text {trans }}=\\ \text { elecv }}} \frac{O C T I_{\text {hi }}}{\eta_{i_{\text {trans }} j y}^{\text {thans }}} \quad \forall b y
$$

Total system's equivalent $\mathrm{CO}_{2}$ emissions:

$$
\begin{aligned}
& C O 2=\sum_{a b y} F U E L_{a b y}^{T O T} \cdot E m_{a b y}^{F}+\sum_{a y} F U E L D_{a y}^{T O T} \cdot E m_{a y}^{F D}+\sum_{a y} F U E L T R_{a y}^{T O T} \cdot E m_{a y}^{F T} \\
&+\sum_{b y} E L E C_{b y}^{T O T} \cdot E m_{b y}^{E}+\sum_{y} E L E C D_{y}^{T O T} \cdot E m_{y}^{E D} \\
&+\sum_{a y} E L E C T R_{y}^{T O T} \cdot E m_{a y}^{E T}-\sum_{h j y} F_{h j \text { elecn } y}^{G E N} \cdot \operatorname{Dur}_{h} \cdot E m_{\text {dom } 1 y}^{E}
\end{aligned}
$$

Yearly $\mathrm{CO} 2$ emissions

$$
\begin{gathered}
Y C O 2_{y}=\sum_{a b} F U E L_{a b y}^{T O T} \cdot E m_{a b y}^{F}+\sum_{b} E L E C_{b y}^{T O T} \cdot E m_{b y}^{E}+\sum_{a} F U E L T R_{a y}^{T O T} \cdot E m_{a y}^{F T} \\
+\sum_{a} E L E C T R_{y}^{T O T} \cdot E m_{a y}^{E T}-\sum_{h j} F_{h j \text { elecn } y}^{G E N} \cdot \operatorname{Dur}_{h} \cdot E m_{\text {dom } 1 y}^{E}
\end{gathered}
$$

Carbon constraints, according to Brazil's iNDCs:

$$
\begin{gathered}
Y C O 2_{2025} \leq\left(1-N d c_{2025}\right) \cdot Y C O 2_{2015} \\
Y C O 2_{2030} \leq\left(1-N d c_{2030}\right) \cdot Y C O 2_{2015} \\
Y C O 2_{2035} \leq Y C O 2_{2030} \\
Y C O 2_{2040} \leq Y C O 2_{2035} \\
Y C O 2_{2045} \leq Y C O 2_{2040}
\end{gathered}
$$


$Y C O 2_{2050} \leq Y C O 2_{2045}$

\section{Appendix C. Techno-economic data}

Table A: Network infrastructure costs and parameters

\begin{tabular}{|c|c|c|c|c|c|}
\hline Network & $\begin{array}{l}\text { Distribution } \\
\text { average cost } \\
{[2015 f / \mathrm{km}]}\end{array}$ & $\begin{array}{l}\text { Distribution } \\
\text { capacity cost } \\
{[2015 f / k W ~ k m]}\end{array}$ & Losses & Lifetime [years] & Source \\
\hline Electricity & 171570 & 2.48 & $\begin{array}{l}\text { Included in price } \\
\text { of electricity }\end{array}$ & 50 & {$[86,87]$} \\
\hline Gas & 493330 & 3.7 & $\begin{array}{l}\text { Included in price } \\
\text { of gas }\end{array}$ & 50 & {$[88,89]$} \\
\hline Hydrogen & 493330 & 3.7 & $\begin{array}{l}\text { Included in price } \\
\text { of hydrogen }\end{array}$ & 50 & {$[88,89]$} \\
\hline Cooling & 411380 & $13.6-12.6$ & $8 \%$ & 50 & {$[40,90]$} \\
\hline
\end{tabular}


Table B: Prices and emission factors of fuels and electricity

\begin{tabular}{|c|c|c|c|c|c|}
\hline Energy supply & $\begin{array}{l}\text { Emission } \\
\text { factor } \\
{\left[\mathrm{kgCO}_{2} \mathrm{e} / \mathrm{kWh}\right]}\end{array}$ & $\begin{array}{l}\text { Price } 2015 \\
\text { [£2015/kWh] }\end{array}$ & $\begin{array}{l}\text { Price } 2030 \\
\text { [f2015/kWh] }\end{array}$ & $\begin{array}{l}\text { Price } 2050 \\
\text { [f2015/kWh] }\end{array}$ & Source \\
\hline Gas $^{4}$ & 0.20196 & 0.010869 & 0.025433 & 0.022800 & $\begin{array}{l}\text { MUSE Brazil } \\
{[36]}\end{array}$ \\
\hline CNG & 0.20196 & 0.104835 & 0.147082 & 0.131851 & $\begin{array}{l}\text { MUSE Brazil } \\
{[36]}\end{array}$ \\
\hline Diesel & 0.26676 & 0.050507 & 0.062810 & 0.060250 & $\begin{array}{l}\text { MUSE Brazil } \\
{[36]}\end{array}$ \\
\hline Ethanol & 0.233532 & 0.032830 & 0.040827 & 0.039162 & $\begin{array}{l}\text { MUSE Brazil } \\
{[36]}\end{array}$ \\
\hline Gasoline & 0.252 & 0.050507 & 0.062810 & 0.039162 & $\begin{array}{l}\text { MUSE Brazil } \\
{[36]}\end{array}$ \\
\hline Hydrogen $^{5}$ & 0.0495 & 0.07812 & 0.07812 & 0.07812 & {$[89,91]$} \\
\hline $\begin{array}{l}\text { Electricity CP: } \\
2015\end{array}$ & 0.156627 & $\begin{array}{l}\text { Commercial: } \\
0.055685\end{array}$ & $\begin{array}{l}\text { Commercial: } \\
0.069606\end{array}$ & $\begin{array}{l}\text { Commercial: } \\
0.069606\end{array}$ & {$[36,81,92]$} \\
\hline 2030 & 0.080336 & Residential: & Residential: & Residential: & \\
\hline 2050 & 0.081285 & 0.085007 & 0.106259 & 0.106259 & \\
\hline \multicolumn{6}{|l|}{ Electricity NP: } \\
\hline 2015 & 0.15663 & & & & \\
\hline 2030 & 0.06076 & & & & \\
\hline 2050 & 0.06333 & & & & \\
\hline \multicolumn{6}{|l|}{ Electricity SD: } \\
\hline 2015 & 0.1566 & & & & \\
\hline 2030 & 0.0191 & & & & \\
\hline 2050 & 0.0158 & & & & \\
\hline
\end{tabular}

${ }^{4}$ The cost of distribution of natural gas and hydrogen is discounted, as the model intrinsically pays for distribution when choosing whether or not to build pipelines. Other fuels are assumed to be transported by tankers.

${ }^{5}$ This is the cost of hydrogen for heat. Hydrogen for transport is assumed to be $10 \%$ more expensive to account for the cost of eventual further purification. 


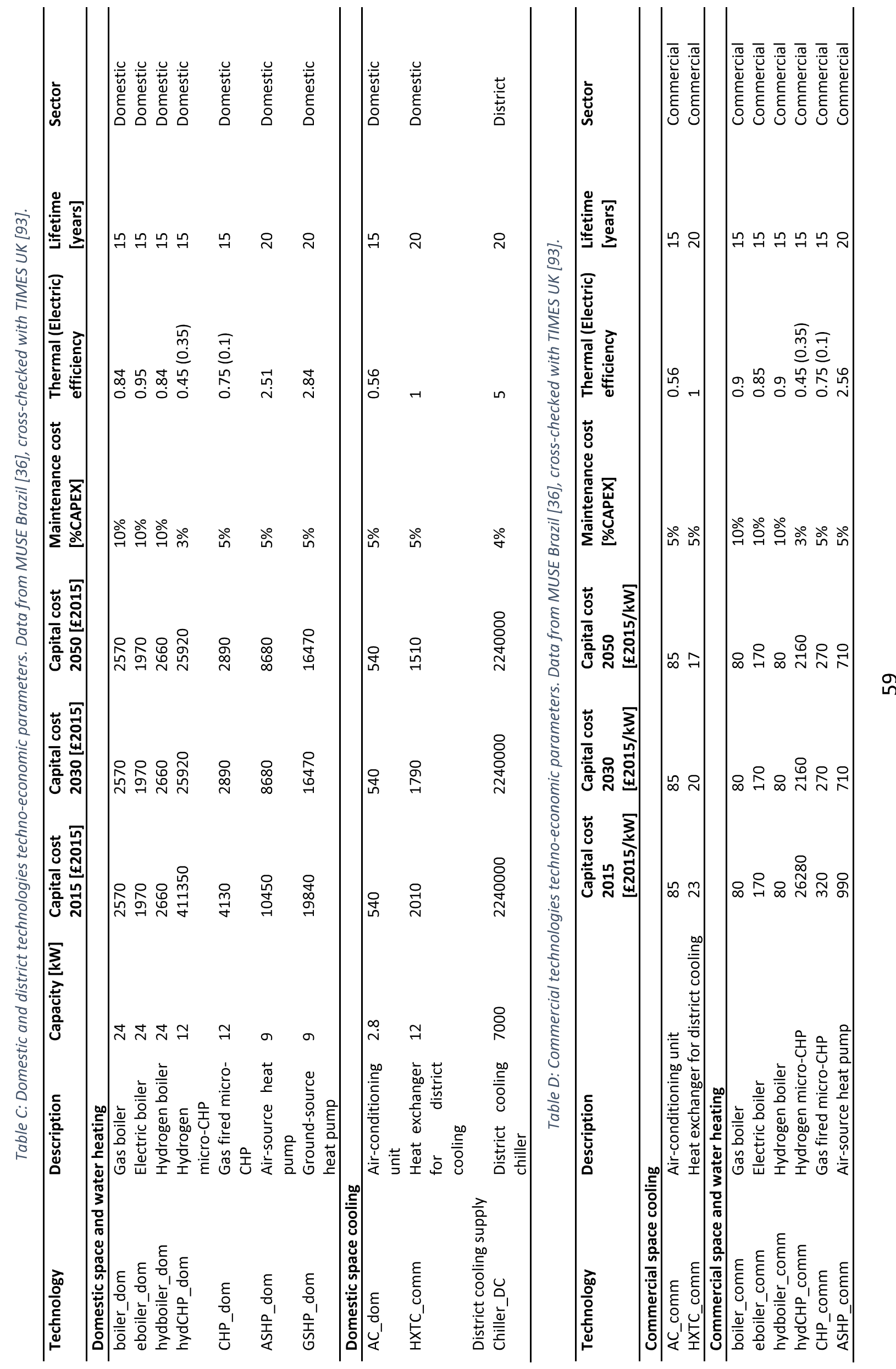




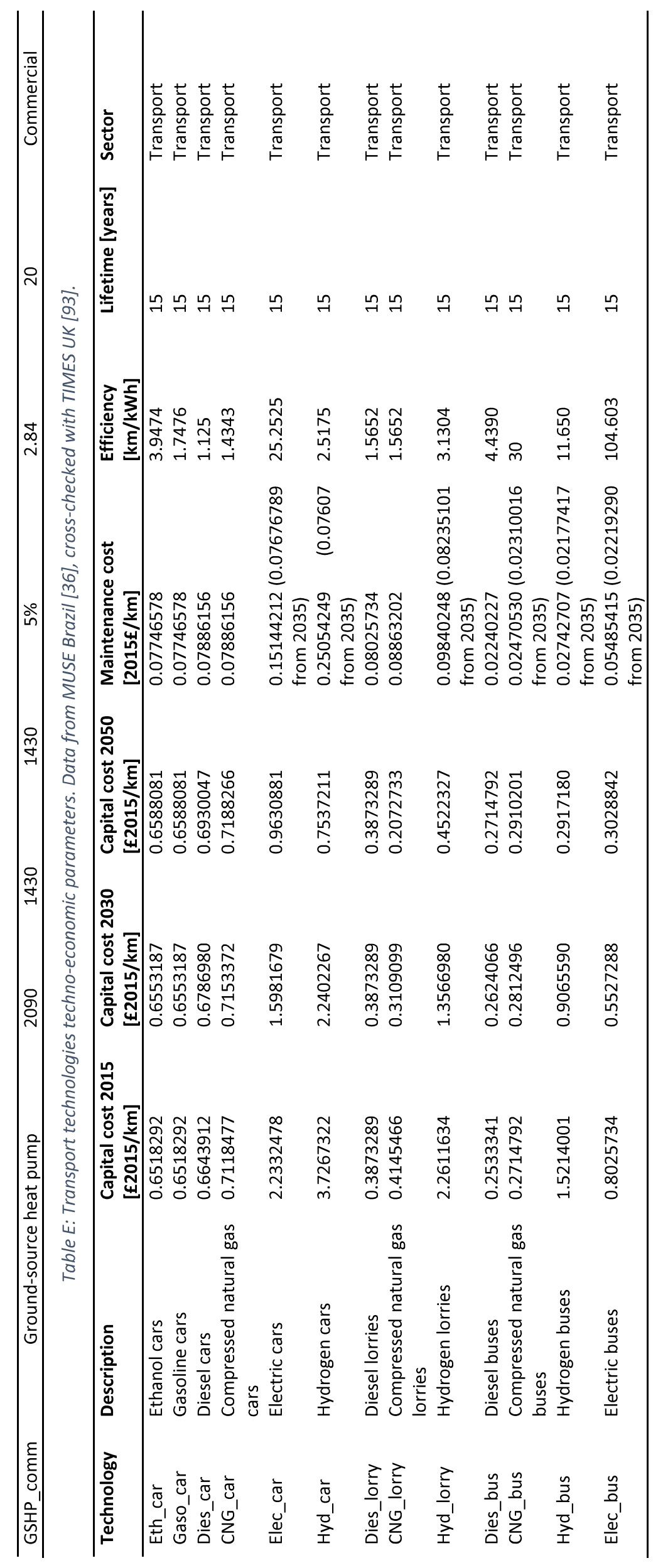




\section{References}

[1] International Energy Agency. Cities are at the frontline of the energy transition 2016 [Available from: https://www.iea.org/newsroom/news/2016/september/cities-are-at-the-frontlineof-the-energy-transition.html.

[2] International Energy Agency. Energy Technology Perspectives 2017- Catalysing Energy Technology Transformations. OECD/IEA; 2017.

[3] International Energy Agency. Cooling- Tracking Clean Energy Progress 2019 [updated Friday May 24, 2019. Available from: https://www.iea.org/tcep/buildings/cooling/.

[4] Pfenninger S, Hawkes A, Keirstead J. Energy systems modeling for twenty-first century energy challenges. Renewable and Sustainable Energy Reviews. 2014;33:74-86.

[5] Jalil-Vega F, Hawkes AD. The effect of spatial resolution on outcomes from energy systems modelling of heat decarbonisation. Energy. 2018;155:339-50.

[6] Siala K, Mahfouz MY. Impact of the choice of regions on energy system models. Energy Strategy Reviews. 2019;25:75-85.

[7] Connolly D, Lund H, Mathiesen BV, Werner S, Möller B, Persson U, et al. Heat Roadmap Europe: Combining district heating with heat savings to decarbonise the EU energy system. Energy Policy. 2014;65:475-89.

[8] Troup H. Electricity is on track for decarbonisation, but what about decarbonising heat? Renewable Energy Focus. 2016;17(5):178-9.

[9] Fischer D, Madani H. On heat pumps in smart grids: A review. Renewable and Sustainable Energy Reviews. 2017;70:342-57.

[10] Dodds PE, Staffell I, Hawkes AD, Li F, Grünewald P, McDowall W, et al. Hydrogen and fuel cell technologies for heating: A review. International Journal of Hydrogen Energy. 2015;40(5):2065-83.

[11] Lund H, Möller B, Mathiesen BV, Dyrelund A. The role of district heating in future renewable energy systems. Energy. 2010;35(3):1381-90.

[12] Keirstead J, Samsatli N, Shah N, Weber C. The impact of CHP (combined heat and power) planning restrictions on the efficiency of urban energy systems. Energy. 2012;41(1):93-103.

[13] Keirstead J, Calderon C. Capturing spatial effects, technology interactions, and uncertainty in urban energy and carbon models: Retrofitting newcastle as a case-study. Energy Policy. 2012;46(0):253-67.

[14] Jalil-Vega F, Hawkes AD. Spatially resolved model for studying decarbonisation pathways for heat supply and infrastructure trade-offs. Applied Energy. 2018;210:1051-72.

[15] Dominković DF, Bin Abdul Rashid KA, Romagnoli A, Pedersen AS, Leong KC, Krajačić G, et al. Potential of district cooling in hot and humid climates. Applied Energy. 2017;208:49-61.

[16] Lake A, Rezaie B, Beyerlein S. Review of district heating and cooling systems for a sustainable future. Renewable and Sustainable Energy Reviews. 2017;67:417-25.

[17] Dominković DF, Dobravec V, Jiang Y, Nielsen PS, Krajačić G. Modelling smart energy systems in tropical regions. Energy. 2018;155:592-609.

[18] Söderman J. Optimisation of structure and operation of district cooling networks in urban regions. Applied Thermal Engineering. 2007;27(16):2665-76.

[19] Khir R, Haouari M. Optimization models for a single-plant District Cooling System. European Journal of Operational Research. 2015;247(2):648-58.

[20] Al-Noaimi F, Khir R, Haouari M. Optimal design of a district cooling grid: structure, technology integration, and operation. Engineering Optimization. 2019;51(1):160-83.

[21] Ameri M, Besharati Z. Optimal design and operation of district heating and cooling networks with CCHP systems in a residential complex. Energy and Buildings. 2016;110:135-48.

[22] Comodi G, Bartolini A, Carducci F, Nagaranjan B, Romagnoli A. Achieving low carbon local energy communities in hot climates by exploiting networks synergies in multi energy systems. Applied Energy. 2019;256:113901. 
[23] Gerboni R, Grosso D, Carpignano A, Dalla Chiara B. Linking energy and transport models to support policy making. Energy Policy. 2017;111:336-45.

[24] Venturini G, Hansen M, Andersen PD. Linking narratives and energy system modelling in transport scenarios: A participatory perspective from Denmark. Energy Research \& Social Science. 2019;52:204-20.

[25] Pye S, Daly H. Modelling sustainable urban travel in a whole systems energy model. Applied Energy. 2015;159:97-107.

[26] Daly HE, Ramea K, Chiodi A, Yeh S, Gargiulo M, Gallachóir BÓ. Incorporating travel behaviour and travel time into TIMES energy system models. Applied Energy. 2014;135:429-39.

[27] Lovrić M, Blainey S, Preston J. A conceptual design for a national transport model with crosssectoral interdependencies. Transportation Research Procedia. 2017;27:720-7.

[28] Sterchele P, Kersten K, Palzer A, Hentschel J, Henning H-M. Assessment of flexible electric vehicle charging in a sector coupling energy system model - Modelling approach and case study. Applied Energy. 2020;258:114101.

[29] Novosel T, Perković L, Ban M, Keko H, Pukšec T, Krajačić G, et al. Agent based modelling and energy planning - Utilization of MATSim for transport energy demand modelling. Energy. 2015;92:466-75.

[30] Helgesen PI, Lind A, Ivanova O, Tomasgard A. Using a hybrid hard-linked model to analyze reduced climate gas emissions from transport. Energy. 2018;156:196-212.

[31] Barone G, Buonomano A, Calise F, Forzano C, Palombo A. Building to vehicle to building concept toward a novel zero energy paradigm: Modelling and case studies. Renewable and Sustainable Energy Reviews. 2019;101:625-48.

[32] Osório B, McCullen N, Walker I, Coley D. Integrating the energy costs of urban transport and buildings. Sustainable Cities and Society. 2017;32:669-81.

[33] Fichera A, Inturri G, La Greca P, Palermo V. A model for mapping the energy consumption of buildings, transport and outdoor lighting of neighbourhoods. Cities. 2016;55:49-60.

[34] Fishbone LG, Abilock $\mathrm{H}$. Markal, a linear-programming model for energy systems analysis: Technical description of the bnl version. International Journal of Energy Research. 1981;5(4):353-75.

[35] Loulou R, Labriet M. ETSAP-TIAM: the TIMES integrated assessment model Part I: Model structure. Computational Management Science. 2008;5(1):7-40.

[36] García Kerdan I, Giarola S, Hawkes A. A novel energy systems model to explore the role of land use and reforestation in achieving carbon mitigation targets: A Brazil case study. Journal of Cleaner Production. 2019;232:796-821.

[37] Lund $\mathrm{H}$, Kempton $\mathrm{W}$. Integration of renewable energy into the transport and electricity sectors through V2G. Energy Policy. 2008;36(9):3578-87.

[38] Collaço FMdA, Simoes SG, Dias LP, Duic N, Seixas J, Bermann C. The dawn of urban energy planning - Synergies between energy and urban planning for São Paulo (Brazil) megacity. Journal of Cleaner Production. 2019;215:458-79.

[39] Jing ZX, Jiang XS, Wu QH, Tang WH, Hua B. Modelling and optimal operation of a small-scale integrated energy based district heating and cooling system. Energy. 2014;73:399-415.

[40] Yang Y, Zhang S, Xiao Y. Optimal design of distributed energy resource systems coupled with energy distribution networks. Energy. 2015;85:433-48.

[41] Jing R, Wang $M$, Liang $H$, Wang $X$, Li N, Shah N, et al. Multi-objective optimization of a neighborhood-level urban energy network: Considering Game-theory inspired multi-benefit allocation constraints. Applied Energy. 2018;231:534-48.

[42] Ersoz I, Colak U. A stochastic evaluation of investments in combined cooling, heat, and power systems. Applied Thermal Engineering. 2019;146:376-85.

[43] Karmellos M, Mavrotas G. Multi-objective optimization and comparison framework for the design of Distributed Energy Systems. Energy Conversion and Management. 2019;180:473-95. 
[44] Chakrabarti A, Proeglhoef R, Turu GB, Lambert R, Mariaud A, Acha S, et al. Optimisation and analysis of system integration between electric vehicles and UK decentralised energy schemes. Energy. 2019;176:805-15.

[45] Büchele R, Kranzl L, Hummel M. Integrated strategic heating and cooling planning on regional level for the case of Brasov. Energy. 2019;171:475-84.

[46] Schweiger G, Larsson P-O, Magnusson F, Lauenburg P, Velut S. District heating and cooling systems - Framework for Modelica-based simulation and dynamic optimization. Energy. 2017;137:566-78.

[47] Jalil-Vega FA, Hawkes AD. Spatially Resolved Optimization for Studying the Role of Hydrogen for Heat Decarbonization Pathways. ACS Sustainable Chemistry \& Engineering. 2018.

[48] Jing R, Wang M, Zhang Z, Wang X, Li N, Shah N, et al. Distributed or centralized? Designing district-level urban energy systems by a hierarchical approach considering demand uncertainties. Applied Energy. 2019;252:113424.

[49] Reynolds J, Ahmad MW, Rezgui Y, Hippolyte J-L. Operational supply and demand optimisation of a multi-vector district energy system using artificial neural networks and a genetic algorithm. Applied Energy. 2019;235:699-713.

[50] Pye S, Sabio N, Strachan N. An integrated systematic analysis of uncertainties in UK energy transition pathways. Energy Policy. 2015;87:673-84.

[51] Chiam Z, Easwaran A, Mouquet D, Fazlollahi S, Millás JV. A hierarchical framework for holistic optimization of the operations of district cooling systems. Applied Energy. 2019;239:23-40.

[52] del Hoyo Arce I, Herrero López S, López Perez S, Rämä M, Klobut K, Febres JA. Models for fast modelling of district heating and cooling networks. Renewable and Sustainable Energy Reviews. 2018;82:1863-73.

[53] Liu WH, Ho WS, Lee MY, Hashim H, Lim JS, Klemeš JJ, et al. Development and optimization of an integrated energy network with centralized and decentralized energy systems using mathematical modelling approach. Energy. 2019.

[54] GaWC. Globalization and World Cities Research Network 2019 [Available from: https://www.lboro.ac.uk/gawc/.

[55] Prefeitura de São Paulo. Prefeitura de São Paulo - Subprefeituras 2017 [cited 2019 March 11]. Available

from: https://www.prefeitura.sp.gov.br/cidade/secretarias/subprefeituras/subprefeituras/mapa/index.ph $\mathrm{p} ? \mathrm{p}=250449$.

[56] Governo Federal Brasil. e-SIC: Sistema eletrônico do serviço de informação ao cidadão [cited 2018 July 24]. Available from: https://esic.cgu.gov.br/sistema/site/index.aspx.

[57] Ghisi E, Gosch S, Lamberts R. Electricity end-uses in the residential sector of Brazil. Energy Policy. 2007;35(8):4107-20.

[58] Mosquim RF, de Oliveira Junior S, Keutenedjian Mady CE. Modelling the exergy behavior of São Paulo State in Brazil. Journal of Cleaner Production. 2018;197:643-55.

[59] Instituto Brasileiro de Geografía e Estatística, Contas Nacionais [Internet]. 2018 [cited 8 July 2018]. Available from: https://www.ibge.gov.br/estatisticas-novoportal/economicas/contasnacionais.html.

[60] Empresa de Pesquisa Energética (EPE). Projeção da demanda de energia elétrica. Rio de Janeiro: Ministério de Minas e Energia; 2017.

[61] Governo do Estado de São Paulo-Secretaria de Energia. Anuário estatístico de energéticos por município no estado de São Paulo - 2007. 2008.

[62] Governo do Estado de São Paulo-Secretaria de Energia. Anuário estatístico de energéticos por município no estado de São Paulo - 2008. 2009.

[63] Governo do Estado de São Paulo-Secretaria de Energia. Anuário estatístico de energéticos por município no estado de São Paulo - 2009. 2010.

[64] Governo do Estado de São Paulo-Secretaria de Energia. Anuário estatístico de energéticos por município no estado de São Paulo - 2010. 2011. 
[65] Governo do Estado de São Paulo-Secretaria de Energia. Anuário estatístico de energéticos por município no estado de São Paulo - 2011. 2012.

[66] Governo do Estado de São Paulo-Secretaria de Energia. Anuário estatístico de energéticos por município no estado de São Paulo - 2012. 2013.

[67] Governo do Estado de São Paulo-Secretaria de Energia. Anuário estatístico de energéticos por município no estado de São Paulo - 2013. 2014.

[68] Governo do Estado de São Paulo-Secretaria de Energia. Anuário estatístico de energéticos por município no estado de São Paulo - 2014. 2015.

[69] Governo do Estado de São Paulo-Secretaria de Energia. Anuário estatístico de energéticos por município no estado de São Paulo - 2016. 2017.

[70] Dados Energéticos [Internet]. 2018 [cited July 2018]. Available from: http://dadosenergeticos.energia.sp.gov.br/Portalcev2/Municipios/index.html.

[71] Audiência 025/2015 [Internet]. ANEEL. 2015 [cited 13 August 2018]. Available from: http://www.aneel.gov.br/audiencias-publicas.

[72] SINPHA - Sistema de Informação de Posses e Hábitos de Uso de Aparelhos Elétrico [Internet]. 2006 [cited 07 August 2018]. Available from: http://www.procelinfo.com.br/data/Pages/LUMIS2C33EOC2PTBRIE.htm.

[73] Arcuri B, Spataru C, Barrett M. Evaluation of ice thermal energy storage (ITES) for commercial buildings in cities in Brazil. Sustainable Cities and Society. 2017;29:178-92.

[74] Uso do Solo Urbano - Tabelas [Internet]. 2017 [cited 08 August 2018]. Available from: https://www.prefeitura.sp.gov.br/cidade/secretarias/urbanismo/dados estatisticos/info cidade/us o do solo urbano/.

[75] US Department of Energy (DOE). EnergyPlusTM version 8.9.0 Documentation: Engineering Reference 2019 [Available from: www.energyplus.net.

[76] Secretaria de Energia e Mineração. Balanço Energético do Estado de São Paulo 2018: Ano Base 2017 Sao Paulo; 2018.

[77] INMETRO. Tabelas de Consumo / Eficiência Energética - Veículos Automotores Leves. INMETRO; 2018.

[78] Flammini MG, Prettico G, Julea A, Fulli G, Mazza A, Chicco G. Statistical characterisation of the real transaction data gathered from electric vehicle charging stations. Electric Power Systems Research. 2019;166:136-50.

[79] IPCC. Climate Change 2014: Synthesis Report. Contribution of Working Groups I, II and III to the Fifth Assessment Report of the Intergovernmental Panel on Climate Change IPCC, Geneva, Switzerland; 2014.

[80] SEEG. SEEG Brasil 2019 [Available from: http://plataforma.seeg.eco.br/map.

[81] International Energy Agency. World Energy Outlook 2017. Paris, France; 2017.

[82] GAMS Development Corp. GAMS 2017 [Available from: https://www.gams.com/.

[83] Eveloy V, Ayou DS. Sustainable District Cooling Systems: Status, Challenges, and Future Opportunities, with Emphasis on Cooling-Dominated Regions. Energies. 2019;12(2):235.

[84] Lind A, Espegren $K$. The use of energy system models for analysing the transition to lowcarbon cities - The case of Oslo. Energy Strategy Reviews. 2017;15:44-56.

[85] The World Bank. São Paulo Statement on Urban Sustainability: A Call to Integrate Our Responses to Climate Change, Biodiversity Loss, and Social Inequality 2019 [Available from: https://www.worldbank.org/en/news/statement/2019/09/18/sao-paulo-statement-on-urbansustainability-a-call-to-integrate-our-responses-to-climate-change-biodiversity-loss-and-socialinequality.

[86] Velasco GDN, Lima AMLP, Couto HTZd. Análise comparativa dos custos de diferentes redes de distribuição de energia elétrica no contexto da arborização urbana. Revista Árvore. 2006;30:67986.

[87] Vaillancourt K. Electricity Transmission and Distribution, ETSAP Technology Brief E12. https://iea-etsap.org/E-TechDS/PDF/E12 el-t\&d KV Apr2014 GSOK.pdf: IEA; 2014. 
[88] Schoots K, Rivera-Tinoco R, Verbong G, van der Zwaan B. Historical variation in the capital costs of natural gas, carbon dioxide and hydrogen pipelines and implications for future infrastructure. International Journal of Greenhouse Gas Control. 2011;5(6):1614-23.

[89] Speirs J, Balcombe P, Johnson E, Martin J, Brandon N, Hawkes A. A greener gas grid: What are the options? White paper. Sustainable Gas Institute, Imperial College London; 2017.

[90] Element Energy. Research on district heating and local approaches to heat decarbonisation A study for the Committee on Climate Change. 2015.

[91] Sadler D, Cargill A, Crowther M, Rennie A, Watt J, Burton S, et al. H21 Leeds City Gate Northern Gas Networks; 2016.

[92] ANEEL. Tarifas Consumidores 2019 [Available from: http://www.aneel.gov.br/tarifasconsumidores.

[93] UCL Energy Institute. UKTM-UCL 2016 [Available from: https://www.ucl.ac.uk/energymodels/models/uktm-ucl. 